\title{
Essays on Financial Markets
}

BY

\section{Pengfei Liu}

\begin{abstract}
A thesis
submitted to the Victoria University of Wellington in fulfilment of the requirements for the degree of Doctor of Philosophy
\end{abstract}

Victoria University of Wellington

2022 
This has been an amazing journey for me. I thank everyone who has made this journey possible and fulfilling.

Pengfei Liu 
Abstract vii

Acknowledgments $\quad$ ix

List of tables $\quad$ xii

List of figures $\quad$ xiii

1 Preliminaries 1

1.1 Motivation for Chapter $2 \ldots \ldots \ldots \ldots 2$

1.2 Motivation for Chapter $3 \ldots \ldots \ldots \ldots \ldots$

1.3 Motivation for Chapter $4 \ldots \ldots \ldots \ldots$

References ....................... 5

2 Equity Exchange-Traded Funds and the Cost of Debt 7

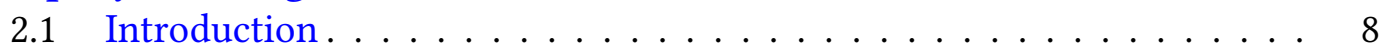

2.2 Related Literature . . . . . . . . . . . . . . . . . . . . . . . . . . 14

2.3 Sample and Variables Construction . . . . . . . . . . . . . . . . . 16

2.3.1 Sample and data sources. . . . . . . . . . . . . . . 17

2.3 .2 Key variables . . . . . . . . . . . . . . . . . 18

2.3.3 Control variables . . . . . . . . . . . . . . . . . . . . . . . 19

2.3 .4 Summary statistics . . . . . . . . . . . . . . . . 21

2.4 Empirical Results . . . . . . . . . . . . . . . . . . . . 21

2.4 .1 Baseline results . . . . . . . . . . . . . . . . 22

2.4 .2 Cross-sectional analyses. . . . . . . . . . . . . 23

2.5 Channels Analysis . . . . . . . . . . . . . . . . . . . . 25

2.5.1 Disciplinary effect of short-selling activities . . . . . . . . 25

2.5.2 Corporate governance . . . . . . . . . . . . . 28

2.6 Endogeneity and Robustness Checks . . . . . . . . . . . . . . . 29

2.6 .1 Endogeneity . . . . . . . . . . . . . . . . . . 29

2.6.2 Robustness tests. . . . . . . . . . . . . . . . . . 32

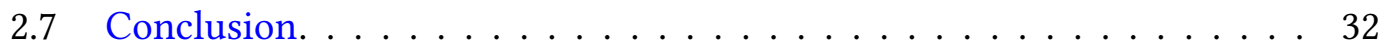

References .......................... 34

Tables and figures. . . . . . . . . . . . . . . . . . . . 41

Appendix: Definitions of Variables . . . . . . . . . . . . . . . . . 51 
3 The Trend Premium around the World: Evidence from the Stock $\begin{array}{lr}\text { Market } & \mathbf{5 7}\end{array}$

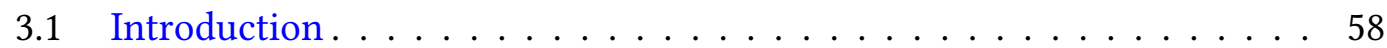

3.2 Methodology . . . . . . . . . . . . . . . . . . 62

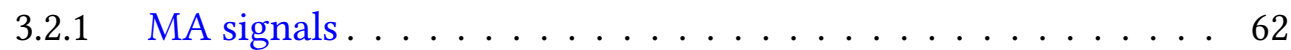

3.2.2 Trend portfolio construction . . . . . . . . . . . . 63

3.3 Data. . . . . . . . . . . . . . . . . . . . . . 64

3.3.1 Firm-level data . . . . . . . . . . . . . . . . . . . 64

3.3.2 Market-level data . . . . . . . . . . . . . . . . . . . . 66

3.3.3 Summary statistics . . . . . . . . . . . . . . . . 66

3.4 Trend premium: Individual market evidence . . . . . . . . . . . . . 67

3.4.1 Returns of trend portfolios . . . . . . . . . . . . . 67

3.4.2 Alphas of trend portfolios . . . . . . . . . . . . . . . 68

3.4.3 Transaction cost of trend portfolios . . . . . . . . . . . . . 69

3.5 Trend premium: Global-level evidence . . . . . . . . . . . . . 70

3.5.1 Global trend portfolio . . . . . . . . . . . . . . 70

3.5.2 Fama-MacBeth regression. . . . . . . . . . . . . . 72

3.5.3 Information horizon and trend premium . . . . . . . . . 74

3.5.4 Trend strategy and momentum strategy . . . . . . . . . . . 75

3.6 Macroeconomic fundamentals, culture, information environment, and the trend premium . . . . . . . . . . . . . . . 77

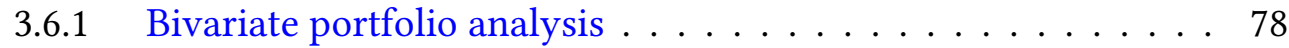

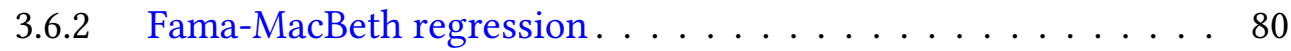

3.7 Conclusion. . . . . . . . . . . . . . . . . . . . . . 82

References ........................... . . 84

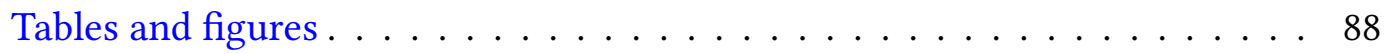

Appendix: Definitions of Variables. . . . . . . . . . . . . . . . . 103

4 Does Margin-Trading Reflect Information or Sentiment? Evidence $\begin{array}{lr}\text { from the Chinese Stock Market } & 105\end{array}$

4.1 Introduction . . . . . . . . . . . . . . . . . 106

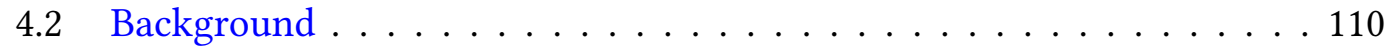

4.2.1 Margin-trading program. . . . . . . . . . . . . . . 110

4.2.2 The 2015 Chinese stock market crisis . . . . . . . . . . . . 111

4.2.3 The implementation of strict regulation . . . . . . . . . 112

4.3 Data and methodology . . . . . . . . . . . . . . . . . . . . . 113

4.3.1 Data and sample . . . . . . . . . . . . . . . . . . 113

4.3.2 Stock-level margin-trading interest . . . . . . . . . . . . . 114

4.3.3 Market-level margin-trading interest . . . . . . . . . . . . . 115 
4.4 Information-driven or sentiment-driven $\ldots \ldots \ldots \ldots \ldots \ldots$

4.4 .1 Market-level analysis. . . . . . . . . . . . . . . . . 116

4.4 .2 Individual stock-level analysis . . . . . . . . . . . . . . . 119

4.4.3 Why sentiment-driven trading exists . . . . . . . . . 120

4.5 The decrease in sentiment-driven trading . . . . . . . . . . . . . 121

4.5.1 Preliminary analysis . . . . . . . . . . . . . . . 122

4.5.2 Panel logit model analysis. . . . . . . . . . . . . . . . 124

4.5.3 Reasons for the decline of sentiment-driven trading . . . . . . 127

4.6 Robustness checks . . . . . . . . . . . . . . . . . . . . . . . . 129

4.6.1 Different definition of pre-crisis and post-crisis . . . . . . . . 129

4.6.2 Different logit model specification. . . . . . . . . . . . . . . 129

4.7 Conclusion. . . . . . . . . . . . . . . . . . . 130

References . . . . . . . . . . . . . . . . . . . . . 132

Tables and figures . . . . . . . . . . . . . . . . . . . . . . . . . . . . . . . . . . . . . . . . . .

Appendix: Definitions of Variables . . . . . . . . . . . . . . . . . 144

5 Discussion 149

5.1 Discussion for Chapter $2 \ldots \ldots \ldots \ldots \ldots \ldots$

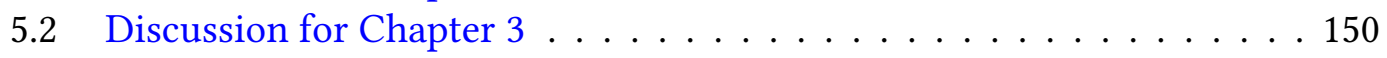

5.3 Discussion for Chapter $4 \ldots \ldots \ldots 151$

References . . . . . . . . . . . . . . . . . . . . . 153 



\section{Abstract}

This thesis consists of five chapters. Chapter 1 is the preliminaries. Chapter 2 to chapter 4 are the three main chapters of this thesis, which covers the U.S. market, international market, and the Chinese market, respectively. Chapter 5 is the discussion.

Chapter 1 is the preliminaries. It introduces the setting and motivations for the three topics covered in this thesis.

Chapter 2 investigates how equity exchange-traded fund (ETF) ownership affects the cost of debt. I find that, by facilitating short-selling activities to execute disciplinary effects, equity ETF ownership decreases a firm's cost of debt. This negative association between equity ETF ownership and the cost of debt is more pronounced for firms with weaker information environments and lower bond ratings. The disciplinary effect works through a more active short-selling market provided by equity ETF ownership. However, I fail to establish the corporate governance channel, which is consistent with Schmidt and Fahlenbrach (2017) and Heath, Macciocchi, Michaely, and Ringgenberg (2021). Those results are also robust to endogeneity.

Chapter 3 studies the predictive power of the trend strategy in the international stock market. Using data from 49 markets, I find that a trend signal exploiting the short-, intermediate-, and long-term price information can predict stock returns crosssectionally in the international market. The significance of the trend strategy is associated with market-level characteristics such as macroeconomic conditions, culture, and the information environment. The trend premium is more pronounced in markets with a more advanced macroeconomic status, a higher level of information uncertainty and individualism, and better accessibility to foreign investors. Nevertheless, the trend strategy only outperforms the momentum strategy in a relatively short horizon.

Chapter 4 investigates whether margin-trading in the Chinese stock market reflects information or sentiment. At the aggregate level, I find no evidence of informationdriven or sentiment-driven margin-trading behavior. At the individual stock level, both 
information-driven and sentiment-driven margin-trading exists, which are relevant to firm characteristics. I also find the likelihood of sentiment-driven margin-trading significantly declined after the regulator enforced tighter rules for margin-trading in 2015.

Chapter 5 summarizes the main findings of the three topics, discusses the implications of the findings, and points out the future direction for research. 


\section{Acknowledgments}

I am greatly indebted to my supervisor Prof. Hai Lin and Assistant Prof. Cheng Zhang. I could not say more about my gratitude towards them. For many times I just thought I could not be a good researcher. Their patience and encouragement give me tremendous support during the course of my study. Besides, I learn from what they do. I learn from them through our weekly meetings, through our finance $\mathrm{PhD}$ study group, through emails communication, through their comments about research ideas, and through the slides they make. Their attitudes toward research and teaching have shaped my understanding of what a good scholar could be.

I would like to acknowledge the tremendous support from my wife, my parents, and my wife's family. I cannot reach this final point without their support. My son's arrival has changed my perspective of life, which makes my life more meaningful. The time spent with my fellow PhDs at SEF, visiting PhDs, and my friends have always been enjoyable. The staff and professional staff at SEF have given me great help. I also acknowledge the use of the third party for editorial help. I can confirm that my thesis was copy edited for conventions of language, spelling and grammar by Marianne Lown at the University of Otago and editors at Proof-Reading-Service.com.

I guess I am one of the students who have made the most use of the multiple campuses of Victoria University of Wellington. I am familiar with every building in Pipitea, Kelburn, and Te Aro campus. Thanks for the great locations of different campuses, making it possible for me to conduct research whenever needed. Student Learning, Victoria International, and the library have provided excellent support and help during my study, which is second to none.

When I look back at my study at Victoria University of Wellington, I could say the past several years have been one of the most fulfilling and happy times in my life to now. I often feel like in a dream when I look at the Oriental bay and mountain Victoria from the library on the Kelburn campus. I know how hard it has been to reach this 
point and how precious this opportunity is. I sincerely thank everyone who has made this journey possible and fulfilling.

Pipitea, Kelburn, Te Aro Campus

Wellington, 2021 


\section{LIST OF TABLES}

2.1 Summary Statistics . . . . . . . . . . . . . . .

2.2 Baseline Regressions: Equity ETF Ownership and Bond Offering

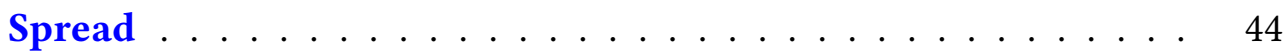

2.3 Cross-sectional Analyses . . . . . . . . . . . . . . . . . 45

2.4 Channel Analyses: Short-Sale Constraints . . . . . . . . . . . . . 46

2.5 Equity ETF Ownership and Short Interest: Earnings Announce-

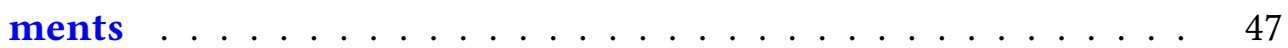

2.6 Channel Analyses: Corporate Governance _ . . . . . . . . . . 48

2.7 Endogeneity Checks . . . . . . . . . . . . . . . . . . . . . 49

2.8 Robustness Tests . . . . . . . . . . . . . . . . . . . . . . 50

B.1 Definitions of Variables $\ldots \ldots \ldots \ldots$

3.1 Sample Summary . . . . . . . . . . . . . . . . . . . . . . . 89

3.2 Trend Premium of International Stock Market . . . . . . . . . . 91

3.3 Alphas of the Trend Portfolio . . . . . . . . . . . . . . . . . 93

3.4 Turnover Ratio and Break-even Transaction Cost of the Trend Portfolios . . . . . . . . . . . . . . . . . . . . . 95

3.5 Trend Strategy at the Global-level . . . . . . . . . . . . . . 97

3.6 Firm-level Fama-MacBeth Regression ～. . . . . . . . . . . . . 98

3.7 Trend Premium Using Information of Different Horizons . . . 99

3.8 Trend Premium and Momentum _ . . . . . . . . . . . . . 100

3.9 Bivariate Portfolio Analysis _ . . . . . . . . . . . . . . . . 101

3.10 Market-level Fama-MacBeth Regression . . . . . . . . . . . . . . 102

C.1 Definitions of Variables . . . . . . . . . . . . . . . . . . . . 104

4.1 Summary of the Margin-trading and Short-selling Program . . 135

$4.2 \beta$ of Market-level Predictive Regressions . . . . . . . . . . . . . 136 
4.3 Results of Firm-level Predictive Regressions . . . . . . . . . . . . 137

4.4 Percentage of Information-driven and Sentiment-driven Stocks 138

4.5 Summary Statistics of Variables Used in Logit Model . . . . . . 139

4.6 Logit Model Results for Sentiment-driven Category Versus Nonsignificant Category . . . . . . . . . . . . . . . . . 140

4.7 Logit Model Results for Information-driven Category Versus Non-significant Category . . . . . . . . . . . . . . . . . . . 141

4.8 Percentage of Information-driven and Sentiment-driven Stocks 142

4.9 Multinomial Logit Model . . . . . . . . . . . . . . . . . . . . . . . 143

D.1 Definitions of Variables . . . . . . . . . . . . . . . . . . . . . 144 


\section{List OF Figures}

2.1 Average Bond Offering Spread by Year . . . . . . . . . . . . . 41

2.2 Average Equity ETF Ownership by Year . . . . . . . . . . . . . 42

3.1 Monthly Return of the Global Trend Strategy $\ldots \ldots$. . . . . 88 



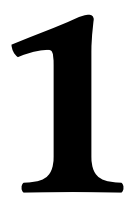

\section{Preliminaries}

This chapter is the preliminaries. It introduces the setting and motivations for the three topics covered in this thesis. 
His thesis examines the financial markets around the world, which are at different

stages of development and offer important perspectives for research questions that are unique and particularly relevant in different markets. The thesis focuses in particular on empirical asset pricing in both the stock market and the bond market.

\subsection{Motivation for Chapter 2}

Chapter 2 explores the influence of important financial innovations on the financial market in the U.S. It explores the effect of equity exchange-traded funds (ETFs) on the cost of debt in the U.S. primary bond market. The financial market is quickly evolving and more innovations have emerged in the past several decades. As the leading financial market in the world, the U.S. market is at the frontier of the innovations. ETF is one of the most important innovations in past decades. The debate between passive and active investing has further sparked interest in ETFs among practitioners, researchers, and regulators. The U.S. represented $69 \%$ of the total assets of ETFs around the world in 2020. ${ }^{1}$ The importance of passive investing and leading the market in terms of ETF development makes the U.S. an ideal market to study the effect of ETFs.

The U.S. setting for chapter 2 deepens our understanding of the influence of financial innovations. First, it adds to the ongoing research that studies the influence of ETFs on financial markets. Second, it identifies equity ETF ownership as a new factor that is related to the cost of debt. Specifically, it extends the literature by linking financial market innovations to the cost of debt. Third, it highlights the importance of equity ETFs in facilitating short-sellers to discipline a firm. Fourth, this paper links equity ETFs with bond pricing and contributes to the literature that studies the interactions between the equity market and the bond market.

\subsection{Motivation for Chapter 3}

Chapter 3 belongs to international finance. It evaluates the applicability of the trend premium, which has been shown to be effective in predicting returns on the U.S. stock market. Following Han, Zhou, and Zhu (2016), this chapter uses moving average prices

\footnotetext{
${ }^{1}$ This statistic comes from Investment Company Institute and ETFGI.
} 
with lag lengths of $3,5,10,20,50,100,200,400,600,800$, and 1,000 days, which roughly indicate the daily, weekly, monthly, quarterly, 6-month, 1-year, 2-year, 3-year, 4-year, and 5-year price trends to evaluate the effectiveness of the trend strategy. International finance is important in the sense it will evaluate the effectiveness and applicability of the financial theory developed mainly from leading financial markets, which will contribute to the future development of financial theories. Besides, new methods to extract the information from the existing return predictors are of great importance to the empirical asset pricing.

The international setting for chapter 3 advances our understanding of the existing financial theory. First, it uses historical price information to forecast stock returns out-of-sample. The findings on the predictive power of trend signals in 49 international stock markets expand the understanding of investor behaviors in an international setting. Second, this chapter documents that the performance of the trend premium is related to market-level characteristics. These findings extend our understanding of the extent to which the cross-market variations can explain stock returns (see, for example, Chan, Covrig, and Ng, 2005; Chui, Titman, and Wei, 2010; Lau, Ng, and Zhang, 2010; Jacobs, 2016). Third, it also relates to the literature on whether and how synthesizing more information improves return predictability. This chapter helps to understand the conditions under which a better out-of-sample performance can be achieved when employing more information.

\subsection{Motivation for Chapter 4}

Chapter 4 focuses on the important reforms in a major emerging market and studies a recent policy change of the Chinese stock market. As China becomes the second largest economy in the world, its financial market is increasingly attracting the attention of both researchers and practitioners. Compared with the U.S., the Chinese stock market has many unique features, which offer a different and potentially meaningful perspective for the financial economics. As China is one of the most important emerging markets and its financial market is undergoing many reforms, this provides an ideal setting for researchers. China started to allow the margin-trading and short-selling in 2010, which provides an interesting setting to study the consequence of this reform in 
a one-sided market featuring retail investors.

The emerging market setting for chapter 4 makes several important contributions to our understanding of financial markets. First, it provides a comprehensive analysis of margin-trading at both aggregate and individual stock level and contributes to the literature about leveraged trading. Second, it documents the importance of both information and sentiment on margin-trading. It also provides empirical support for both rational and behavioral finance (Stambaugh, Yu, and Yuan, 2012; Hirshleifer, 2015). Third, the empirical analysis uses the margin-trading data of the Chinese stock market which features more retail investors. This study thus provides a perspective different that of the markets dominated by institutional investors (Seguin, 1990; Hardouvelis and Peristiani, 1992; Hirose, Kato, and Bremer, 2009). Fourth, it shows that sentimentdriven margin-trading has decreased dramatically since the 2015 Chinese stock market crisis. These changes demonstrate how the government, financial intermediaries, and investors responded to the sudden market crash (Cong, Grenadier, and Hu, 2020; Swagel, 2015). 


\section{References}

Chan, K., Covrig, V., Ng, L., 2005. What determines the domestic bias and foreign bias? Evidence from mutual fund equity allocations worldwide. The Journal of Finance 60, 1495-1534.

Chui, A. C., Titman, S., Wei, K. J., 2010. Individualism and momentum around the world. The Journal of Finance 65, 361-392.

Cong, L. W., Grenadier, S. R., Hu, Y., 2020. Dynamic interventions and informational linkages. Journal of Financial Economics 135, 1-15.

Han, Y., Zhou, G., Zhu, Y., 2016. A trend factor: Any economic gains from using information over investment horizons? Journal of Financial Economics 122, 352375.

Hardouvelis, G. A., Peristiani, S., 1992. Margin requirements, speculative trading, and stock price fluctuations: the case of Japan. The Quarterly Journal of Economics 107, 1333-1370.

Hirose, T., Kato, H. K., Bremer, M., 2009. Can margin traders predict future stock returns in Japan? Pacific-Basin Finance Journal 17, 41-57.

Hirshleifer, D., 2015. Behavioral finance. Annual Review of Financial Economics 7, 133-159.

Jacobs, H., 2016. Market maturity and mispricing. Journal of Financial Economics 122, $270-287$.

Lau, S. T., Ng, L., Zhang, B., 2010. The world price of home bias. Journal of Financial Economics 97, 191-217.

Seguin, P. J., 1990. Stock volatility and margin trading. Journal of Monetary Economics 26, 101-121.

Stambaugh, R. F., Yu, J. F., Yuan, Y., 2012. The short of it: investor sentiment and anomalies. Journal of Financial Economics 104, 288-302. 
Swagel, P., 2015. Legal, political, and institutional constraints on the financial crisis policy response. Journal of Economic Perspectives 29, 107-22. 


\section{Equity Exchange-Traded Funds And The}

\section{Cost of DeBt}

This chapter investigates how equity exchange-traded fund (ETF) ownership affects the cost of debt. We find that, by facilitating short-selling activities to execute disciplinary effects, equity ETF ownership decreases a firm's cost of debt. This negative association between equity ETF ownership and the cost of debt is more pronounced for firms with weaker information environments and lower bond ratings. The disciplinary effect works through a more active short-selling market provided by equity ETF ownership. However, we fail to establish the corporate governance channel, which is consistent with Schmidt and Fahlenbrach (2017) and Heath, Macciocchi, Michaely, and Ringgenberg (2021). Our results are also robust to endogeneity. 


\subsection{Introduction}

The gradual shifting of market shares between passive and active investing has changed the landscape of the asset management industry. Due to the high liquidity, low cost, and good diversification, exchange-traded funds (ETFs) provide investors with more choices to invest, speculate, and hedge. ${ }^{1}$ Recent studies, such as those by Fichtner, Heemskerk, and Garcia-Bernardo (2017) and Azar, Schmalz, and Tecu (2018), have shown that passive investors have become the largest investors for many firms. ${ }^{2}$ Being an important passive investing instrument, the ETF industry has experienced enormous growth in the last decade. The value of assets managed by ETFs is over $\$ 5.4$ trillion, accounting for $18 \%$ of the net total assets of U.S. registered investment companies by the end of 2020 . In addition, around $26 \%$ of the trading volume of the U.S. stock markets was contributed by ETFs in 2020. Such rapid development of ETFs has attracted huge attention from practitioners, researchers, and regulators, raising fundamentally important questions about the effects of ETFs on financial markets. ${ }^{3}$ See, for example, Broman (2016), Ben-David, Franzoni, and Moussawi (2018), Da and Shive (2018), Lee (2018), Brown, Davies, and Ringgenberg (2018), and Hao, Kim, Sul, and Wang (2019) on asset pricing and Boone and White (2015), Appel, Gormley, and Keim (2016, 2019), and Heath et al. (2021) on corporate governance.

Despite a large body of studies examining the impact of ETFs, the effects of equity ETFs on a firm's cost of debt have been less studied. As a measure of a firm's cost of debt, the bond yield spread that a firm pays when issuing debt is an important aspect

\footnotetext{
${ }^{1}$ According to TrackInsight Global ETF Survey 2021, jointly conducted by J.P. Morgan and leading ETF analysis platform TrackInsight, the four most important attributes of ETFs for investors are low investment costs, ease of trading or liquidity, simplicity, and diversification and risk management. As reported by the 2021 Investment Company Fact Book (ICI, 2021), the asset-weighted average expense ratio for equity ETFs in 2020 is $0.18 \%$, whereas the expense ratio for equity mutual funds is $0.5 \%$.

${ }^{2}$ Azar et al. (2018) point out that the combined holdings of BlackRock, Vanguard, and State Street make them the largest investor for $88 \%$ of firms in the S\&P500 index. According to the data retrieved from ETF.com, those three companies are also the three largest providers of ETFs in the U.S. The values of ETF assets managed by BlackRock, Vanguard, and State Street were $\$ 2137.59$ billion, $\$ 1625.24$ billion, and $\$ 886.07$ billion as of February 2021, respectively.

${ }^{3}$ At a talk of the 2021 AFA annual conference, the founder and CEO of Citadel emphasized the important influence of ETFs on financial markets, in particular, the equilibrium between passive and active investing. Some theoretical studies such as those of Bond and Garcia (2018) and Corum, Malenko, and Malenko (2020) investigate this issue.
} 
of capital structures. Prior studies have explored various factors that are relevant to the cost of debt. These factors include political rights and government ownership (Qi, Roth, and Wald, 2010; Borisova and Megginson, 2011; Borisova, Fotak, Holland, and Megginson, 2015), media coverage (Gao, Wang, Wang, Wu, and Dong, 2020), analyst and management forecast (Mansi, Maxwell, and Miller, 2011; Cao, Myers, Tsang, and Yang, 2017), equity cross-listing (Ball, Hail, and Vasvari, 2018), and international IFRS adoption (Florou and Kosi, 2015). However, few studies have examined the effect of financial market innovations on the cost of debt financing. In this paper, we aim to fill this gap and provide evidence on the relationship between equity ETF ownership and corporate bond pricing.

There are several reasons that we investigate the effect of financial market innovations such as equity ETFs on the cost of debt. First, debt is an important and frequent source of external capital for many firms (Henderson, Jegadeesh, and Weisbach, 2006; Florou and Kosi, 2015). It is critical to understand the debt market consequences stemming from the equity ETF's popularity. Further, the bond market has been traditionally dominated by sophisticated institutional investors (Bessembinder, Kahle, Maxwell, and Xu, 2008; Mansi et al., 2011). As argued by previous studies, ETFs can facilitate information incorporation and thus improve information efficiency. It is therefore interesting to explore the responses of institutional investors to equity ETFs by employing the bond pricing setting.

More importantly, the association between equity ETF ownership and the cost of debt is not obvious. Debt investors face information asymmetry to monitor a firm's behavior and the bond yield spread reflects the information risk. Theoretically, the effects imposed by equity ETF ownership on information asymmetry are ambiguous. On the one hand, many ETFs engage in the security lending market, which increases the lendable shares for short-sellers (Glosten, Nallareddy, and Zou, 2021), and ETFs can facilitate the synthetic shorting ( $\mathrm{Li}$ and $\mathrm{Zhu}, 2018$ ). Both allow negative information to be incorporated into stock prices in a timelier manner (Boehmer, Jones, and Zhang, 2008; Rapach, Ringgenberg, and Zhou, 2016). The increased threat of short-selling could discipline managers and thus mitigate the adverse effect of information asymmetry. This will generate an influence on firm value or risk. Merton (1974) states 
that a bond contains a short put position on the underlying value of the firm. As a consequence, such disciplinary effect will also affect bond yield spread. Therefore a negative association between equity ETF ownership and bond yield spread is expected to be observed. On the other hand, some studies document a deterioration of internal governance after an increase in equity ETF ownership, which, in turn, exacerbates the information asymmetry (Schmidt and Fahlenbrach, 2017; Heath et al., 2021). It follows that bond investors would require a higher yield spread to compensate for the increased risk.

To address the above questions, we study the effects of equity ETF ownership on the cost of debt. We use the bond offering yield spread at the primary market as a proxy for firms' cost of debt. Using fixed-rate straight bond issuance data from 2008 to 2018, we document a negative association between equity ETF ownership and firms' cost of debt. After controlling for firm and bond issuance characteristics, the coefficient estimate of ETF ownership on the bond spread is statistically significant and economically meaningful. Specifically, a one standard deviation increase in equity ETF ownership leads to a decrease in the bond offering yield spread by 20.7 basis points, which amounts to $7.7 \%$ of the average bond offering yield spread. The magnitude is comparable to the one documented by Dannhauser (2017), which shows that a one standard deviation increase in the bond ETF ownership reduces bond spreads for high-yield and investment-grade bonds by 20.3 and 9.2 basis points in the secondary market, respectively. In sum, our results indicate that equity ETF ownership reduces the cost of debt, suggesting an interaction between the equity market and the debt market induced by ETFs.

We extend our analysis by examining whether the impact of equity ETF ownership on the cost of debt varies with firm characteristics. The results show that the negative association between equity ETF ownership and the cost of debt is more pronounced for firms with weaker information environments and lower bond ratings. In this sense, our study complements those of Dannhauser (2017) and Glosten et al. (2021). Firms with weaker information environments and lower bond ratings are usually subject to more severe information asymmetry problems. As a result, it is more difficult to monitor those firms due to the lack of information. 
We then move on to explore the channels through which equity ETF ownership affects the cost of debt. Specifically, we investigate two possible channels. The first one is the disciplinary effect brought by more active short-selling activities. Given the passive investment style, many ETFs engage in share lending, which facilitates the short-selling activities of underlying stocks by providing more lendable shares. For example, Glosten et al. (2021) document that the lendable shares of firms with high equity ETF ownership are more than those of other firms. In addition, the security lending fee has become an important income source for many ETFs. ${ }^{4}$ By providing easier access to incorporate negative news into stock prices efficiently, the equity ETFs impose a disciplinary effect and reduce the information asymmetry in financial markets.

To substantiate the short-selling channel, we conduct two tests. First, we examine whether the negative association between equity ETF ownership and bond spread is stronger for firms facing tighter short-sale constraints. Following prior studies, we use idiosyncratic volatility and Amihud illiquidity (Amihud, 2002) as proxies for short-sale constraints (Pontiff, 2006; Li and $\mathrm{Zhu}, 2018$ ). We find that the negative relationship between equity ETF ownership and the cost of debt is more pronounced for firms with a high level of idiosyncratic volatility and Amihud illiquidity measure. The findings provide support for our conjectures on the disciplinary effect of short-selling activities.

Second, we employ our sample firms' earnings events to study the relationship between equity ETF ownership and short-selling activities. The motives of employing the setting of earnings announcements are twofold. On the one hand, the importance of financial statements has received huge attention from financial market participants such as short-sellers (Christophe, Ferri, and Angel, 2004) and analysts (Johnson, Kim, and So, 2019). On the other hand, there is a relatively clear rule to evaluate the performance of firms by checking whether firms meet/beat the market's expectation. Following Livnat and Mendenhall (2006) and Huang, O'Hara, and Zhong (2021), we use standardized unexpected earnings (SUE) as a proxy for earnings surprises. To measure

\footnotetext{
${ }^{4}$ According to iShares Annual Report and iShares Securities Lending Report, the iShares Russell 2000 ETF lent out securities of 4.27 and 4.8 billion USD in 2016 and 2017, respectively, which account for $16.86 \%$ and $12.60 \%$ of assets under management, respectively. The ratio of security lending income of iShares Russell 2000 ETF ranged from $0.15 \%$ to $0.21 \%$ during $2017-2020$. These numbers are close to the expense ratios charged to their ETF investors.
} 
a firm's short-selling activity, we use the abnormal short interests proposed in Karpoff and Lou (2010). Christophe et al. (2004) show that short-sellers pay close attention to firms' financial statements. We find that firms with higher equity ETF ownership experience a larger increase in abnormal short interest in the scenario of negative earnings surprises. However, we fail to find such a relationship when earnings surprises are positive. The different results between negative and positive earnings surprises suggest that equity ETFs provide a more accessible short-selling market, especially in events with negative earnings surprises. This test further establishes the relevancy of the short-selling channel. By facilitating short-sellers to incorporate negative information quickly into stock prices, the equity ETFs implement a disciplinary effect and reduce the cost of debt. This channel test corroborates with Huang et al. (2021), who show that ETFs improve the informational efficiency of the firm-specific component.

The second channel we study is corporate governance. Previous studies ,such as those by Boone and White (2015), Appel et al. (2016, 2019), and Heath et al. (2021), have utilized different settings to explore whether equity ETF ownership improves corporate governance. However, the results are not conclusive. Following Appel et al. (2016) and Heath et al. (2021), we use a wide range of proxies to capture corporate governance. These measures include the percentage of independent directors, the existence of restrictions for investors to call a special meeting, whether the firm has a classified board, whether a firm has a dual-class share structure, and whether a poison pill provision is in place. We find insignificant results for the majority of the proxies within our sample firms. Consistent with Heath et al. (2021), our results do not support corporate governance as one channel through which equity ETF ownership can operate to influence a firm's cost of debt.

Further, we employ several approaches to address endogeneity concerns. First, we include the industry-by-year fixed effects to control the time-varying industry confounding factors that bias our results. We continue to find a significant decline in the cost of debt after controlling for industry-by-year fixed effects. Second, following Zou (2019) and Antoniou, Li, Liu, Subrahmanyam, and Sun (2020), we use BlackRock's acquisition of iShares ETF from Barclays Global Investors in 2009 as an exogenous shock to ETF ownership. As shown by Zou (2019) and Antoniou et al. (2020), there 
has been an exogenous increase in ETF ownership for stocks with higher iShares ETF ownership relative to those stocks with lower iShares ETF ownership since the acquisition of iShares ETFs by BlackRock, which results from the branding and scale benefits and distribution channels of BlackRock. The acquisition essentially induced an exogenous change in equity ETF ownership, which is not relevant to firm characteristics but is caused by the influence of BlackRock. We use a four-year window and two specifications, a difference-in-differences (DID) specification (Zou, 2019) and IV model (Antoniou et al., 2020), to re-examine the effect of ETF ownership on the bond pricing. Our results suggest that the negative association between equity ETF ownership and bond offering yield spread is more likely to be causal. Finally, we carry out several robustness tests and show that our results continue to hold when using a different sample and an alternative measure of ETF ownership.

Our study is closely related to that of Dannhauser (2017). Dannhauser (2017) studies the effect of bond ETFs on bond pricing in the secondary market and establishes a negative relation between bond ETF ownership and bond spreads. Our paper differs from Dannhauser (2017) in several ways. First, due to the difference in voting rights, the disciplinary effect of short-selling is more relevant in the equity market than the corporate bond market. We study the different roles played by ETFs in financial markets and identify different channels through which they affect a company's bonds. Dannhauser (2017) concentrates on the roles of bond ETFs in the price responsiveness of corporate bonds. In contrast, we explore the disciplinary effect of short-selling facilitated by equity ETFs and the potential influence of equity ETFs on corporate governance. The disciplinary effect of short-selling facilitated by equity ETFs is unique to the equity ETF market and not present in the bond ETF market. Second, we focus on the effects of equity ETF ownership on the cost of debt in the primary bond market, while Dannhauser (2017) examines the price dynamics in the secondary bond market. Third, the size of equity ETFs is much larger than that of bond ETFs. In the U.S. market, the assets under the management of equity ETFs had surpassed 5 trillion U.S. dollars at the end of 2020, while it was 1.2 trillion U.S. dollars for the bond ETFs.

Our paper contributes to the current literature in several ways. First, our study adds to the ongoing research that studies the influence of ETFs on financial markets and 
answers the call made by Lettau and Madhavan (2018) and the Securities and Exchange Commission (SEC) for more studies to enhance our understanding of the impact of ETFs. ${ }^{5}$ Second, we identify equity ETF ownership as a new factor that is related to the cost of debt. Specifically, we extend the literature by linking financial market innovations to the cost of debt. As financial markets evolve and innovations emerge, it is important to evaluate the effect of innovations, like equity ETFs, on the cost of debt, given the importance of the cost of debt in the previous theoretical and empirical literature (Valta, 2012; Borisova et al., 2015; Gao et al., 2020). Third, we highlight the importance of equity ETFs in facilitating short-sellers to discipline a firm. The enhancement in the external monitoring from short-sellers facilitated by ETFs mitigates concerns that passive ETF shareholders weaken the internal monitoring (Heath et al., 2021). Fourth, this paper links equity ETFs with bond pricing and contributes to the literature that studies the interactions between the equity market and the bond market (Gebhardt, Hvidkjaer, and Swaminathan, 2005; Even-Tov, 2017).

The rest of the paper is organized as follows: Section 2.2 reviews the related literature; Section 2.3 describes the sample and variables construction; Section 2.4 presents the results; Section 2.5 investigates the channels through which the equity ETF ownership affects the bond pricing; In Section 2.6, we address endogeneity concerns and perform several robustness checks; and Section 2.7 concludes the paper.

\subsection{Related Literature}

Our paper relates to the literature on the effects of equity ETFs, which covers a wide range of topics in asset pricing, corporate governance, the real effect of the financial markets, and market microstructures. Some studies find a positive impact of equity ETFs, while others document a negative effect.

A number of studies document the positive side of equity ETFs. First, equity ETFs could facilitate the incorporation of systematic and industry information and increase the liquidity of underlying securities. Existing studies show that equity ETFs can facilitate the transfer of industry information (Bhojraj, Mohanram, and Zhang, 2020), the timely incorporation of systematic information during earnings

${ }^{5}$ Please see https://www.sec.gov/news/speech/speech-piwowar-2017-09-08 for more details. 
announcements (Glosten et al., 2021), lead to higher factor information in prices (Cong and $\mathrm{Xu}, 2019$ ), and facilitate managers' learning from the stock market (Antoniou et al., 2020). Consequently, liquidity will be increased during the process of information transmission and ETF arbitrage (Boehmer and Boehmer, 2003; Hamm, 2014; Saglam, Tuzun, and Wermers, 2019). Second, the equity ETFs facilitate short-selling activities by increasing lendable shares (Glosten et al., 2021; Karmaziene and Sokolovski, 2015), allowing for synthetic shorting and operational shorting (Li and Zhu, 2018; Evans, Moussawi, Pagano, and Sedunov, 2019), and increasing the probability of industry hedging by shorting sector ETFs (Huang et al., 2021). Third, equity ETFs have a longterm investment horizon and less room to exit due to their passive management styles. Some studies document that equity ETF ownership improves corporate governance (Appel et al., 2016, 2019) and firm transparency (Boone and White, 2015) and reduce misconduct (Baig, DeLisle, and Zaynutdinova, 2018).

On the other hand, some studies demonstrate the negative impact of equity ETFs. First, equity ETFs could transit non-fundamental shocks to their underlying securities. As a result, equity ETFs increase volatility and generate excessive co-movement and contagion effects (Krause, Ehsani, and Lien, 2014; Ben-David et al., 2018; Da and Shive, 2018; Iwadate, 2021). Broman (2016) and Bhattacharya and O'Hara (2018) show that equity ETFs attract more short-term noise traders and speculators' herding, while Israeli, Lee, and Sridharan (2017) find that equity ETFs decrease the pricing efficiency of the underlying securities. Second, because of the passive investment feature, equity ETFs could reduce the incentives of investors to monitor the underlying firms. Several studies find that an increase in equity ETF ownership results in more CEO power and fewer new independent directors (Schmidt and Fahlenbrach, 2017), less possibility of voting against a firm's management (Heath et al., 2021), and more low-quality share repurchases to beat or meet the analysts' forecasts (Bratten, Huang, and Payne, 2020). Third, with the evolution of the ETF industry (Easley, Michayluk, O'Hara, and Putninšs, 2020), the complexity and search cost of the ETF products might put unsophisticated investors in a disadvantaged position and increase their irrational behaviors (Brown, Cederburg, and Towner, 2021; Gao, Hu, Kelly, Peng, and Zhu, 2021).

Recently, several papers explore the effects of bond ETFs. Most of these studies 
focus on the impact of bond ETFs on asset pricing. Dannhauser (2017) documents a negative association between bond ETFs and bond spread in the secondary market. Hao et al. (2019) find the bond ETF returns lead to the price discovery of constituent bonds. Pan and Zeng (2019) find that authorized participants (AP) act as both arbitragers and bond dealers in the bond ETF market. This feature causes persistent mispricing in the bond market. Ye (2018) shows that bond ETFs increase the liquidity of the underlying bonds through the channel of ETF arbitrage. However, Lee (2018) documents an increase in the liquidity for high yield bonds, which results from an improvement in informational efficiency, and a decrease in the liquidity for investment-grade bonds because of trader migration and adverse selection problems.

Our paper is also related to work on the cost of debt. Previous studies identify factors that influence the cost of debt. For example, political rights and government ownership are shown to be an important factor for the determination of the cost of debt. Qi et al. (2010) document that greater political rights are associated with lower yield spreads in the global corporate bonds markets. Borisova and Megginson (2011) show that there is a negative relationship between government ownership and the cost of debt in the setting of privatization. Borisova et al. (2015) show that government equity ownership in public firms is generally positively associated with the cost of debt. A negative association between media coverage and cost of debt is documented by Gao et al. (2020). Prior studies also show that the forecasts from analysts (Mansi et al., 2011) and managers (Cao et al., 2017) are negatively related to the cost of debt. Finally, the literature shows that the cost of debt can be reduced by improved report quality caused by the mandatory IFRS adoption (Florou and Kosi, 2015) and improved transparency and monitoring due to the cross-listing in the U.S. (Ball et al., 2018).

\subsection{Sample and Variables Construction}

In this section, we describe the construction of the sample and the calculation of variables used in the empirical analysis. Specifically, we discuss how to compute bond offering yield spread, equity ETF ownership, abnormal short interest (ABSI), standardized unexpected earnings (SUE), and other control variables. We present the summary statistics at the end of this section. 


\subsubsection{Sample and data sources}

We compile the list of U.S. domestic equity ETFs using the following procedures. First, we merge the CRSP stock database (share code equals 73) with the CRSP SurvivorBias-Free Mutual Fund database (ETF flag equals F). We restrict our sample to U.S. domestic equity ETFs by using the first two digits of the CRSP style code of "E.D." (equity domestic). We further exclude ETFs that use a hedged position, short position, and options, and filter out ETFs that have "bear", "hedged", and "bond" in their names. Finally, we use the MFLINKS table to merge the ETFs data with ETF holdings data from the Refinitiv Mutual Fund Holding database (S12). The final sample consists of 595 ETFs, which is comparable to recent studies such as those of Antoniou et al. (2020) and Glosten et al. (2021).

We then collect bond issuance information from the Refinitiv Securities Data Company (SDC) database. ${ }^{6}$ Similarly to previous studies such as that by Gao et al. (2020), we exclude callable, putable, convertible, and exchangeable bonds to mitigate confounding effects caused by embedded options. Our analysis focuses on fixed-rate straight bonds issued by U.S. public firms in the primary bond market. In the main analysis, we also exclude financial and utility firms because bonds issued by those firms behave differently (Gao et al., 2020). ${ }^{7}$

We collect the Treasury spot rates information from the Federal Reserve Board. The stock returns and accounting information come from the CRSP and Compustat. We consider stocks traded on the NYSE, AMEX, and NASDAQ with share codes of 10 or 11. We obtain the short interest data from Compustat Supplement Short Interest File, the analyst-related information from Institutional Brokers' Estimate System (IBES), and directors and corporate governance measures from the Institutional Shareholder Service database (ISS). To avoid the potential confounding impact of the Regulation SHO Pilot Program, our sample starts from 2008. The sample stops in 2018 due to the availability of the MFLINKS table. ${ }^{8}$

\footnotetext{
${ }^{6}$ After being acquired by Blackstone in 2018, the Thomson Reuters Financial \& Risk unit was renamed Refinitv. Some databases involved are referred to as both Thomson Reuters and Refinitv. To avoid confusion, we use the name Refinitiv throughout the paper.

${ }^{7}$ We include firms from all industries in the robustness analysis in Section 2.6.2.

${ }^{8}$ The Regulation SHO Pilot Program started on May 2, 2005, and ended on April 28, 2006. During this period, the short-selling constraints were reduced for a random sample of firms to evaluate the
} 


\subsubsection{Key variables}

\section{Bond offering yield spread}

Following Gao et al. (2020), we use the offering yield spread of corporate bonds as a proxy for firms' cost of debt, which is the offering yield minus the synthetic riskfree yield. To calculate the synthetic risk-free yield, we first construct the complete Treasury yield curve using the Treasury spot rates from the Federal Reserve Board. The construction of the yield curve follows the method by Gürkaynak, Sack, and Wright (2007). Then we compute the price of a synthetic risk-free bond with the same maturity, coupons, and principals as each corporate bond in our sample. Using the price of the synthetic risk-free bond obtained in the previous step, we back out the yield to maturity of such synthetic risk-free bond and use it to calculate the bond offering yield spread.

\section{Equity ETF ownership}

The firm-level equity ETF ownership is calculated as shares held by U.S. domestic equity ETFs scaled by shares outstanding at the end of each quarter,

$$
\operatorname{ETF}_{i, t}=\frac{\sum_{j \in J} \text { Shares }_{i, j, t}}{\text { shares outstanding }} \text {, }
$$

where $J$ is the set of ETFs holding firm $i^{\prime} s$ stock, and Shares $s_{i, j, t}$ is the number of shares of firm $i$ held by ETF $j$ at the end of quarter $t$.

\section{Abnormal short interest}

We follow Karpoff and Lou (2010) to calculate the abnormal short interest, $A B S I$, as follows:

$$
A B S I_{i, t}=S I_{i, t}-E S I_{i, t}
$$

In equation (2.2), $S I_{i, t}$ is the raw short interest of firm $i$ at time $t$, which is the firm's shorted shares scaled by its shares outstanding. $E S I_{i, t}$ is the expected short interest of firm $i$ at time $t$, which is calculated as the fitted value from a monthly cross-sectional regression. To run the regression, in each month we independently classify stocks into three groups by size, book-to-market ratio, and momentum. As a result, each stock is 
assigned to one of the $27(3 \times 3 \times 3)$ constructed portfolios. We further put each stock into industry groups based on the Fama-French 48 industry classifications. Then we run the following regression in each month,

$$
S I_{i, t}=\sum_{g=l o w}^{\text {medium }} s_{g, t} S_{i z e_{i, g, t}}+\sum_{g=\text { low }}^{\text {medium }} b_{g, t} B T M_{i, g, t}+\sum_{g=l o w}^{\text {medium }} m_{g, t} M_{\text {om }} m_{i, g, t}+\sum_{k=1}^{48} \phi_{k, t} I_{1 n d_{i, k, t}}+u_{i, t} .
$$

The first three sets of independent variables are dummy variables that collectively determine the 27 size, book-to-market, and momentum portfolios. For example, if firm $i$ is sorted into the lowest book-to-market portfolio in month $t$, then $B T M_{i, l o w, t}=1$ and $B T M_{i, \text { medium }, t}=0$. Industry dummy $I n d_{i, k, t}$ equals 1 if firm $i$ is classified into industry $k$ in month $t$. The fitted value $E S I_{i, t}$ is calculated using the monthly updated coefficients.

\section{Standardized unexpected earnings}

Following Livnat and Mendenhall (2006) and Huang et al. (2021), we define earnings surprises as the standardized unexpected earnings (SUE), which is calculated as the difference between the actual value of earnings per share (EPS) and the expected value of EPS scaled by stock prices. Regarding the expected EPS, we employ two proxies: i) stock analysts' median estimates of EPS and ii) the same quarter EPS of the previous year. The two SUEs are denoted by SUE - Analyst and SUE - Seasonal, respectively. We apply standard filters used by previous studies for the calculation of SUEs. Follow Livnat and Mendenhall (2006), we require firms to have positive quarterly sales and assets and filter out firms whose price is below $\$ 1$ and market capitalization is below $\$ 5$ million. We require the earnings announcement date is non-missing in Compustat. If the date recorded is different in Compustat and IBES, we require that the earnings announcement date recorded in two sources should differ by no more than one calendar day and we set the earnings announcement date as the earliest one of the two sources. We keep the last EPS estimate of each analyst issued 90 days prior to the earnings announcement.

\subsubsection{Control variables}

We include three sets of control variables in the regressions. The first set of variables consists of firm characteristics. Mansi et al. (2011) and Ball et al. (2018) show larger 
and more mature firms with a relatively good information environment can receive more favorable financing conditions. We use firm size (Size) and age (Age) to control for these two factors. In addition, we use the leverage ratio (Leverage) to measure the financial risk (Collin-Dufresne and Goldstein, 2001; Eom, Helwege, and Huang, 2004). Following Kogan and Papanikolaou (2014), we control for the firm's future growth opportunity using the book-to-market ratio $(B T M)$. We also include return on assets $(R O A)$ in our analysis to control the operating performance (Core, Guay, and Rusticus, 2006). The second category of variables include stock returns (Return) and stock return volatility (Volatility), measuring the risk and returns of firms (Campbell and Taksler, 2003). The third group of control variables is related to the bond offering information, including issue size (Issue size), issue maturity (Issue maturity), and credit ratings (Rating). We primarily use the rating information given by Moody's. If such information is not available, we supplement it using Standard \& Poor's rating. We define each variable as follows:

- Size: the natural logarithm of market capitalization;

- Age: the number of years since the firm's IPO date;

- Leverage: the total liabilities divided by total assets;

- BTM: the book value of equity divided by the market value of equity;

- $R O A$ : operating income before depreciation divided by total assets;

- Return: the average daily stock returns over the past year;

- Volatility: the standard deviation of daily stock returns over the sample period;

- Issue size: the natural logarithm of total proceeds from bond issuance;

- Issue maturity: the natural logarithm of bond maturity;

- Rating: we follow Blume, Lim, and MacKinlay (1998) and convert the original rating system to a numerical rating system. The numerical scale of the bond rating ranges from zero for AAA bonds to twenty for $\mathrm{C}$ bonds. 


\subsubsection{Summary statistics}

Table 2.1 presents the descriptive statistics of the main variables used in our empirical analysis. The average bond offering yield spread is $2.7 \%$ in our sample. Figure 2.1 plots the offering yield spread by year over the sample period of 2008 through 2018 and shows a decreasing trend except for the periods around the Global Financial Crisis (GFC). The average bond spread changes from around 4\% in 2008 to $2 \%$ in 2018 and spikes to more than $6 \%$ during the GFC period.

[Insert Table 2.1 about here.]

[Insert Figure 2.1 about here.]

The average equity ETF ownership is 5.3\%, with a standard deviation of $2.7 \%$. Figure 2.2 displays an increasing pattern of equity ETF ownership, indicating the tremendous growth of ETFs over the past decade.

\section{[Insert Figure 2.2 about here.]}

We also report summary statistics of firm and bond characteristics related to bond pricing, including firm size, firm age, leverage, BTM, ROA, return, volatility, issue size, issue maturity, and credit rating. The sample firms appear to have a larger size, which is consistent with previous studies that firms with publicly traded debt tend to be larger (Mansi et al., 2011; Florou and Kosi, 2015). In addition, firms in our sample generally have high profitability, with an average $R O A$ of $15.5 \%$, and good growth opportunities, with an average $B T M$ of $0.51 .^{9}$ On average, the log bond offering proceeds are 7.12 million, the log bond maturity is 2.35 years, and the mean bond rating is 7.92, which corresponds to a rating of Baa2 in Moody's rating system.

\subsection{Empirical Results}

This section presents our main empirical results on the association between equity ETF ownership and firms' cost of debt. We begin with the baseline regressions and then extend our analysis by examining whether the impact of equity ETF ownership on the cost of debt varies with firm and bond attributes.

\footnotetext{
${ }^{9}$ For comparison, the average firm size, $R O A$, and $B T M$ for the common equities in the CRSP and Compustat universe in the same sample period are $19.988,1.9 \%$, and 0.827 , respectively.
} 


\subsubsection{Baseline results}

To examine whether a firm's equity ETF ownership affects its cost of debt, we run the following regression,

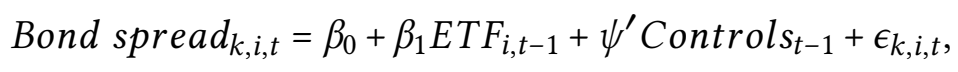

where Bond spread s $_{k, i, t}$ is the offering yield spread of bond $k$ issued by firm $i$ in quarter $t$, $E T F_{i, t-1}$ is the lagged equity ETF ownership of firm $i$, and Controls $s_{t-1}$ contains the lagged control variables including firm size, firm age, leverage ratio, book-to-market ratio, return on assets, return volatility, stock returns, bond issuing size, issuing maturity, and bond rating. In addition, we control for the Fama-French 48 industry fixed effect and year fixed effect and cluster the standard errors at the firm level.

Table 2.2 reports the baseline regression results using the specification in equation (2.4). Columns (1)-(3) use different sets of control variables. We include firm characteristics in column (1) and further augment the regression by adding stock returns and return volatility in column (2). Column (3) adds controls for issuance related variables.

[Insert Table 2.2 about here.]

Across all specifications, we find a statistically negative coefficient estimate of $E T F$, suggesting that higher ETF ownership is associated with a lower cost of firm borrowing. The coefficient estimate of $\beta_{1}$ in column (3) is -0.077 and significant at the $1 \%$ level. It implies that a one standard deviation increase of equity ETF ownership leads to a decrease of offering yield spread by 20.7 basis points $(-0.077 \times 0.027)$, which is $7.7 \%$ of the average bond spread and economically meaningful. This magnitude is comparable with the one documented by Dannhauser (2017), which shows a one standard deviation increase of the bond ETF ownership reduces the bond spreads for high-yield and investment-grade bonds by 20.3 and 9.2 basis points in the secondary bond market, respectively. In addition, our result is stronger than the one shown in Gao et al. (2020), which reports a drop of 14.4 basis point in the offering yield spread induced by an additional unit of media coverage. 
The other control variables have the expected signs. For example, bond offering yield spreads are lower for firms that are larger, lower leveraged, and with higher growth opportunities (lower BTM ratio). These findings are consistent with the corporate finance literature. Bond spreads are positively related to stock return volatility, which is consistent with the prediction by Campbell and Taksler (2003).We also find that the yield spreads are higher for bonds with larger issuance proceeds, longer maturities, and worse credit ratings.

Overall, our results support a negative association between equity ETF ownership and firms' cost of debt. The finding provides evidence on the positive influence of equity ETFs, which complements several recent papers that document positive effects of ETFs (see, e.g., Glosten, Nallareddy, and Zou, 2021; Antoniou, Li, Liu, Subrahmanyam, and Sun, 2020).

\subsubsection{Cross-sectional analyses}

In this section, we carry out two cross-sectional tests on the differential effects of ETF ownership on a firm's cost of borrowing. Specifically, we explore whether the impact of ETF ownership is related to a firm's information environment and credit rating.

Glosten et al. (2021) show that the effect of equity ETF ownership is related to a firm's information environment. They find that the positive impact of ETF ownership on facilitating the incorporation of systematic earnings information is more pronounced for firms with weaker information environments. Dannhauser (2017) demonstrates that the effect of bond ETF ownership on yield spread is different between investment-grade and junk-grade bonds. Inspired by Glosten et al. (2021) and Dannhauser (2017), we investigate whether the effects of equity ETF ownership on bond spreads vary with information environments and bond credit ratings by adding interaction terms between ETF ownership and proxies for information environments and credit ratings.

Following Glosten et al. (2021), we use firm size and the number of analysts following as proxies for information environments. We construct the firm size variable, Size decile, using the decile group to which a firm's market capitalization belongs before the bond issuing date. The smallest firms are assigned a value of ten, whereas 
the largest firms are assigned a value of one. Since larger firms tend to have stronger information environments, higher values of Size decile indicate weaker information environments. Similarly, we calculate the analyst number variable, Analyst decile, based on the number of analysts following a firm in the quarter before the bond offering date. Specifically, firms with the least analyst coverage (bottom 10\%) are assigned a value of ten, whereas firms with the most analyst coverage (top 10\%) are assigned a value of one. Given that firms with fewer analysts following tend to have weaker information environments, higher values of Analyst decile indicate weaker information environments. For credit rating, we use a dummy variable of junk bonds. Junk dummy is a dummy variable that takes a value of one for bonds below BBB rating; and zero otherwise.

The regression models are as follows:

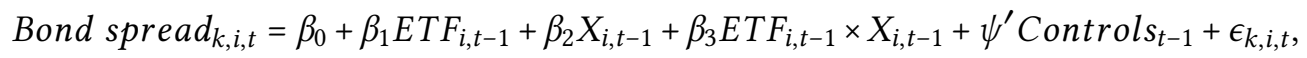

where $X_{i, t-1}$ denotes the information environment or credit rating variables. That is, $X_{i, t-1}=$ Size decile $_{i, t-1}$, Analyst decile $e_{i, t-1}$, or Junk dummy $y_{i, t-1}$. Similar to equation (2.4), we control for the Fama-French 48 industry and year fixed effect and cluster the standard errors at the firm level.

We present the regression results in Table 2.3. The coefficient on the interaction term ETF $\times$ Size decile is -0.025 and significant at the $1 \%$ level, indicating that the negative relationship between equity ETF ownership and the cost of debt is stronger for smaller firms that have weaker information environments. Similarly, as shown in column (2), the coefficient of ETF $\times$ Analyst decile is significantly negative, suggesting a stronger effect of ETF ownership for firms with less analyst coverage. The negative coefficient estimates of the interaction terms imply that the negative association between equity ETF ownership and bond spreads is more pronounced for firms with weak information environments.

Column (3) presents results on the credit rating. The coefficient of the interaction term ETF $\times$ Junk dummy is -0.09 and significant at the $1 \%$ level. The decrease in bond spread induced by ETF ownership is more pronounced for junk-grade bonds, which is consistent with Dannhauser (2017). 
[Insert Table 2.3 about here.]

Collectively, the results on cross-sectional tests show that the negative association between equity ETF ownership and the bond spread is more pronounced for firms with weaker information environments and lower ratings.

\subsection{Channels Analysis}

In this section, we explore two possible channels through which equity ETF ownership influences the cost of debt. The first one is the disciplinary effects imposed by short-selling activities, which are facilitated by equity ETFs. Most equity ETFs participate in the security lending market. By providing easier access to the short-selling market, equity ETFs facilitate short-sellers exploiting their information advantage and incorporating negative news into the stock price efficiently. Karpoff and Lou (2010) demonstrate a disciplinary effect brought by short-selling activities, which reduces earnings manipulations and other misconduct. Consequently, a lower bond yield spread for firms with higher equity ETF ownership is expected to be observed. The second channel is the improvement in corporate governance brought by ETFs. As documented by previous studies, passive index ownership can improve corporate governance (Boone and White, 2015; Appel et al., 2016, 2019). Such an improvement might be able to reduce the cost of debt (Bhojraj and Sengupta, 2003; Anderson, Mansi, and Reeb, 2004; Klock, Mansi, and Maxwell, 2005). To make the channels in our application more relevant, we only include those firms used in our baseline regression.

\subsubsection{Disciplinary effect of short-selling activities}

We conduct two tests to examine the disciplinary channel through which ETF ownership operates to impact bond pricing. First, we test whether the effects of equity ETF ownership is stronger for firms that are subject to greater limits to arbitrage. Equity ETF ownership could significantly reduce arbitrage constraints by actively participating in the security lending market. If the disciplinary effect of short-selling is indeed the channel behind our findings, the influence of equity ETF ownership should be more pronounced for firms that are subject to greater limits to arbitrage. Second, 
we employ negative earnings surprises events to analyze whether firms with higher equity ETF ownership have a more active short-selling market.

\section{Limits to arbitrage}

Pontiff (2006) and Hong, Li, Ni, Scheinkman, and Yan (2015) show that the short-selling of more volatile and illiquid stocks is less active because of the higher arbitrage costs. Following Pontiff (2006) and Li and Zhu (2018), we use two proxies to measure shortsale constraints. The first measure is idiosyncratic volatility, which is the standard deviation of the residuals when regressing daily stock returns on the Fama-French three-factor (Fama and French, 1993) plus the momentum factor (Carhart, 1997) using the past six months' data. We sort all firms into deciles according to their idiosyncratic volatility levels. Then we construct a decile variable, Idiosyncratic decile, where firms with the highest idiosyncratic volatility are assigned a value of ten and firms with the lowest volatility are assigned a value of one. The second proxy is the Amihud illiquidity decile variable, Amihud decile, calculated based on the decile of Amihud illiquidity measure to which a firm belongs before the bond issuing date. Firms in the top $10 \%$ of the Amihud illiquidity measure group (least liquid) are assigned a value of ten, while firms in the bottom $10 \%$ of the Amihud measure group (most liquid) are assigned a value of one. To run the regression, we use the same framework as equation (2.5) but with a different $X_{i, t-1}$. That is, $X_{i, t-1}=$ Idiosyncratic decile $_{i, t-1}$ or Amihud decile $_{i, t-1}$. We conjecture that the coefficient estimates of interaction terms $E T F \times$ Idiosyncratic decile and $E T F \times$ Amihud decile have a negative sign, indicating a stronger effect of ETF ownership for firms facing tighter short-sale constraints.

[Insert Table 2.4 about here.]

Table 2.4 presents the regression results. In column (1), we use the idiosyncratic volatility as a proxy for short-sale constraints. The coefficient of ETF $\times$ idiosyncratic decile is -0.022 and significant at the $5 \%$ level, implying a more pronounced effect of ETF ownership for firms with higher idiosyncratic volatility. As reported in column (2), the coefficient for ETF $\times$ Amihud decile is -0.030 and significant at the $1 \%$ level. This result indicates a larger decline in the cost of debt for less liquid firms. Collectively, our results show that the effects of equity ETF ownership on reducing the cost of debt 
are more pronounced for firms that are difficult to arbitrage. This finding is in line with that of Li and Zhu (2018).

\section{Negative news and short interest}

The above analysis on limits to arbitrage indirectly supports that equity ETF ownership might ease short-sale constraints for firms facing greater limits to arbitrage. A more direct test is to explore the relationship between equity ETF ownership and short interests. Glosten et al. (2021) show that firms with higher equity ETF ownership have higher lendable shares. ${ }^{10}$ Different from Glosten et al. (2021), we study short interest that is the outcome of both supply and demand. Specifically, we conduct an event study to explore the change in short interests around earnings announcements. We run regressions using the following specification:

$$
A B S I_{i, t}=\beta_{0}+\beta_{1} E_{T F} F_{i, t-1}+\beta_{2} S U E \text { decile }_{i, t}+\beta_{3} E_{T F} F_{i, t-1} \times S U E \text { decile }_{i, t}+\psi^{\prime} \text { Controls }_{t-1}+\epsilon_{i, t} \text {, }
$$

where $A B S I_{i, t}$ is the abnormal short interest of firm $i$ in quarter $t$. SUE decile $e_{i, t}$ is the SUE decile variable constructed using SUE for firm $i$ in quarter $t$ (SUE-Analyst or $S U E$-Seasonal). To construct $S U E$ decile $e_{i, t}$, we sort firms into deciles by their $S U E-$ Analyst or SUE-Seasonal. Firms in the top group of SUE-Analyst or SUESeasonal are assigned a value of one, whereas firms in the bottom group are assigned a value of ten. We construct SUE decile $e_{i, t}$ for negative and positive SUE, respectively. Since short-sellers have an information advantage and might establish their positions before the release of quarterly earnings, we use the latest ABSI information before the earnings announcement as the dependent variable. We control for the Fama-French 48 industry and year fixed effect and cluster the standard errors at the firm level.

Table 2.5 reports the results. Columns (1)-(2) report the results when using negative earnings surprises events and columns (3)-(4) report the results of positive earnings surprises events. As shown in columns (1)-(2), the coefficient estimates of the interaction term between ETF ownership and SUE decile are positively significant across

\footnotetext{
${ }^{10}$ In an untabulated analysis, we explore the relationship between equity ETF ownership and abnormal short interests. Our results show that the short interests of stocks increase with their corresponding ETF ownership.
} 
both specifications. The results support our conjecture that the short interests increase more for firms with higher equity ETF ownership during negative earnings surprises events. However, the coefficient estimates of the interaction term between equity ETF ownership and SUE decile are not significant for positive earnings surprises events, suggesting that short-selling activities facilitated by ETFs are not relevant when firms perform well. Collectively, by using the setting of earnings announcements, we document that the short-selling facilitated by ETFs is more relevant when firms do not perform well. Equity ETFs facilitate an active short-selling market around negative announcements, which enhances the external monitoring for firms to generate the disciplinary effect.

[Insert Table 2.5 about here.]

\subsubsection{Corporate governance}

Previous studies have shown that increased equity ETF ownership could improve corporate governance. For example, Appel et al. (2016) find that equity ETF ownership improves corporate governance by increasing the number of independent directors, removing takeover defenses, and having more equal voting rights. Boone and White (2015) document a positive association between institutional ownership and firm transparency. We test whether the reduced cost of debt associated with ETF ownership operates through the improved corporate governance channel. The improvement in corporate governance is the enhancement of the internal monitoring, which differs from the external disciplinary effect brought by short-sellers.

Following Appel et al. (2016) and Heath et al. (2021), we use five measures to capture corporate governance: (1) Independent director, calculated by the percentage of independent directors on the board, (2) Special meeting, a dummy variable indicating whether there exist restrictions for investors to call a special meeting, (3) Classified board, a dummy variable indicating whether the firm has a classified board, (4) Dualclass, a dummy variable indicating whether a firm has a dual-class share structure, and (5) Takeover defense, a dummy variable indicating whether a poison pill provision is in place. If the improvement in corporate governance is a relevant channel, the coefficient of ETF would be significantly positive for Independent director, and 
negative for others. We thus run the following regressions:

$$
\text { Governance proxies }_{i, t}=\beta_{0}+\beta_{1} \text { ETF }_{i, t-1}+\psi^{\prime} \text { Controls }_{t-1}+\epsilon_{i, t} \text {, }
$$

where Governance proxies $_{i, t}$ denotes one of five corporate governance measures for firm $i$ in year $t$. We add the Fama-french 48 industry and year fixed effect and cluster the standard errors at the firm level. We run the OLS regression for Independent director and logit regressions for the other four variables.

Table 2.6 presents the results. Most of the coefficient estimates of ETF are insignificant, except when Dualclass is used as the measure of corporate governance. The results in column (4) suggest that higher ETF ownership can increase the possibility of a firm's usage of a dual-class structure, which contrasts with the expected sign if the improvement in corporate governance is a relevant channel in our application. The results in Table 2.6 imply that the improvement in corporate governance is not the channel that explains our primary empirical results. These findings are consistent with those of Schmidt and Fahlenbrach (2017) and Heath et al. (2021), which fail to document improved corporate governance induced by an increase in equity ETF ownership.

[Insert Table 2.6 about here.]

\subsection{Endogeneity and Robustness Checks}

In this section, we address the endogeneity concerns and perform several robustness checks of our findings.

\subsubsection{Endogeneity}

In the primary analyses, we include industry-level fixed effects to control for industrylevel unobserved heterogeneity. However, sector/industry ETFs might be created to cover promising industries that tend to have a lower cost of debt. Our results may purely pick up an industry trend that could generate a spurious correlation between ETF ownership and the cost of debt. To control for the time-varying industry confounding effect that might bias our results, we include industry-by-year fixed effects in the regressions. Panel A of Table 2.7 reports the results. We continue to find a significant 
and negative relationship between equity ETF ownership and the cost of debt after controlling for industry-by-year fixed effects.

[Insert Table 2.7 about here.]

Moreover, the ETF ownership can correlate with unobserved firm characteristics that affect the bond pricing. To address this concern, we follow Zou (2019) and Antoniou et al. (2020) in employing BlackRock's acquisition of iShares ETF from Barclays Global Investors at the end of 2009 as an exogenous shock to ETF ownership. After the global financial crisis (GFC), Barclays sold iShares ETFs to BlackRock to strengthen its balance sheet and avoid a possible bailout by the UK government. The acquisition increased the asset holdings of BlackRock by $37 \%$ and strengthened BlackRock's leading position in the ETF industry (Zou, 2019). Zou (2019) and Antoniou et al. (2020) show due to the branding and scale benefits and distribution channels of BlackRock, there has been an exogenous increase in ETF ownership for stocks with higher iShares ETF ownership relative to those stocks with lower iShares ETF ownership since the acquisition of iShares ETFs by BlackRock. The value of asset management under iShares ETFs increased by $19 \%$ one year after the acquisition. This acquisition essentially induced an exogenous change in equity ETF ownership, which is not relevant to firm characteristics but is caused by the influence of BlackRock.

As the acquisition was completed by the end of 2009 , we use a four-year window around 2009 to run the regression. The sample period covers from 2008 to 2011. Following Antoniou et al. (2020), we classify firms in the top 30\% of the iShares ETF ownership averaged over 2008 and 2009 as the treatment group (Treat $=1)$ and the rest of the firms as the control group $($ Treat $=0) .{ }^{11}$ The indicator variable Post is one for the period in 2010 and 2011 and zero otherwise. When exploring the impact of this acquisition, we use two specifications.

\footnotetext{
${ }^{11}$ We use this approach to induce more variation in the Treat, as most of the firms in our sample have some ownership by iShares ETF. In each year, the iShares ETF ownership is a firm-level ratio defined as the shares owned by iShares ETF normalized by the shares outstanding. We calculate the mean of the iShares ETF ownership in 2008 and 2009 and rank firms by this mean.
} 
First, we follow Zou (2019) to use the difference-in-differences (DID) specification to test the relationship between equity ETF ownership and the cost of debt,

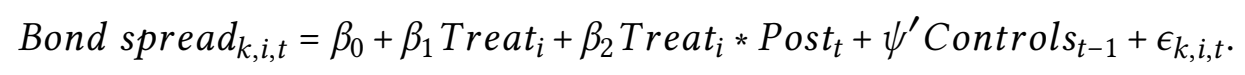

The coefficient of the interaction term Treat $\times$ Post captures the relationship between exogenous equity ETF ownership and the cost of debt. ${ }^{12}$ Column (1) in Panel B of Table 2.7 reports the results. The coefficient of interest, $\beta_{2}$, is negative and significant at the $5 \%$ level, implying that firms with higher iShares ETF ownership before the acquisition indeed have a lower cost of bond relative to other firms.

Second, we follow Antoniou et al. (2020) and estimate the IV model jointly using two-stage least-squares (2SLS) method to explore the effects of ETF ownership on the cost of debt. The first and second stage of regressions are in Equation (2.9),

$$
\begin{aligned}
\text { ETF }_{i, t} & =\beta_{0}+\beta_{1} \text { Treat }_{i} * \text { Post }_{t}+\psi^{\prime} \text { Controls }_{t-1}+\epsilon_{i, t}, \\
\text { Bond spread }_{k, i, t} & =\beta_{0}+\beta_{1} \operatorname{ETF}\left(\text { fitted }_{i, t-1}+\psi^{\prime} \text { Controls }_{t-1}+\epsilon_{k, i, t} .\right.
\end{aligned}
$$

Our variable of interest is the coefficient of the fitted ETF (ETF $(f i t t e d))$ in the second stage regression. We present the results of the IV regressions in columns (2)-(3) of Table 2.7 Panel B. In the first stage, we find a significantly positive relationship between our instrument variable (Treat $\times$ Post) and equity ETF ownership, indicating that the instrument variable Treat $\times$ Post meets the relevancy criteria. The exclusion criteria of IV is also likely to be met as the BlackRock's acquisition of iShares ETF is unlikely driven by fundamental characteristics of stocks with higher iShares ETF ownership. In the second stage, we regress the offering yield spread on the fitted value of equity ETF ownership (ETF( itted)) obtained from the first stage to re-examine the effect of ETF ownership on the bond pricing. As reported in column (3), we continue to find a negative association between ETF ownership and the cost of debt, consistent with the main results.

${ }^{12}$ When including year fixed effects, we exclude the Post variable in the regressions as the year fixed effects will absorb the Post variable. 


\subsubsection{Robustness tests}

We conduct two robustness tests to study whether our results are robust to a different sample and an alternative definition of ETF ownership. Given the unique characteristics of the financial and utility industries, we follow Gao et al. (2020) and do not include them in our primiary regressions. As a robustness check, we include the financial and utility industries in the regressions. In addition, we follow Antoniou et al. (2020) in using the number of ETFs holding the stock, Number of ETFs, as an alternative measure of ETF ownership. Number of ETFs is calculated using the natural log of one plus the number of ETFs holding a firm.

[Insert Table 2.8 about here.]

Table 2.8 reports the results of the robustness checks. Column (1) presents the results when including the financial and utility industries. Our results still hold. Column (2) reports the results of using Number of ETFs as the measure of ETF ownership. The coefficient of Number of ETFs is statistically negative. These results indicate that our results continue to hold when employing a different sample or a different measure of ETF ownership.

\subsection{Conclusion}

The recent decade has witnessed tremendous growth in ETFs. The ETF industry is increasingly playing an important role because of its low cost, high liquidity, and good diversification. Therefore it is critical to understand the impact of ETF ownership on asset pricing and corporate governance. This paper explores the influence of equity ETF ownership on the cost of debt in the primary bond market.

We document a negative association between equity ETF ownership and bond spreads. This negative association is more pronounced for firms with weaker information environments and lower bond ratings. We further explore the channels through which equity ETF ownership could influence bond pricing. We identify the disciplinary effect of short-selling facilitated by ETFs as one channel but find no support for the improvement of corporate governance. 
We address the issue of endogeneity from two aspects. First, by controlling for the industry-by-year fixed effect, we mitigate the concern that the ETF fund managers might follow some good-performing industries. Second, we use BlackRock's acquisition of iShares ETF from Barclays Global Investors at the end of 2009 as a quasi-experiment to run the test. Our results continue to hold.

This study uses bond price information in the primary market. To extend this analysis, it might be fruitful to study the influence of equity ETF ownership on the bond prices in the secondary bond market in future research. 


\section{References}

Amihud, Y., 2002. Illiquidity and stock returns: cross-section and time-series effects. Journal of Financial Markets 5, 31-56.

Anderson, R. C., Mansi, S. A., Reeb, D. M., 2004. Board characteristics, accounting report integrity, and the cost of debt. Journal of Accounting and Economics 37, $315-342$.

Antoniou, C., Li, F. W., Liu, X., Subrahmanyam, A., Sun, C., 2020. The real effects of exchange-traded funds. Unpublished working paper.

Appel, I. R., Gormley, T. A., Keim, D. B., 2016. Passive investors, not passive owners. Journal of Financial Economics 121, 111-141.

Appel, I. R., Gormley, T. A., Keim, D. B., 2019. Standing on the shoulders of giants: the effect of passive investors on activism. The Review of Financial Studies 32, $2720-2774$.

Azar, J., Schmalz, M. C., Tecu, I., 2018. Anticompetitive effects of common ownership. The Journal of Finance 73, 1513-1565.

Baig, A., DeLisle, J., Zaynutdinova, G. R., 2018. Passive ownership and earnings manipulation. Unpublished working paper.

Ball, R. T., Hail, L., Vasvari, F. P., 2018. Equity cross-listings in the US and the price of debt. Review of Accounting Studies 23, 385-421.

Ben-David, I., Franzoni, F., Moussawi, R., 2018. Do ETFs increase volatility? The Journal of Finance 73, 2471-2535.

Bessembinder, H., Kahle, K. M., Maxwell, W. F., Xu, D., 2008. Measuring abnormal bond performance. The Review of Financial Studies 22, 4219-4258.

Bhattacharya, A., O’Hara, M., 2018. Can ETFs increase market fragility? Effect of information linkages in ETF markets. Unpublished working paper. 
Bhojraj, S., Mohanram, P., Zhang, S., 2020. ETFs and information transfer across firms. Journal of Accounting and Economics 70, 1-20.

Bhojraj, S., Sengupta, P., 2003. Effect of corporate governance on bond ratings and yields: the role of institutional investors and outside directors. The Journal of Business 76, 455-475.

Blume, M. E., Lim, F., MacKinlay, A. C., 1998. The declining credit quality of US corporate debt: myth or reality? The Journal of Finance 53, 1389-1413.

Boehmer, B., Boehmer, E., 2003. Trading your neighbor's ETFs: competition or fragmentation? Journal of Banking \& Finance 27, 1667-1703.

Boehmer, E., Jones, C. M., Zhang, X., 2008. Which shorts are informed? The Journal of Finance 63, 491-527.

Bond, P., Garcia, D., 2018. The equilibrium consequences of indexing. Unpublished working paper.

Boone, A. L., White, J. T., 2015. The effect of institutional ownership on firm transparency and information production. Journal of Financial Economics 117, 508-533.

Borisova, G., Fotak, V., Holland, K., Megginson, W. L., 2015. Government ownership and the cost of debt: evidence from government investments in publicly traded firms. Journal of Financial Economics 118, 168-191.

Borisova, G., Megginson, W. L., 2011. Does government ownership affect the cost of debt? Evidence from privatization. The Review of Financial Studies 24, 2693-2737.

Bratten, B., Huang, M., Payne, J. L., 2020. Passive investment and stock repurchase activity. Unpublished working paper.

Broman, M. S., 2016. Liquidity, style investing and excess comovement of exchangetraded fund returns. Journal of Financial Markets 30, 27-53.

Brown, D. C., Cederburg, S., Towner, M., 2021. Dominated ETFs. Unpublished working paper. 
Brown, D. C., Davies, S., Ringgenberg, M., 2018. ETF arbitrage and return predictability. Unpublished working paper.

Campbell, J. Y., Taksler, G. B., 2003. Equity volatility and corporate bond yields. The Journal of Finance 58, 2321-2350.

Cao, Y., Myers, L. A., Tsang, A., Yang, Y. G., 2017. Management forecasts and the cost of equity capital: international evidence. Review of Accounting Studies 22, 791-838.

Carhart, M. M., 1997. On persistence in mutual fund performance. The Journal of Finance 52, 57-82.

Christophe, S. E., Ferri, M. G., Angel, J. J., 2004. Short-selling prior to earnings announcements. The Journal of Finance 59, 1845-1876.

Collin-Dufresne, P., Goldstein, R. S., 2001. Do credit spreads reflect stationary leverage ratios? The Journal of Finance 56, 1929-1957.

Cong, L. W., Xu, D., 2019. Rise of factor investing: asset prices, informational efficiency, and security design. Unpublished working paper.

Core, J. E., Guay, W. R., Rusticus, T. O., 2006. Does weak governance cause weak stock returns? An examination of firm operating performance and investors' expectations. The Journal of Finance 61, 655-687.

Corum, A. A., Malenko, A., Malenko, N., 2020. Corporate governance in the presence of active and passive delegated investment. Unpublished working paper.

Da, Z., Shive, S., 2018. Exchange traded funds and asset return correlations. European Financial Management 24, 136-168.

Dannhauser, C. D., 2017. The impact of innovation: evidence from corporate bond exchange-traded funds (ETFs). Journal of Financial Economics 125, 537-560.

Easley, D., Michayluk, D., O’Hara, M., Putniņ̌s, T. J., 2020. The active world of passive investing. Unpublished working paper. 
Eom, Y. H., Helwege, J., Huang, J. Z., 2004. Structural models of corporate bond pricing: an empirical analysis. The Review of Financial Studies 17, 499-544.

Evans, R. B., Moussawi, R., Pagano, M. S., Sedunov, J., 2019. ETF short interest and failures-to-deliver: naked short-selling or operational shorting? Unpublished working paper.

Even-Tov, O., 2017. When does the bond price reaction to earnings announcements predict future stock returns? Journal of Accounting and Economics 64, 167-182.

Fama, E. F., French, K. R., 1993. Common risk factors in the returns on stocks and bonds. Journal of Financial Economics 33, 3-56.

Fichtner, J., Heemskerk, E. M., Garcia-Bernardo, J., 2017. Hidden power of the big three? Passive index funds, re-concentration of corporate ownership, and new financial risk. Business and Politics 19, 298-326.

Florou, A., Kosi, U., 2015. Does mandatory IFRS adoption facilitate debt financing? Review of Accounting Studies 20, 1407-1456.

Gao, H., Wang, J., Wang, Y., Wu, C., Dong, X., 2020. Media coverage and the cost of debt. Journal of Financial and Quantitative Analysis 55, 429-471.

Gao, P., Hu, A., Kelly, P., Peng, C., Zhu, N., 2021. Exploited by complexity. Unpublished working paper.

Gebhardt, W. R., Hvidkjaer, S., Swaminathan, B., 2005. Stock and bond market interaction: does momentum spill over? Journal of Financial Economics 75, 651-690.

Glosten, L., Nallareddy, S., Zou, Y., 2021. ETF activity and informational efficiency of underlying securities. Management Science 67, 22-47.

Gürkaynak, R. S., Sack, B., Wright, J. H., 2007. The US Treasury yield curve: 1961 to the present. Journal of Monetary Economics 54, 2291-2304.

Hamm, S., 2014. The effect of ETFs on stock liquidity. Unpublished working paper. 
Hao, X., Kim, D., Sul, H. K., Wang, Q., 2019. Underlying bond return predictability by ETF returns. Unpublished working paper.

Heath, D., Macciocchi, D., Michaely, R., Ringgenberg, M., 2021. Do index funds monitor? The Review of Financial Studies forthcoming.

Henderson, B. J., Jegadeesh, N., Weisbach, M. S., 2006. World markets for raising new capital. Journal of Financial Economics 82, 63-101.

Hong, H., Li, W., Ni, S. X., Scheinkman, J. A., Yan, P., 2015. Days to cover and stock returns. Unpublished working paper.

Huang, S., O’Hara, M., Zhong, Z., 2021. Innovation and informed trading: evidence from industry ETFs. The Review of Financial Studies 34, 1280-1316.

ICI, 2021. Investment company fact book (2021): a review of trends and activities in the investment company industry, vol. 61. Investment Company Institute.

Israeli, D., Lee, C. M., Sridharan, S. A., 2017. Is there a dark side to exchange traded funds? An information perspective. Review of Accounting Studies 22, 1048-1083.

Iwadate, M. B., 2021. Mind thy neighbor's portfolio: a network approach to contagion in the ETF market. Unpublished working paper.

Johnson, T. L., Kim, J., So, E. C., 2019. Expectations management and stock returns. The Review of Financial Studies 33, 4580-4626.

Karmaziene, E., Sokolovski, V., 2015. Beware of the spider: exchange traded funds and the 2008 short-sale ban. Unpublished working paper.

Karpoff, J. M., Lou, X., 2010. Short sellers and financial misconduct. The Journal of Finance 65, 1879-1913.

Klock, M. S., Mansi, S. A., Maxwell, W. F., 2005. Does corporate governance matter to bondholders? Journal of Financial and Quantitative Analysis 40, 693-719.

Kogan, L., Papanikolaou, D., 2014. Growth opportunities, technology shocks, and asset prices. The Journal of Finance 69, 675-718. 
Krause, T., Ehsani, S., Lien, D., 2014. Exchange-traded funds, liquidity and volatility. Applied Financial Economics 24, 1617-1630.

Lee, Y. K., 2018. Three essays in asset pricing. Unpublished working paper.

Lettau, M., Madhavan, A., 2018. Exchange-traded funds 101 for economists. Journal of Economic Perspectives 32, 135-54.

Li, F. W., Zhu, Q., 2018. Short selling ETFs. Unpublished working paper.

Livnat, J., Mendenhall, R. R., 2006. Comparing the post-earnings announcement drift for surprises calculated from analyst and time series forecasts. Journal of Accounting Research 44, 177-205.

Mansi, S. A., Maxwell, W. F., Miller, D. P., 2011. Analyst forecast characteristics and the cost of debt. Review of Accounting Studies 16, 116-142.

Merton, R. C., 1974. On the pricing of corporate debt: the risk structure of interest rates. The Journal of Finance 29, 449-470.

Pan, K., Zeng, Y., 2019. ETF arbitrage under liquidity mismatch. Unpublished working paper.

Pontiff, J., 2006. Costly arbitrage and the myth of idiosyncratic risk. Journal of Accounting and Economics 42, 35-52.

Qi, Y., Roth, L., Wald, J. K., 2010. Political rights and the cost of debt. Journal of Financial Economics 95, 202-226.

Rapach, D. E., Ringgenberg, M. C., Zhou, G., 2016. Short interest and aggregate stock returns. Journal of Financial Economics 121, 46-65.

Saglam, M., Tuzun, T., Wermers, R., 2019. Do ETFs increase liquidity? Unpublished working paper.

Schmidt, C., Fahlenbrach, R., 2017. Do exogenous changes in passive institutional ownership affect corporate governance and firm value? Journal of Financial Economics 124, 285-306. 
Valta, P., 2012. Competition and the cost of debt. Journal of Financial Economics 105, 661-682.

Ye, S., 2018. How do ETFs affect the liquidity of the underlying corporate bonds. Unpublished working paper.

Zou, Y., 2019. Lost in the rising tide: exchange-traded fund flows and valuation. Unpublished working paper. 


\section{Tables and figures}

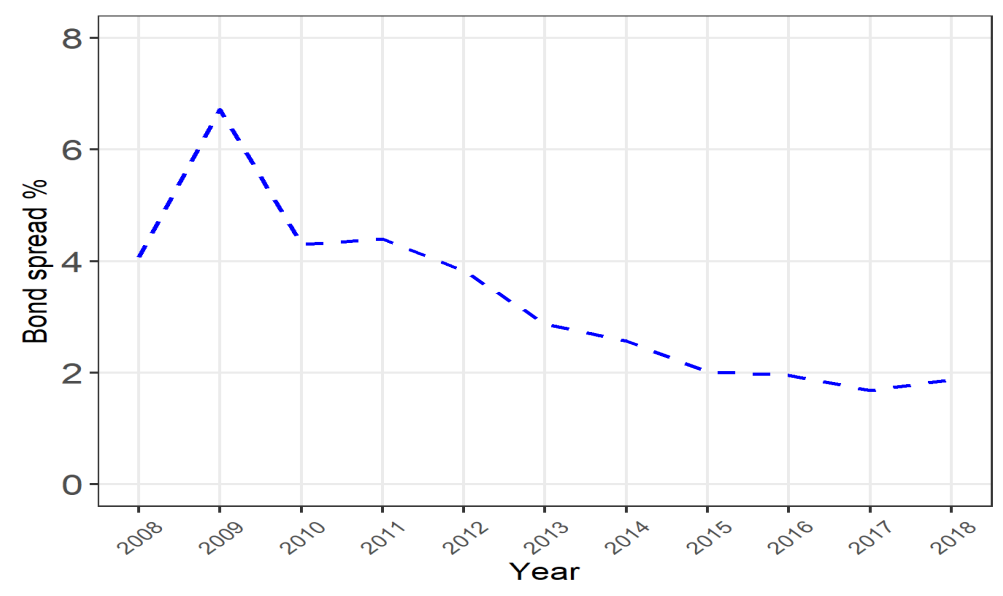

Figure 2.1: Average Bond Offering Spread by Year

This figure plots the average bond offering spread over the sample period of 2008 through 2018. Following Gao et al. (2020), we calculate the bond offering spread (in percentage) as the difference between the offering yield and the synthetic risk-free yield. 


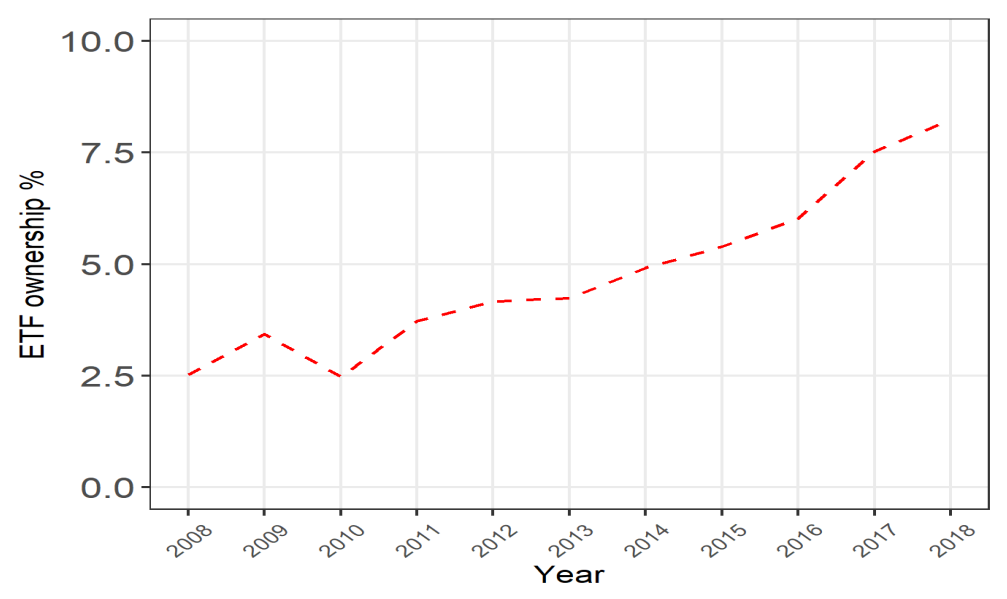

Figure 2.2: Average Equity ETF Ownership by Year

This figure displays the average equity ETF ownership over the sample period of 2008 through 2018. The equity ETF ownership (in percentage) is calculated as shares held by U.S. domestic equity ETFs scaled by shares outstanding at the end of each quarter. The sample includes firms that have issued a fixed-rate straight bond during the sample period. 


\section{Table 2.1: Summary Statistics}

This table reports the summary statistics of the variables used in our empirical analysis. ETF is shares owned by U.S. domestic equity ETFs scaled by the share outstanding. Bond spread is defined as the difference between the bond offering yield and the yield of the synthetic risk-free bond. Size is the natural log of market capitalization. Age is the number of years since the firm's IPO date. Leverage is defined as the total liabilities divided by total assets. BTM is measured as the book value of equity divided by the market value of equity. $R O A$ is measured as operating income before depreciation divided by total assets. Return is the average daily stock returns over the past year. Volatility is defined as the standard deviation of daily stock returns over the past year. Issue size is the natural log of total proceeds from the bond issuance. Issue maturity is the natural log maturity of the bond. Following Blume et al. (1998), we convert the original rating system to a numerical rating system. The numerical scale of the bond rating ranges from zero for AAA bonds to twenty for $\mathrm{C}$ bonds. The sample period is from 2008 to 2018 . We provide the detailed variable descriptions in the appendix.

\begin{tabular}{lcccccc}
\hline Variable & Obs. & Mean & Std. Dev. & P25 & P50 & P75 \\
\hline ETF & 1,190 & 0.053 & 0.027 & 0.039 & 0.053 & 0.065 \\
Bond spread & 1,190 & 0.027 & 0.024 & 0.011 & 0.017 & 0.039 \\
Size & 1,190 & 23.758 & 2.113 & 22.040 & 24.110 & 25.645 \\
Age & 1,190 & 35.756 & 26.781 & 15.000 & 29.000 & 47.000 \\
Leverage & 1,190 & 0.304 & 0.150 & 0.209 & 0.284 & 0.389 \\
BTM & 1,190 & 0.510 & 0.546 & 0.233 & 0.373 & 0.657 \\
ROA & 1,190 & 0.155 & 0.093 & 0.112 & 0.154 & 0.193 \\
Volatility & 1,184 & 0.020 & 0.013 & 0.012 & 0.016 & 0.023 \\
Return & 1,184 & 0.001 & 0.001 & 0.000 & 0.001 & 0.001 \\
Issue size & 1,190 & 7.117 & 1.374 & 6.109 & 6.964 & 8.006 \\
Issue maturity & 1,190 & 2.354 & 0.648 & 1.963 & 2.318 & 2.382 \\
Rating & 1,190 & 7.917 & 4.466 & 5.000 & 7.000 & 12.000 \\
\hline
\end{tabular}




\section{Table 2.2: Baseline Regressions: Equity ETF Ownership and Bond Offering Spread}

This table reports the results of regressing the bond offering yield spread on equity ETF ownership and other control variables. The dependent variable, denoted by Bond spread, is calculated as the difference between the bond offering yield and the yield of the synthetic risk-free bond. The variable ETF is calculated as shares held by U.S. domestic equity ETFs scaled by shares outstanding at the end of each quarter. We control firm characteristics, stock performance, and issue-related information in the regressions. The Fama-French 48 industry fixed effect and year fixed effect are controlled in all specifications. Robust $t$-statistics clustered at the firm level are reported in brackets. The sample period is from 2008 to $2018 .{ }^{*},{ }^{* *}$, and ${ }^{* * *}$ denote the statistical significance at the $10 \%, 5 \%$, and $1 \%$ levels, respectively. We provide the detailed variable descriptions in the appendix.

\begin{tabular}{|c|c|c|c|}
\hline & \multicolumn{3}{|c|}{ Bond spread } \\
\hline & (1) & (2) & (3) \\
\hline ETF & $\begin{array}{c}-0.099^{* * *} \\
(-3.77)\end{array}$ & $\begin{array}{c}-0.086^{\star * *} \\
(-3.46)\end{array}$ & $\begin{array}{c}-0.077^{\star \star *} \\
(-3.34)\end{array}$ \\
\hline Size & $\begin{array}{c}-0.009^{* * *} \\
(-19.19)\end{array}$ & $\begin{array}{c}-0.008^{\star * *} \\
(-15.03)\end{array}$ & $\begin{array}{c}-0.005^{* * *} \\
(-6.67)\end{array}$ \\
\hline Age & $\begin{array}{l}-0.000 \\
(-0.98)\end{array}$ & $\begin{array}{l}-0.000 \\
(-0.75)\end{array}$ & $\begin{array}{l}0.000 \\
(1.04)\end{array}$ \\
\hline Leverage & $\begin{array}{l}0.009^{* *} \\
(2.02)\end{array}$ & $\begin{array}{l}0.007^{*} \\
(1.65)\end{array}$ & $\begin{array}{l}0.001 \\
(0.32)\end{array}$ \\
\hline BTM & $\begin{array}{c}0.005^{* * *} \\
(3.02)\end{array}$ & $\begin{array}{l}0.003^{* *} \\
(2.07)\end{array}$ & $\begin{array}{l}0.003^{*} \\
(1.73)\end{array}$ \\
\hline ROA & $\begin{array}{l}-0.010 \\
(-1.55)\end{array}$ & $\begin{array}{l}-0.005 \\
(-0.89)\end{array}$ & $\begin{array}{l}0.002 \\
(0.38)\end{array}$ \\
\hline Volatility & & $\begin{array}{c}0.381^{\star \star \star} \\
(3.95)\end{array}$ & $\begin{array}{c}0.334^{* \star *} \\
(3.54)\end{array}$ \\
\hline Return & & $\begin{array}{l}-0.271 \\
(-0.40)\end{array}$ & $\begin{array}{l}-0.824 \\
(-1.38)\end{array}$ \\
\hline Issue size & & & $\begin{array}{c}0.001^{* *} \\
(2.13)\end{array}$ \\
\hline Issue maturity & & & $\begin{array}{l}0.001^{*} \\
(1.78)\end{array}$ \\
\hline Rating & & & $\begin{array}{c}0.002^{* * *} \\
(5.31)\end{array}$ \\
\hline Year FE & Yes & Yes & Yes \\
\hline FF48 FE & Yes & Yes & Yes \\
\hline Obs & 1,190 & 1,184 & 1,184 \\
\hline Adj. $R^{2}$ & 0.773 & 0.790 & 0.814 \\
\hline
\end{tabular}




\section{Table 2.3: Cross-sectional Analyses}

This table examines the heterogeneous effects of equity ETF ownership on bond offering yield spread as a function of the information environment (columns (1)-(2)), and the bond's credit rating (column (3)). We use firm size and analyst following as proxies for information environments. We construct the firm size decile variable, Size decile, which equals the decile group to which a firm's market capitalization belongs before the bond issuing date. The smallest firms are assigned a value of ten, whereas the largest firms are assigned a value of one. Similarly, a decile variable based on the number of analysts following a firm, Analyst decile, is calculated in the quarter before the bond offering date. Specifically, firms with less analyst coverage are assigned a value of ten, whereas firms with more analyst coverage are assigned a value of one. Junk dummy is a dummy variable that takes a value of one for bonds below $\mathrm{BBB}$ rating, and zero otherwise. Lagged control variables include firm size, firm age, leverage ratio, book-to-market ratio, return on assets, return volatility, stock returns, bond issuing size, issuing maturity, and bond rating. The Fama-French 48 industry fixed effect and year fixed effect are controlled in all specifications. Robust $t$-statistics clustered at the firm level are reported in brackets. The sample period is from 2008 to 2018 . * **, and ${ }^{* * *}$ denote the statistical significance at the $10 \%, 5 \%$, and $1 \%$ levels, respectively. We provide the detailed variable descriptions in the appendix.

\begin{tabular}{lccc}
\hline & \multicolumn{3}{c}{ Bond spread } \\
\cline { 2 - 4 } & $(1)$ & $(2)$ & $(3)$ \\
\hline ETF & $-0.217^{* * *}$ & $-0.224^{* * *}$ & -0.004 \\
Size decile & $(-4.39)$ & $(-3.06)$ & $(-0.12)$ \\
ETF $\times$ Size decile & $0.004^{* * *}$ & & \\
& $(7.28)$ & & \\
Analyst decile & $-0.025^{* * *}$ & & \\
& $(-3.58)$ & & $0.003^{* * *}$ \\
ETF $\times$ Analyst decile & & $(3.15)$ & \\
& & $-0.022^{* *}$ & \\
Junk dummy & & $(-2.37)$ & \\
& & & $0.023^{* * *}$ \\
ETF $\times$ Junk dummy & & & $-0.090^{* * *}$ \\
& & & $(-2.78)$ \\
Control variables & & & \\
Year FE & Yes & Yes & Yes \\
FF48 FE & Yes & Yes & Yes \\
Obs & Yes & Yes & Yes \\
Adj. $R^{2}$ & & & \\
\hline
\end{tabular}




\section{Table 2.4: Channel Analyses: Short-Sale Constraints}

This table examines the heterogeneous effects of equity ETF ownership on the bond offering yield spread as a function of short-sale constraints. Following prior studies, we employ idiosyncratic volatility (column (1)) and the Amihud (2002) illiquidity measure (column (2)) as proxies for short-sale constraints. The decile variable, Idiosyncratic decile, is based on idiosyncratic volatility, which is the standard deviation of the residuals when regressing daily stock returns on the Fama-French three-factor (Fama and French, 1993) plus the momentum factor (Carhart, 1997). Firms with the highest idiosyncratic volatility are assigned a value of ten and firms with the lowest volatility are assigned a value of one. The Amihud illiquidity decile variable, Amihud decile, is calculated based on the decile of the Amihud illiquidity measure to which a firm belongs before the bond issuing date (Amihud, 2002). Firms with a high Amihud illiquidity measure (less liquid) are assigned a value of ten, while firms with a low Amihud measure (more liquid) are assigned a value of one. Lagged control variables include firm size, firm age, leverage ratio, book-to-market ratio, return on assets, return volatility, stock returns, bond issuing size, issuing maturity, and bond rating. The Fama-French 48 industry fixed effect and year fixed effect are controlled in all specifications. Robust $t$-statistics clustered at the firm level are reported in brackets. The sample period is from 2008 to $2018 .{ }^{*},{ }^{* *}$, and ${ }^{* * *}$ denote the statistical significance at the $10 \%, 5 \%$, and $1 \%$ levels, respectively. We provide the detailed variable descriptions in the appendix.

\begin{tabular}{lcc}
\hline & \multicolumn{2}{c}{ Bond spread } \\
\cline { 2 - 3 } & $(1)$ & $(2)$ \\
\hline ETF & 0.005 & 0.026 \\
& $(0.15)$ & $(0.84)$ \\
Idiosyncratic decile & $0.003^{* * *}$ & \\
& $(5.01)$ & \\
ETF $\times$ Idiosyncratic decile & $-0.022^{* *}$ & \\
& $(-2.54)$ & \\
Amihud decile & & $0.007^{* * *}$ \\
& & $(7.16)$ \\
ETF $\times$ Amihud decile & \multicolumn{2}{c}{$-0.030^{* * *}$} \\
& \multicolumn{2}{c}{$(-2.71)$} \\
Control variables & Yes & Yes \\
Year FE & Yes & Yes \\
FF48 FE & Yes & Yes \\
Obs & & \\
Adj. $R^{2}$ & 1,184 & 1,184 \\
& 0.818 & 0.844 \\
\hline
\end{tabular}




\section{Table 2.5: Equity ETF Ownership and Short Interest: Earnings An- nouncements}

This table reports the results of regressing abnormal short interest (ABSI) on equity ETF ownership and standardized unexpected earnings (SUE). We only include firms used in the baseline regression. We run the regressions for negative earnings surprises events (column (1)-(2)) and positive earnings surprises events (column (3)-(4)) separately. The standardized unexpected earnings (SUE) is calculated as the difference between the actual value of earnings per share (EPS) and the expected value of EPS scaled by stock prices. Regarding the expected EPS, we employ two proxies: i) stock analysts' median estimates of EPS and ii) the same quarter EPS of the previous year. The two SUE measures are denoted by SUE - Analyst and SUE-Seasonal, respectively. For two SUE decile variables, firms with high SUEs are assigned a value of one while firms with low SUEs are assigned a value of ten. Lagged control variables include firm size, firm age, leverage ratio, book-to-market ratio, return on assets, return volatility, and stock returns. The Fama-French 48 industry fixed effect and year fixed effect are controlled in all specifications. Robust $t$-statistics clustered at the firm level are reported in brackets. The sample period is from 2008 to 2018 . *, **, and *** denote the statistical significance at the $10 \%, 5 \%$, and $1 \%$ levels, respectively. We provide the detailed variable descriptions in the appendix.

\begin{tabular}{|c|c|c|c|c|}
\hline & \multicolumn{4}{|c|}{ ABSI } \\
\hline & \multicolumn{2}{|c|}{ Negative SUE events } & \multicolumn{2}{|c|}{ Positive SUE events } \\
\hline & (1) & (2) & (3) & (4) \\
\hline ETF & $\begin{array}{c}0.253^{* * *} \\
(2.67)\end{array}$ & $\begin{array}{c}0.237^{* * *} \\
(3.09)\end{array}$ & $\begin{array}{c}0.410^{* * *} \\
(4.85)\end{array}$ & $\begin{array}{c}0.386^{* * *} \\
(5.38)\end{array}$ \\
\hline SUE-Analyst: SUE decile & $\begin{array}{l}-0.001 \\
(-1.30)\end{array}$ & & $\begin{array}{l}0.000 \\
(0.13)\end{array}$ & \\
\hline SUE-Analyst: ETF $\times$ SUE decile & $\begin{array}{c}0.031^{* *} \\
(2.42)\end{array}$ & & $\begin{array}{l}-0.009 \\
(-0.89)\end{array}$ & \\
\hline SUE-Seasonal: SUE decile & & $\begin{array}{c}-0.002^{* *} \\
(-2.38)\end{array}$ & & $\begin{array}{l}0.001 \\
(1.11)\end{array}$ \\
\hline SUE-Seasonal: ETF $\times$ SUE decile & & $\begin{array}{c}0.039^{* * *} \\
(3.77)\end{array}$ & & $\begin{array}{l}-0.013 \\
(-1.52)\end{array}$ \\
\hline Control variables & Yes & Yes & Yes & Yes \\
\hline Year FE & Yes & Yes & Yes & Yes \\
\hline FF48 FE & Yes & Yes & Yes & Yes \\
\hline Obs & 3,426 & 5,265 & 9,101 & 8,471 \\
\hline$A d j . R^{2}$ & 0.271 & 0.293 & 0.282 & 0.246 \\
\hline
\end{tabular}




\section{Table 2.6: Channel Analyses: Corporate Governance}

This table reports the results of regressing various measures of corporate governance on equity ETF ownership. We only include firms used in the baseline regression. We use five different measures of corporate governance: (1) the percentage of independent directors on the board Independent director, (2) a dummy variable, Special meeting, indicating whether restrictions exist regarding investors calling a special meeting, (3) a dummy, Classified board, indicating whether the firm has a classified board, (4) a dummy, Dualclass, indicating whether a firm has a dual-class share structure, and (5) a dummy, Takeover defense, indicating whether a poison pill provision is in place. Column (1) reports OLS regression results and columns (2)-(5) present logit estimates. Lagged control variables include firm size, firm age, leverage ratio, book-to-market ratio, return on assets, return volatility, and stock returns. The Fama-French 48 industry fixed effect and year fixed effect are controlled in all specifications. Robust $t$-statistics clustered at the firm level are reported in brackets. The sample period is from 2008 to 2018. *, ${ }^{* *}$, and ${ }^{* * *}$ denote the statistical significance at the $10 \%, 5 \%$, and $1 \%$ levels, respectively. We provide the detailed variable descriptions in the appendix.

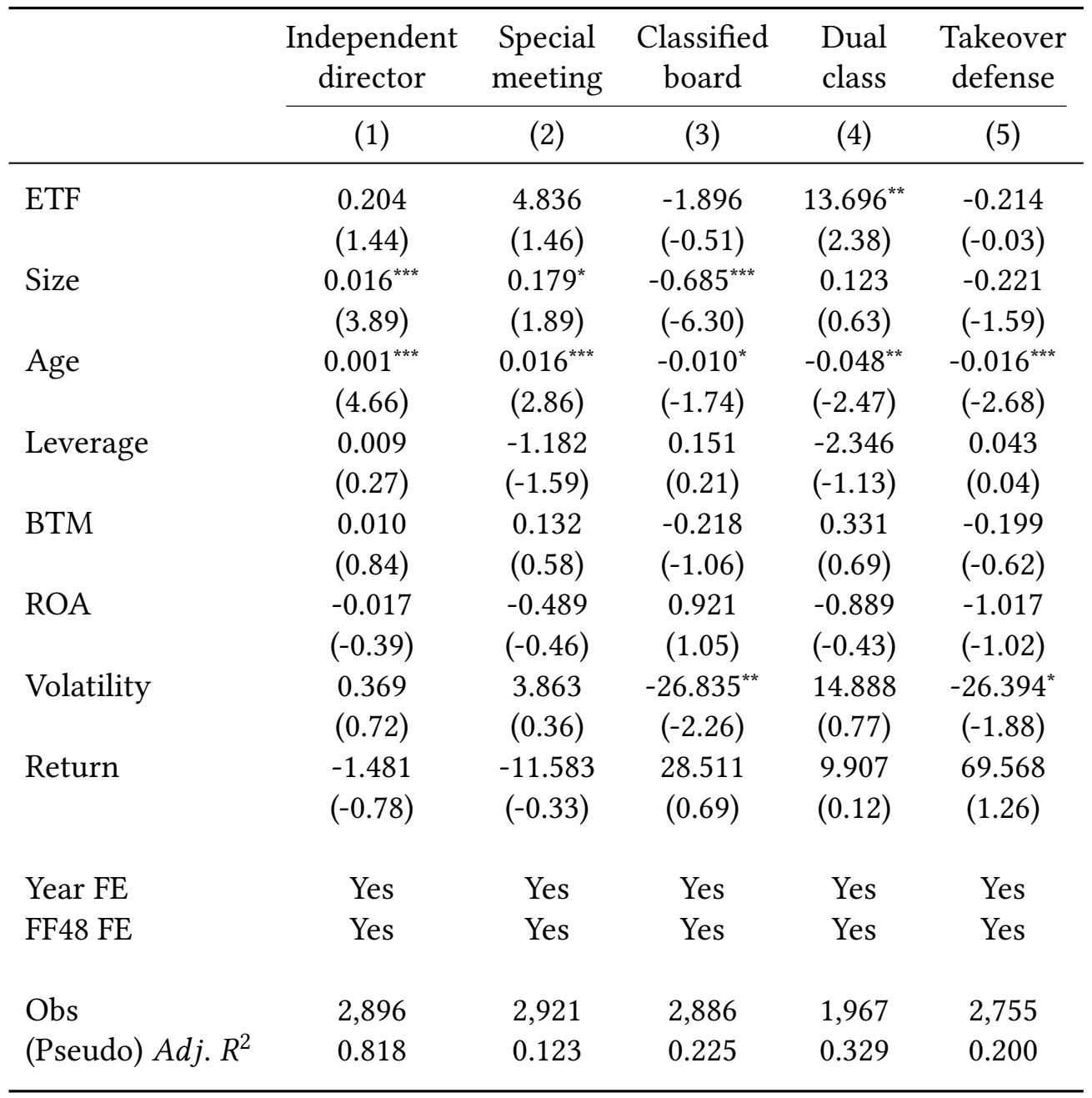




\section{Table 2.7: Endogeneity Checks}

This table reports the results of endogeneity checks. In panel A, we include industry-by-year fixed effects to remove the time-varying unobservable industry factors that might bias our results. Panel B reports the results when employing BlackRock's acquisition of iShares at the end of 2009 as an exogenous shock to the firm's ETF ownership. We use a four-year window and the sample in this exercise is from 2008 to 2011. Column (1) examines the association between ETF ownership and the cost of debt financing using the DID specification in Zou (2019). In addition, we present the IV model results in columns (2)-(3) (Antoniou et al., 2020). We classify firms in the top 30\% of the iShares ETF ownership averaged over 2008 and 2009 as the treatment group $($ Treat $=1)$ and the rest of the firms as the control group $($ Treat $=0)$. Dummy variable Post is one for the period on and after 2010 and zero otherwise. Lagged control variables include firm size, firm age, leverage ratio, book-to-market ratio, return on assets, return volatility, stock returns, bond issuing size, issuing maturity, and bond rating. Robust $t$-statistics clustered at the firm level are reported in brackets. *, ${ }^{* *}$, and ${ }^{* * *}$ denote the statistical significance at the $10 \%, 5 \%$, and $1 \%$ levels, respectively. We provide the detailed variable descriptions in the appendix.

Panel A: Industry-by-year fixed effect

\begin{tabular}{|c|c|c|c|}
\hline & Bond spread & & \\
\hline ETF & $\begin{array}{c}-0.066^{* *} \\
(-2.56)\end{array}$ & & \\
\hline Control variables & Yes & & \\
\hline Industry-by-year FE & Yes & & \\
\hline Obs & 1,087 & & \\
\hline $\operatorname{Adj.} R^{2}$ & 0.828 & & \\
\hline \multicolumn{4}{|c|}{ Panel B: BlackRock's acquisition } \\
\hline & Bond spread & ETF & Bond spread \\
\hline & DID & First Stage & Second Stage \\
\hline & (1) & $(2)$ & (3) \\
\hline Treat $\times$ Post & $\begin{array}{c}-0.013^{* *} \\
(-2.31)\end{array}$ & $\begin{array}{l}0.013^{* *} \\
(2.09)\end{array}$ & \\
\hline ETF(fitted) & & & $\begin{array}{l}-0.611^{*} \\
(-1.76)\end{array}$ \\
\hline Treat & $\begin{array}{l}0.006 \\
(1.02)\end{array}$ & & \\
\hline Control variables & Yes & Yes & Yes \\
\hline Year FE & Yes & Yes & Yes \\
\hline FF48 FE & Yes & Yes & Yes \\
\hline Obs & 233 & 233 & 233 \\
\hline $\operatorname{Adj} . R^{2}$ & 0.806 & 0.297 & 0.661 \\
\hline
\end{tabular}




\section{Table 2.8: Robustness Tests}

This table reports the results of robustness tests. In column (1), we include the financial and utility industries in our sample. In column (2), we follow Antoniou et al. (2020) in using the number of ETFs holding firm $i$ (Number of ETFs) as an alternative definition of ETF ownership. Lagged control variables include firm size, firm age, leverage ratio, book-to-market ratio, return on assets, return volatility, stock returns, bond issuing size, issuing maturity, and bond rating. The Fama-French 48 industry fixed effect and year fixed effect are controlled in all specifications. Robust $t$-statistics clustered at the firm level are reported in brackets. The sample period is from 2008 to 2018 . *, **, and *** denote the statistical significance at the $10 \%, 5 \%$, and $1 \%$ levels, respectively. We provide the detailed variable descriptions in the appendix.

\begin{tabular}{|c|c|c|}
\hline & \multicolumn{2}{|c|}{ Bond spread } \\
\hline & Include financial and utility & Alternative definition \\
\hline & (1) & (2) \\
\hline ETF & $\begin{array}{c}-0.052^{* * *} \\
(-3.87)\end{array}$ & \\
\hline Number of ETFs & & $\begin{array}{c}-0.001^{* *} \\
(-2.27)\end{array}$ \\
\hline Control variables & Yes & Yes \\
\hline Year FE & Yes & Yes \\
\hline FF48 FE & Yes & Yes \\
\hline Obs & 2,365 & 1,184 \\
\hline Adj. $R^{2}$ & 0.790 & 0.802 \\
\hline
\end{tabular}




\section{Appendix: Definitions of Variables}

Table B.1: Definitions of Variables

\begin{tabular}{ll}
\hline Variable & Definition \\
\hline
\end{tabular}

Bond-level Variables

Bond spread

Bond offering yield spread, defined as the difference between the bond offering yield and the yield of the synthetic risk-free bond, following Gao et al. (2020). Source: SDC.

Issue size

The natural log of total proceeds from the bond issuance. Source: SDC.

Issue maturity

The natural log of bond maturity. Source: SDC.

Rating

Following Blume et al. (1998), we convert the original rating system to a numerical rating system. The numerical scale of the bond rating ranges from zero for AAA bonds to twenty for C bonds. Source: SDC.

Junk dummy

Dummy variable that takes value one for bonds below BBB rating, and zero otherwise. Source: SDC.

\section{Firm-level Variables}

ETF

Shares owned by U.S. domestic equity ETFs divided by the share outstanding. Source: S12.

Size

The natural log of market capitalization. Source: CRSP. 
Table B.1 - continued from previous page

Variable Definition

Age

Leverage

BTM

ROA

Volatility

Return

Size decile

Analyst decile
The number of years since the firm's IPO date. Source: CRSP.

Leverage ratio, defined as the total liabilities divided by total assets. Source: Compustat.

Book-to-market ratio, measured as the book value of equity divided by the market value of equity. Source: Compustat.

Return on assets, measured as operating income before depreciation divided by total assets. Source: Compustat.

Standard deviation of daily stock returns over the past year. Source: CRSP.

Average daily stock returns over the past year. Source: CRSP.

This equals the decile group to which a firm's market capitalization belongs before the bond issuing date. The smallest firms are assigned a value of ten, whereas the largest firms are assigned a value of one. Source: CRSP and French data library.

This is calculated based on the decile of the number of analysts following before the issuing date. Firms with less analyst coverage are assigned a value of ten, while firms with more analyst coverage are assigned a value of one. Source: IBES. 
Table B.1 - continued from previous page

Variable Definition

Idiosyncratic decile

Amihud decile

Raw short interest

ABSI

Independent director
This is calculated based on the decile of idiosyncratic volatility to which a firm belongs before the issuing date. Firms with high idiosyncratic volatility are assigned a value of ten, while firms with low idiosyncratic volatility are assigned a value of one. The idiosyncratic volatility is the standard deviation of the residuals when regressing daily stock returns on the Fama-French three-factor (Fama and French, 1993) plus the momentum factor (Carhart, 1997) using the past six months' data. Source: CRSP.

This is calculated based on the decile of the Amihud (2002) illiquidity measure to which a firm belongs before the bond issuing date. Less liquid firms are assigned a value of ten, while more liquid firms are assigned a value of one. Source: CRSP.

The number of shares shorted divided by the number of shares outstanding. Source: Compustat.

Abnormal short interest, defined as the raw short interest minus the expected short interest, following Karpoff and Lou (2010). The expected short interest is the fitted value of regressing raw short interest on size, book to market ratio, momentum, and industry groups as specified in equation (2.3). Source: Compustat.

The percentage of independent directors on the board. Source: ISS. 
Table B.1 - continued from previous page

Variable Definition

Special meeting

Classified board

Dualclass

Takeover defense

SUE-Analyst decile
Dummy variable that takes a value of one if restrictions exist regarding investors calling a special meeting and zero otherwise. Source: ISS.

Dummy variable that takes a value of one if a firm has a classified board and zero otherwise. Source: ISS.

Dummy variable that takes a value of one if the firm has a dual-class share structure and zero otherwise. Source: ISS.

Dummy variable that takes a value of one if a poison pill provision is in place and zero otherwise. Source: ISS.

Standardized unexpected earnings is defined as the earnings difference scaled by the most recent stock price. The earnings difference is the actual EPS minus the median of stock analyst's estimates of EPS. Based on the SUE calculated, we construct a decile variable where firms with high SUEs are assigned a value of one and firms with low SUEs are assigned a value of ten. We generate the SUEAnalyst decile for negative earnings events and positive earnings events separately in each quarter. Source: IBES and Compustat. 
Table B.1 - continued from previous page

Variable Definition

SUE-Seasonal decile

Treat

Post

Number of ETFs
Standardized unexpected earnings is defined as the earnings difference scaled by the most recent stock price. The earnings difference is actual EPS minus the EPS from the same quarter of the previous year. Special items have been adjusted. Based on the SUE calculated, we construct a decile variable where firms with high SUEs are assigned a value of one and firms with low SUEs are assigned a value of ten. We generate the SUE-Seasonal decile for negative earnings events and positive earnings events separately in each quarter. Source: IBES and Compustat.

We employ BlackRock's acquisition of iShares ETFs of Barclays Global Investors at the end of 2009 as the endogenous shock to ETF ownership. Following Antoniou et al. (2020), we classify firms in the top 30\% of the iShares ETF ownership averaged over 2008 and 2009 as the treatment group $($ Treat $=1)$ and the rest of the firms as the control group (Treat $=0)$. Source: S12 and CRSP.

Dummy variable that takes a value of one in 2010 and 2011, and zero in 2008 and 2009. Source: S12 and CRSP.

The natural log of one plus the number of ETFs holding a firm. Source: S12. 



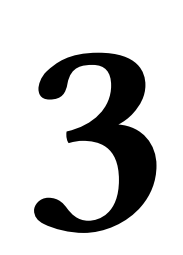

\section{The Trend Premium around the World: Evidence from the Stock Market}

This chapter studies the predictive power of the trend strategy in the international stock market. Using data from 49 markets, we find that a trend signal exploiting the short-, intermediate-, and long-term price information can predict stock returns cross-sectionally in the international market. The significance of the trend strategy is associated with market-level characteristics such as macroeconomic conditions, culture, and the information environment. The trend premium is more pronounced in markets with a more advanced macroeconomic status, a higher level of information uncertainty and individualism, and better accessibility to foreign investors. Nevertheless, the trend strategy only outperforms the momentum strategy in a relatively short horizon. 


\subsection{Introduction}

A central issue in finance is whether asset returns are predictable. The literature has documented the importance of historical price information in predicting stock returns. For example, Greenwood and Shleifer (2014) and Hirshleifer, Li, and Yu (2015) follow behaviour theory to show that historical average returns or past trends contain information for expected returns when investors extrapolate expectations from the past. Other studies also show the importance of technical analysis. Treynor and Ferguson (1985), Brown and Jennings (1989), Brock, Lakonishok, and LeBaron (1992), Lo, Mamaysky, and Wang (2000), Cespa and Vives (2011), Neely, Rapach, Tu, and Zhou (2014), and Han, Zhou, and Zhu (2016), among others, demonstrate that past returns have predictive power on future returns. Besides, Covel (2004) and Lo and Hasanhodzic (2009) document that moving averages (MAs) of prices are widely used by practitioners. The knowledge on the applicability of technical indicators is beneficial for us to understand the real-world operation of the financial market in addition to the fundamental information. Nevertheless, little attention has been paid to examining the importance of historical price signals in an international setting, which is crucial to expand our understanding of cross-market variations in the international stock market.

As shown in a recent study by Han et al. (2016), a trend strategy using the MA information in stock prices ranging from 3 days to 1000 days can generate statistically significant and economically meaningful returns in the US market. Inspired by Han et al. (2016), we address three questions in this study. First, we examine whether the trend strategy proposed by Han et al. (2016) applies to other stock markets as is the case for the momentum strategy (Rouwenhorst, 1998; Chan, Hameed, and Tong, 2000; Chui, Titman, and Wei, 2010). Second, we investigate the information structure of the trend strategy to analyze the contribution of information across different horizons. We compare our results with the momentum strategy that merely uses the information of one particular time horizon. Third, we try to identify factors that can explain the difference in the trend premia across different markets. Specifically, we explore the relationship between the performance of the trend strategy and market-level characteristics. 
We conduct the analysis using a large sample that consists of 49 markets and more than 72,000 stocks. Following Han et al. (2016), we forecast the monthly stock returns cross-sectionally and sort stocks into quintile portfolios by their expected returns. A portfolio that longs the stocks with the highest expected returns (quintile 5) and shorts the stocks with the lowest expected returns (quintile 1) is constructed. The performance of this long-short (H-L) trend portfolio measures the profitability of the trend strategy, which is defined as trend premium throughout the paper. We analyze the trend premia at both the individual market level and the global level and document several findings.

First, we find convincing evidence that the trend strategy generates significant returns in the international stock market. At the individual market level, in 39 out of 49 markets, the trend portfolio can generate economically meaningful and statistically significant returns when employing the equal-weighted portfolios. At the global level, the trend strategy generates $1.22 \%$ and $1.67 \%$ monthly return under the market average method and the market composite method from the perspective of a US investor, respectively. The results suggest the existence of the trend premium in the international stock market.

Second, the trend premium could not be explained by the traditional asset pricing models. Specifically, we use the CAPM, Fama and French (1993) three-factor and Carhart (1997) four-factor models to calculate the adjusted returns of $\mathrm{H}-\mathrm{L}$ portfolios and find that the adjusted returns are still statistically significant. Besides, the trend strategy survives transaction costs, indicating that the trend premium in the international stock market is economically meaningful.

Third, price information across different horizons jointly contributes to the performance of the trend strategy, while the most significant proportion comes from the short-term information. To examine the contribution of different horizon information to the trend premium, we divide the MA signals into the short-, intermediate-, and long-term, respectively. We find that even if the short-term information contributes the most to the trend premium in terms of magnitude, adding intermediate- and long-term signals can improve the performance of the trend strategy further. A global portfolio that employs only the short-term information generates a monthly return of $1.04 \%$ 
under the market average method. When adding the intermediate- and long-term information, the trend premium increases by $0.18 \%$, which is statistically significant at the $1 \%$ level.

Fourth, the trend strategy outperforms the momentum strategy in a relatively short horizon. To compare the performance of the trend strategy and that of the momentum strategy, we use the same holding period returns ranging from one to six months. We find that, at the one-month horizon, the profits of the trend strategy are significantly higher than that of the momentum strategy under both the market average method and the market composite method. On top of that, the trend premium is not as stable as the momentum premium. Specifically, the trend premium in the international stock market decays quickly as holding period increases. Our finding reveals that the advantage of the trend strategy over the momentum strategy in the global stock markets mainly lies in the short investment horizon.

Finally, there exist significant cross-market variations in the trend premium in the international stock market. The literature has documented several explanations on the cross-sectional difference in the international stock market. The first explanation is the macroeconomic fundamentals. For example, Chan, Covrig, and $\mathrm{Ng}$ (2005) show that economic development could explain the foreign bias (investors underweight or overweight foreign markets) of mutual funds from 26 developed and developing countries. The second explanation is related to culture. For example, Chui et al. (2010) find that individualism could explain the cross-market variations in the momentum of 41 countries. The momentum strategy is more profitable in markets with high individualism. The third explanation is about the information environment. Hirshleifer, Lim, and Teoh (2009) document that limited investor attention causes market underreactions, while Zhang (2006) and Han et al. (2016) show the importance of information uncertainty on the cross-sectional of stock returns. Following these studies, we consider three possible explanations for the cross-market variations in the trend premium, including macroeconomic fundamentals, culture, and information environment. Utilizing both a bivariate portfolio analysis and the Fama-MacBeth regression, we find that the trend premium is more pronounced in markets with a more advanced macroeconomic status, a higher level of information uncertainty and individualism, and better accessibility to 
foreign investors.

Our study contributes to the literature in several ways. First, we use the historical price information to forecast stock returns out-of-sample, which is closely related to the studies that extrapolate return expectations using technical analysis. Therefore, our paper complements the existing studies in terms of extrapolative return expectation (Greenwood and Shleifer, 2014; Hirshleifer et al., 2015; Barberis, Greenwood, Jin, and Shleifer, 2018) and technical analysis (Treynor and Ferguson, 1985; Brown and Jennings, 1989; Brock et al., 1992; Lo et al., 2000; Cespa and Vives, 2011; Neely et al., 2014; Han et al., 2016). The findings on the predictive power of trend signals in 49 international stock markets expand the understanding of investor behaviours in an international setting.

Second, we document that the performance of the trend premium is related to market-level characteristics, which confirms the importance of market-level variables in explaining asset returns. Consistent with the literature, we document the importance of macroeconomic fundamentals, culture, and information environment on explaining the cross-market difference in the trend premium. These findings extend our understanding as to what extent the cross-market variations can explain stock returns (see, for example, Chan et al., 2005; Chui et al., 2010; Lau, Ng, and Zhang, 2010; Jacobs, 2016).

Third, our study also relates to the literature on whether and how synthesizing more information improves return predictability. Many studies find that using a large set of predictors can get better performance. For example, Kelly and Pruitt (2013, 2015) and Huang, Jiang, Tu, and Zhou (2015) show that the partial least squares (PLS) method provides a powerful procedure for extracting information from a large set of predictors. Lin, $\mathrm{Wu}$, and Zhou (2018) extend the PLS method and document its superior forecasting performance on the corporate bond market. In our study, we show that using more information does not necessarily yield a higher return than using less information. Although the trend strategy utilizes more information than the momentum strategy, it merely outperforms the momentum strategy in short horizons. This finding extends the study of Han et al. (2016) about the relationship between the trend and the momentum strategy. In this regard, our analysis helps to understand the 
conditions under which a better out-of-sample performance can be achieved when employing more information.

The remainder of the paper is organized as follows. Section 3.2 explains how we implement the trend strategy. Section 3.3 describes the data. Section 3.4 reports the performance of the trend strategy at the individual market level, while Section 3.5 shows the results of the trend strategy at the global level. Section 3.6 explores market-level characteristic variables that explain variations in trend premia across different markets. Section 3.7 concludes the paper.

\subsection{Methodology}

In this section, we describe the methodology used to calculate the expected return of the trend strategy. First, we explain the predictors of the trend strategy, including the normalized MA signals in the short-, intermediate-, and long-horizon. Then we present the procedure employed to forecast the cross-sectional returns and the construction of portfolios.

\subsubsection{MA signals}

The main inputs for the trend strategy are the normalized MA signals of different horizons, which are calculated as follows:

$$
M A_{m, j, t}^{L}=\frac{\frac{p_{m, j, t}^{L-1}+p_{m, j, t}^{L-2}+\ldots+p_{m, j, t}^{1}+p_{m, j, t}^{0}}{L}}{p_{m, j, t}^{0}}, L=3,5, \ldots, 800,1000
$$

where $M A_{m, j, t}^{L}$ is the MA signal of lag length $L$ days for stock $j$ of market $m$ in month $t$, and $p_{m, j, t}^{k}$ represents the $k$-day lag price of stock $j$ of market $m$ in month $t$. Following Han et al. (2016), we use MA prices of lag lengths 3, 5, 10, 20, 50, 100, 200, 400, 600, 800 , and 1,000 days, which roughly indicate the daily, weekly, fortnightly, monthly, quarterly, 6-month, 1-year, 2-year, 3-year, 4-year, and 5-year price trends, respectively. The MA signals are normalized by the most recent daily price $p_{m, j, t}^{0}$. The US dollardenominated daily closing prices are used to calculate the MA signals for each stock. 


\subsubsection{Trend portfolio construction}

Following Han et al. (2016), we use a two-step procedure to forecast stock returns in each market. First, we run a cross-sectional ordinary least squares (OLS) regression as follows,

$$
r_{m, j, t}=\beta_{m, 0, t}+\sum_{i=1}^{11} \beta_{m, i, t} M A_{m, j, t-1}^{L_{i}}+\epsilon_{m, j, t}, \quad m=1, \ldots, M, \quad j=1, \ldots, n,
$$

where $r_{m, j, t}$ is the return for stock $j$ of market $m$ in month $t, M A_{m, j, t-1}^{L_{i}}$ is the trend signal at the end of month $t-1$ with a lag length $L_{i}$ days defined in Eq. (3.1), $\beta_{m, i, t}$ is the coefficient of the trend signal with lag $L_{i}$ for market $m$ in month $t$, and $\beta_{m, 0, t}$ is the intercept. We run the regression in each month for each market and obtain the time series of $\beta_{m, i, t}$. Second, we forecast stock $j$ 's return in month $t+1$ from

$$
E_{t}\left[r_{m, j, t+1}\right]=\sum_{i=1}^{11} E_{t}\left[\beta_{m, i, t+1}\right] M A_{m, j, t}^{L_{i}}
$$

where $E_{t}\left[\beta_{m, i, t+1}\right]=\frac{1}{12} \sum_{q=0}^{11} \beta_{m, i, t-q}$. In other words, we use the moving averaged coefficients obtained from the cross-sectional regression outlined in Eq. (3.2) between month $t-11$ and month $t$ with the trend signals in month $t$ to forecast the stock returns in month $t+1$. We only use past information in forecasting the future returns, therefore, our study is an out-of-sample analysis.

We sort all stocks by their forecasted returns obtained from Eq. (3.3) and form quintile portfolios. A trend portfolio is constructed by buying stocks with forecasted returns in the top $20 \%(\mathrm{H})$ group and selling stocks with forecasted returns in the bottom $20 \%$ (L) group. The return difference between the quintile portfolios with the highest and lowest forecasted returns measures the trend premium. We rebalance the portfolio each month.

We construct the trend portfolios at the individual market level and the global level, respectively. For each market, we construct portfolios using three different weights: equal-weighted (EW), valued-weighted (VW), and rank-weighted (RW). To determine the rank of stocks, we rank stocks into deciles by their market capitalization values 
each month and use the rank of the decile in which the stock lies as the weight. ${ }^{1}$

We consider two different ways of constructing the global trend portfolio: the market average method and the market composite method. For the market average method, we use the mean of the trend premia of different markets, which suggests that each market has the same weight in the global trend portfolio. For the market composite method, we pool all stocks with the highest and lowest forecasted returns within each market together to form the long and the short leg, respectively, which means that a market with more stocks has a larger weight in the global trend portfolio.

\subsection{Data}

We analyze the performance of the trend strategy in 49 markets, including 48 non-US markets and the US market. The data used in our analysis include firm-level stock price information and market-level characteristic variables. The detailed variable descriptions and data sources are provided in the appendix.

\subsubsection{Firm-level data}

\section{Non-US data}

For the 48 non-US markets in our sample, we mainly collect the firm-level stock data from Datastream through Eikon, which covers both active and dead stocks and can thus avoid survivorship bias. ${ }^{2}$ Specifically, we collect information of stock closing price, market capitalization, and return index and download all variables denominated

\footnotetext{
${ }^{1}$ For example, in market $m$ and month $t$, if a stock lies in decile 4 of the capitalization distribution, a weight of 4 will be given to the stock. Under the rank-weighted scheme, the largest stock gets a weight of 10 , whereas the smallest stock gets a weight of 1 . This weighting method can mitigate the size difference between large and small stocks.

${ }^{2}$ The newly added feature in Datastream through an Eikon Excel add-in allows us to choose the primary, major, and active and dead stocks from one specific exchange. Previous studies in this strand of the literature mainly extract data using the stock constituent list maintained by Thomson Reuters, which is usually shorter than the stock list downloaded using the newly added feature. As noticed by Ince and Porter (2006), some listed stocks do not appear in either the active or dead stock list maintained by Thomson Reuters. Besides, some exchanges have merged into one exchange, and thus our sample may cover firms that belonged to other exchanges previously. Overall, the newly added feature makes our sample more comprehensive.
} 
in US dollars to facilitate comparisons across markets. ${ }^{3}$ The dividends and stock splits have been properly adjusted. Analyst coverage information is retrieved from I/B/E/S.

We then impose several filters to clean the data of the non-US markets. First, in the same spirit of Chui et al. (2010), we require that each market should have a consecutive and relatively long time series, and have more than 30 stocks available in each month to form a well-behaved portfolio. Second, following Hou, Karolyi, and Kho (2011), Lai, Ng, and Zhang (2014), Dang, Moshirian, Wee, and Zhang (2015), and Jacobs (2016), we select a single exchange with the largest number of listed stocks for most markets, whereas we use multiple exchanges for China (Shanghai and Shenzhen) and Japan (Tokyo and Osaka). Third, we only consider common domestic equities. We use the filters provided by Datastream to limit the instruments to equity, primary class, and major stocks from main exchanges for each market. Then we manually do a name check to exclude non-common equities and require a firm to be domestic. In particular, we remove the stocks with names containing "fund", "REIT", "ADR" or other non-common equity-type words. Fourth, following Ince and Porter (2006), we exclude reverse returns. Specifically, if any of the $r_{t}$ and $r_{t-1}$ is greater than $300 \%$ and $\left(1+r_{t}\right)\left(1+r_{t-1}\right)-1<50 \%$, we treat those returns as missing. Finally, we winsorize monthly returns for each market at the top and bottom $1 \%$ to remove outliers.

\section{US data}

For the US market, we collect stock information from the Center for Research in Security Prices (CRSP). To make the US sample comparable to other markets, we use the data spanning from August 1, 1979, to December 31, 2017. We include both the active and dead stocks to avoid survivorship bias. We include common stocks listed on the NYSE, AMEX, and NASDAQ markets. In particular, we only consider the stocks coded 10 or 11 under CRSP classification. We collect the analyst coverage data of the US market from $\mathrm{I} / \mathrm{B} / \mathrm{E} / \mathrm{S}$.

Following Jegadeesh and Titman (1993), Chui et al. (2010), and Han et al. (2016), for non-US markets, we exclude stocks that are below the fifth percentile of market capitalization or below the fifth percentile of the closing price in month $t$. For the

\footnotetext{
${ }^{3}$ For those variables, Datastream padded the observations of the last trading day after the firm has been delisted. Following the literature, we remove the padded observations after one firm is delisted.
} 
US market, we exclude stocks with a price below $\$ 5$ and stocks in the smallest decile using NYSE stocks as breakpoints.

\subsubsection{Market-level data}

To study the association between the significance of the trend strategy and market characteristics, we collect market-level variables from several sources.

- Macroeconomic and financial market data. We collect macroeconomic data for each market from World Development Indicators (WDI). The data include GDP per capita, GDP growth rate, and the total number of domestic stocks in each market. Transaction cost and common language variables are collected from Chan et al. (2005).

- Culture proxy. We collect the culture proxy-individualism-from the website of Geert Hofstede (Hofstede, 2001). Geert Hofstede conducted a psychological survey in 72 markets, and 88,000 IBM employees were subjects of the survey. The survey took place during the period between 1967 and 1973. We use the latest data from Hofstede's website when markets are not covered in the original paper.

- Information coverage and uncertainty. Market capitalization, analyst coverage, and turnover ratio, calculated using firm-level data within each market, are used as proxies for information coverage and uncertainty.

\subsubsection{Summary statistics}

Our sample covers more than 72,000 firms in 49 markets and includes more than 10 million monthly observations. Table 3.1 presents the summary information of our sample. As shown in column (1), our sample covers the major international stock markets and includes markets at different development levels.

[Insert Table 3.1 about here.]

The second and third columns of Table 3.1 report the sample period for each market. The starting time for each market varies according to the availability of the data, and 
the earliest for the non-US markets is January 1982. We collect all the data up to the end of 2017. Columns (4)-(6) report the number of stocks, size (in million USD), and turnover ratio for each market, respectively. There are considerable differences across markets. For example, the US market has the largest number of firms (21,420 firms), while Zimbabwe only has 75 firms.

\subsection{Trend premium: Individual market evidence}

In this section, we investigate whether there exists a trend premium in the individual stock market. We first report the raw and risk-adjusted returns of the trend portfolios in each market, which are used to evaluate the economic value of the trend strategy. We then study other characteristics of trend portfolios in each market, including the turnover ratio, break-even transaction cost (BETC), and correlation of trend portfolios in different markets.

\subsubsection{Returns of trend portfolios}

Table 3.2 presents the returns of trend portfolios for each market. We report both the mean and standard deviation of the trend premium for the equal-weighted (EW), value-weighted (VW), and rank-weighted (RW) portfolios, respectively. The results show that the trend strategy can generate statistically significant raw returns in the majority of markets covered in our sample. Under both the equal-weighted and rankweighted scheme, 39 out of 49 markets have statistically significant trend portfolio returns. Under the value-weighted scheme, significant returns are obtained in 27 markets. The result suggests that the trend premium exists across the international stock markets.

[Insert Table 3.2 about here.]

There also exists a substantial cross-sectional variation in the trend premia across different markets. For example, for the EW portfolios, India has the largest trend premium with the magnitude of $5.33 \%$, while the trend premium in Colombia is only 0.09\% and insignificant. For the VW portfolios, the largest and smallest trend premia occur in Argentina and Colombia, respectively. For the RW portfolios, India and 
Zimbabwe have the highest and lowest trend premia results, respectively. Given the large cross-sectional variation in trend premium, we investigate the underlying variables that explain such variation in a later section.

As illustrated in Table 3.2, the trend strategy performs better in weighting schemes that give more weights to small stocks. In 37 out of 49 markets, the size of the trend premium maintains the following descending order: EW, RW, and VW, which is consistent with the finding of Han et al. (2016) that the trend strategy is more profitable under the EW scheme than under the VW scheme in the US market. It is also in line with the findings of stock momentum in the international market (Chui et al., 2010).

To examine the existence of the comovement of trend premium in the international stock market, we calculate the correlation of the trend portfolios' returns among the 49 markets. This exercise could mitigate the concern that the results of the non-US market are a simple replication of the US market. Untabulated results show that most of the correlation coefficients are not significant. For example, the average of the correlation coefficients between the US trend portfolio and those of the other 48 non-US markets is 0.013 , suggesting that the documented trend premium is mainly driven by market-specific factors rather than a global factor.

\subsubsection{Alphas of trend portfolios}

In this subsection, we examine whether the return generated by the trend strategy can be explained by factor models. Table 3.3 reports the alphas of the long-short trend portfolios in each market obtained using the CAPM model, the Fama-French three-factor model, and the Carhart four-factor model (Fama-French three-factor and a momentum factor). Following Fama and French (2012), we use the global risk factors downloaded from French's data library. ${ }^{4}$

\section{[Insert Table 3.3 about here.]}

The left, middle, and right panels of Table 3.3 report the results of the EW, VW, and RW portfolios, respectively. In general, the asset pricing models could not explain the

${ }^{4}$ Fama and French (2012) construct the global risk factors using the data from 23 developed markets from 1990 to 2017. 
trend premium in the international stock market. As shown in the first column of the EW portfolio panel, the alphas of the portfolios are still significant after considering the market factor. When we further add the size and value factors, the magnitude of the alphas is little affected. The alphas of the Carhart four-factor model are statistically significant in 38 out of the 49 markets. The results of the VW and RW portfolios are similar. That is, the trend premium in the international stock market challenges international asset pricing models.

\subsubsection{Transaction cost of trend portfolios}

Following the literature (Grundy and Martin, 2001; Novy-Marx and Velikov, 2015; Barroso and Santa-Clara, 2015), we explore the economic significance of the trend strategy by studying whether it survives transaction costs. For each market, we calculate the monthly turnover rates and zero return break-even transaction cost (BETC) of the trend portfolio. The zero return BETC is the cost that completely offsets the gain of a portfolio. The return of a portfolio with a high BETC is less likely to be wiped out by transaction costs.

[Insert Table 3.4 about here.]

Table 3.4 presents the turnover ratio and BETC of the trend strategy in each market. The trend strategy incurs a high turnover ratio. For the EW portfolios, the turnover rates are around or above $120 \%$ for the majority of the markets. This result is comparable with those of the US market reported in Han et al. (2016). The VW portfolios incur a turnover ratio around or above $140 \%$. One potential explanation for this high turnover ratio is that the information structure of the trend strategy is time-varying. ${ }^{5}$

The BETC results in Table 3.4 suggest that the trend strategy survives the transaction cost. Balduzzi and Lynch (1999) show that a strategy will be profitable if it has a BETC higher than $0.5 \%$. As illustrated in Table 3.4, in most markets where the

\footnotetext{
${ }^{5}$ We find that the predictive power of the global trend strategy mainly comes from the short-term information that includes MA signals ranging from 3 to 50 days, and the profitability of the global trend strategy decays quickly when increasing the holding horizon from one month to six months. These results are reported in Section 3.5.3 and Section 3.5.4, respectively.
} 
trend strategy can yield a significant long-short return, the BETCs are above the $0.5 \%$ threshold, indicating that the trend strategy can generate an economically meaningful return.

\subsection{Trend premium: Global-level evidence}

In the preceding section, we explored the performance of the trend strategy at the individual market level. The results show considerable cross-market differences in the performance of the trend strategy, and the trend strategy does not work well in some markets. In this part, to provide an overall assessment of trend premium in the international stock market, we construct a trend portfolio at the global level from the perspective of a US investor. We analyze the performance of the global trend strategy and run a firm-level Fama-MacBeth regression to check the predictive power of the trend strategy in an international setting. We also check the information structure of the global trend strategy and compare the performance between the trend and momentum strategies at the global level.

\subsubsection{Global trend portfolio}

As in Chui et al. (2010), Jacobs (2016), and Gao, Parsons, and Shen (2017), we use both the market average method and the market composite method to construct the global trend portfolios. For the market average method, we calculate the monthly trend portfolio return for each market and then take the average of this return across markets in each group. For the market composite method, we pool stocks from different markets together within each group to construct the global portfolio. The market average method gives each market the same weight, while the market composite method gives larger weights to markets with a greater number of stocks.

The performance of the global trend strategy is presented in Table 3.5. Panel A reports various return attributes of the global trend portfolios. The global trend strategy generates, on average, a monthly return of $1.22 \%$ under the market average method and a return of $1.67 \%$ under the market composite method. Both of them are significant at the $1 \%$ level. Besides, the break-even transaction costs of the global trend strategy under both methods exceed the $0.5 \%$ threshold, implying that the global trend 
premium can survive transaction costs.

\section{[Insert Table 3.5 about here.]}

Panel B of Table 3.5reports the alphas of the global trend strategy. We find the traditional asset pricing models fail to explain the global trend premium. Under both the market average and the market composite methods, the alphas remain close to the raw returns. For example, the alpha obtained from the Carhart four-factor model is $1.07 \%(1.54 \%)$, which is close to the raw return of $1.22 \%$ (1.67\%) under the market average (composite) method. To summarize, the results in Table 3.5 establish the existence of a trend premium at the global level.

Figure 3.1 plots the monthly returns of the global trend portfolios using the market average (Panel A) and the market composite (Panel B) method, respectively. The overall good performance of the global trend strategy is not driven by several extreme return points and the global trend portfolio has positive returns for most of the months. The highest and lowest returns of the trend portfolio constructed using the market average method are around $4 \%$ and $-2 \%$, respectively. The trend portfolio does not show extremely negative returns during the global financial crisis (GFC) period.

[Insert Figure 3.1 about here.]

Next, we discuss the economic significance of the global trend strategy for a US investor. Specifically, we compare the results reported in Table 3.5 and the results of the US market reported in Table 3.2. The global trend strategy using all stocks of the 49 markets generates a higher return than the trend strategy that only uses the US domestic stocks. For example, the EW portfolio of the US trend strategy has an averaged monthly return of $1.21 \%$, while the global trend strategy has a monthly return of $1.22 \%$ under the market average method and $1.67 \%$ under the market composite method. The differences are $0.01 \%$ and $0.46 \%$ with $t$-values being 0.08 and 3.56, respectively. Second, the global trend strategy has a much larger Sharpe ratio. Unreported results show that the annualized Sharpe ratio of the global trend strategy is 3.36 under the market average method and 4.02 under the market composite method, both of which are highly economically significant. The Sharpe ratio of the US trend strategy is only 
$0.97,0.55$, and 0.94 , respectively, under EW, VW, and RW. They are much lower than those of the global trend strategy. Moreover, the global trend strategy has a much smaller crash risk. We calculate the minimum returns of the US trend strategy and the global trend strategy. The minimum returns of the US trend strategy are $-15.95 \%$, $-16.90 \%$, and $-17.00 \%$, respectively, under EW, VW, and RW. They are much higher for the global trend strategy. The minimum return of the market average method is $-2.44 \%$, while it is $-2.47 \%$ for the market composite method. These comparison results show that there exists a huge benefit for a US investor to consider the other stock markets into the trend strategy construction and document the importance of the trend strategy in an international stock market setting.

\subsubsection{Fama-MacBeth regression}

In this subsection, we examine whether the trend signals have predictive power when controlling for other variables. Following Lai et al. (2014) and Han et al. (2016), we run a firm-level Fama-MacBeth cross-sectional regression of stock returns on trend signals and other control variables in each month and then average the coefficients over time. We pool observations from each market except the US and run the following regression:

$$
r_{i, t+1}=\gamma_{0}+\gamma_{1} E_{t}\left[r_{i, t+1}\right]+\gamma_{2} B M_{i t}+\gamma_{3} S_{i z e_{i t}}+\sum_{k=1}^{m} \eta_{k} \text { Othercontrols }{ }_{i t}^{k}+\epsilon_{i t+1},
$$

where $r_{i, t+1}$ is the monthly stock return of firm $i$ in excess of a 30-day US Treasury bill rate in month $t+1 .{ }^{6} E_{t}\left[r_{i, t+1}\right]$ is the forecasted return of firm $i$ in month $t+1$ using the MA signals in month $t . B M_{i t}$ is the natural logarithm of firm $i$ 's book-to-market (BM) ratio and Size $_{i t}$ is the natural logarithm of firm size. ${ }^{7}$ Following Han et al. (2016), to test whether the trend strategy that aggregates information of different horizons can still be useful after controlling past information from a major single horizon, we add last month's return $\left(r_{i, t-1}\right)$, medium-term return (past 6 months' to past 2 months'

\footnotetext{
${ }^{6}$ The risk-free rate is the one-month U.S. Treasury bill rate from the CRSP.

${ }^{7}$ We use the book equity (WC03501) information provided by Worldscope and market equity (MV) in Datastream to calculate the logarithm of the book-to-market ratio. We require a firm to have positive book equity to calculate this ratio.
} 
return, $r_{i, t-6, t-2}$ ), and long-term return (past 60 months' to past 25 months' return, $\left.r_{i, t-60, t-25}\right)$ to the regression as the other control variables. Our variable of interest is the coefficient of $E_{t}\left[r_{i, t+1}\right], \gamma_{1}$, which captures the predictability of trend signals on stock returns. Since the stocks in the US market account for around $30 \%$ of our sample and they have been well studied in Han et al. (2016), we exclude the US firms from our firm-level regression and examine the trend premium beyond the US market. ${ }^{8}$

Table 3.6 reports the results of Fama-MacBeth regression. ${ }^{9}$ We adjust the standard errors using the Newey and West (1987) method with six lags. We consider different models by using different sets of control variables. In model (1), we only use $E_{t}\left[r_{i, t+1}\right]$ as the independent variable. In model (2), we add the size and BM ratio. In model (3), we control for past information of different horizons, and in model (4) we put all control variables together. Results show a significantly positive $\gamma_{1}$ across all specifications, indicating that the trend signals do have predictive power on the future stock return internationally. When we only use $E_{t}\left[r_{i, t+1}\right]$ as the independent variable, the estimate of $\gamma_{1}$ is 0.150 with a $t$-value of 5.55. Across all specifications, we find that the estimates of $\gamma_{1}$ are significantly positive and stay relatively stable. When all control variables are in place, the estimate of $\gamma_{1}$ is 0.144 with a $t$-value of 6.03 , which is similar to that of model (1). These results suggest that the predictive power of the trend signals on stock returns is robust and independent of other firm-level characteristic variables.

[Insert Table 3.6 about here.]

Other control variables also have the expected signs. For example, the book-tomarket ratio is positively related to the future stock return, which is consistent with the empirical asset pricing literature. The size effect is less pronounced in the international stock market. The coefficient of the size variable is negative but insignificant, which is in line with the findings of Lai et al. (2014).

\footnotetext{
${ }^{8}$ The results are qualitatively similar if we add the US firms to the analysis.

${ }^{9}$ As a robustness check, we also run the panel regressions with firm and year fixed effects and cluster the standard errors by firm and year. The results are qualitatively similar.
} 


\subsubsection{Information horizon and trend premium}

Our trend strategy extracts information from the MA signals of the short-, intermediate, and long-horizon jointly. It is therefore of interest to investigate which horizon information contributes the most to the predictive power of the trend signals. For example, does utilizing the long-term information contribute more to the performance of the trend strategy than other horizons information? To address this question, we compare the returns of trend portfolios that use all information with those using different horizon information. The short-term information includes MAs from 3 days, 5 days, 10 days, 20 days, and 50 days. The intermediate-term information includes MAs from 100 days and 200 days, which roughly corresponds to the past 6 months' and past 12 months' signals employed in the momentum literature. The MA signals from 400 days, 600 days, 800 days, and 1000 days are classified as long-term information.

[Insert Table 3.7 about here.]

Concisely, we only report the return differences of global trend portfolios in Table 3.7. The left panel of Table 3.7 presents the return differences between the trend portfolio using all information and using single-term information. The return differences are significant for 17 out of the 18 cases. That is, a portfolio constructed using all horizon information outperforms a portfolio that employs information on a specific horizon only, indicating the importance of information aggregation. Moreover, the improvement over short-term information is the smallest. For example, for the EW portfolio under the market average method, using all information increases the performance of only using long-term information by $0.64 \%$, while it increases the performance of only using short-term information by a mere $0.18 \%$. The results of other portfolios are similar, suggesting that short-term information contributes the largest proportion to the trend premium.

The right panel of Table 3.7 reports the improvement of portfolio performance when adding information of different horizons step by step. First, we evaluate the contribution of long-term information by comparing returns of the trend portfolios using all information with those using short- and intermediate-term information. The improvement is positive and significant for five out of six specifications. For example, 
for the EW portfolio, the improvement by adding long-term information is around $0.07 \%$ and $0.05 \%$ for the market average and the market composite method, respectively. Both of them are significant at the $10 \%$ level. We next evaluate the improvement by adding the intermediate-term information, and the results are presented in the last column of the right panel. A positive return difference exists in most specifications, and two of them are significant at the $1 \%$ level. For the EW portfolio, adding the intermediate-term information improves the performance of the global trend strategy by $0.11 \%$ under the market average method, which is significant at the $1 \%$ level. To summarize, information on different horizons jointly contributes to the performance of the trend strategy, while the most significant proportion is from the short-term information.

\subsubsection{Trend strategy and momentum strategy}

In this subsection, we compare the performance of the trend strategy and the momentum strategy. Intuitively, the trend strategy employs information from multiple horizons, while the momentum strategy only uses the information of one particular term. It is therefore natural to expect that the trend signals can generate stronger predictive power than the momentum signals. However, since the portfolio construction is an out-of-sample study, a stronger in-sample forecast performance does not necessarily result in a similar out-of-sample performance. For example, Welch and Goyal (2007) and Rapach, Strauss, and Zhou (2010) document the inconsistency between in-sample and out-of-sample forecast results.

We follow Jegadeesh and Titman (1993) to construct the momentum portfolio. In each market, we first calculate the cumulative return of one particular historical horizon for each firm as the momentum signal. We then rank the momentum signal in ascending order and form quintile momentum portfolios for each market in each month. The winners are the stocks whose returns are in the top $20 \%$, and the losers are the stocks in the bottom $20 \%$. The momentum strategy is to long the stocks in the winners' group and to short the stocks in the losers' group. Depending on the horizon of past information used as a signal and whether one month is skipped in the portfolio construction, we consider four different momentum strategies. Specifically, 
the strategies constructed are 5-month past/1-month skip, 6-month past/0-month skip, 11-month past/1-month skip, and 12-month past/0-month skip, respectively. The abbreviations for those variants of momentum strategies are 5/1, 6/0,11/1, and 12/0 in Table 3.8, respectively. To make the trend and momentum strategies comparable, we impose the following conditions: (1) using the same size filter and price filter for the momentum strategy as in the trend strategy, (2) using the same investment holding periods. We consider different holding periods ranging from one to six months to assess the performance difference. To account for the data-overlapping issue, we follow Jegadeesh and Titman (1993) to calculate the holding period return longer than one month.

[Insert Table 3.8 about here.]

In Table 3.8, the top and bottom panels present the return comparison between the trend and momentum strategy employing the market average method and the market composite method, respectively. For each case, we report the returns of the trend and momentum strategies and their difference. As shown in Table 3.8, the trend strategy is more profitable than the momentum strategy when the investment horizon is one month. All the return differences are positive, and such differences across most of the specifications are significant at the $1 \%$ level. For example, the return of the momentum strategy using 5-month past/1-month skip (5/1) for the one-month investment horizon is $0.79 \%$, which is $0.43 \%$ lower than that of the trend strategy using the market average method. The difference is significant at the $1 \%$ level. If we use the market composite method, the difference is $1.01 \%$ and also significant at the $1 \%$ level. We obtain similar results for other implementations. We can conclude that the trend strategy outperforms the momentum strategy at the one-month horizon.

However, the superior performance of the trend strategy over the momentum strategy becomes less pronounced when the investment horizon increases. For the two-month holding period scenario, the return differences are significant at the $10 \%$ or above in half of the cases. The most notable difference is $0.61 \%$ (the difference between 6-month past/0-month skip (6/0) momentum strategy and the trend strategy using the market composite method), which is much smaller than the $1.62 \%$ of the one-month holding period. 
The trend strategy becomes significantly less profitable than the momentum strategy when the holding period increases up to six months. As shown in the last column of Table 3.8, all the return differences are negative. For example, the return of the momentum strategy using 5-month past/1-month skip (5/1) for a six-month investment horizon is $0.74 \%$, while the return of the trend strategy using the market average method for the same holding period is only $0.36 \%$. The return difference between the trend and momentum strategies turns to be significantly negative when the holding period increases to six months across most specifications.

Moreover, as documented in Table 3.8, the return of the momentum strategy is stable across different horizons. In contrast, the performance of the trend strategy becomes dramatically worse when the investment horizon increases from one month to six months. Taken together, the superior performance of the trend strategy over the momentum strategy only lasts for a short period. One reason is that the trend strategy extracts useful information from a much broader set of variables that tend to be more time-varying. Hence, they need to be updated more frequently for better performance. This finding extends the study of Han et al. (2016) to understand the relationship between the trend and the momentum strategy.

\subsection{Macroeconomic fundamentals, culture, informa- tion environment, and the trend premium}

As we show in Table 3.2, there exists substantial variations in the trend premia across different markets. It is therefore of interest to study factors explaining such difference. We consider three possible explanations in this paper, including macroeconomic fundamentals, culture, and information environment. First, we use a bivariate portfolio analysis to examine whether the trend premium varies under different conditions based on the aforementioned variables. We then run the market-level Fama-MacBeth cross-sectional regressions to test the relationship between the explanatory variables and the trend premium in the international stock market. 


\subsubsection{Bivariate portfolio analysis}

Table 3.9 presents the results when implementing the market-level bivariate portfolio analysis based on various market characteristics. Following the method in Chui et al. (2010), we first classify markets into three groups based on each market-level characteristic and then construct quintile portfolios based on the trend signals within each group. We then examine whether there is a significant difference in the trend premium between the high group and the low group. This exercise provides a direct way to test whether a specific market-level characteristic can generate an economically meaningful return difference and complements the statistical significance test implemented using the Fama-MacBeth regression.

The market-level variables used in the bivariate portfolio analysis are as follows: (1) Macroeconomic fundamentals. Following Chan et al. (2005), we include the GDP per capita (constant 2010 US\$) (GDP capita) and the annual GDP growth rate of each market (GDP growth). (2) Information environment. As in Zhang (2006) and Han et al. (2016), we utilize the following variables as proxies for information uncertainty: the natural logarithm of firm size (Capitalization), turnover rate (Turnover), and analyst coverage (Analyst) ${ }^{10}$ Besides, motivated by the limited attention assumption in Hirshleifer et al. (2009), which states that investors will be distracted when many firms are issuing announcements during the same day, we add the number of domestic stocks (Domestic number) as a proxy for the information distraction in each market. (3) Individualism measure. Following Chui et al. (2010), we include the measure of individualism in our analysis. (4) Other market-level characteristics. Other market-level characteristics that have been found useful for predicting market-level returns in Chan et al. (2005) and Chui et al. (2010) are also used in the double-sorting procedure. Specifically, we use the common language variable as a proxy for the accessibility of each market, since it is easier for foreign institutions to invest in the market if the language barrier is low. Transaction cost that measures the development of the financial market is incorporated in the analysis as well.

\footnotetext{
${ }^{10}$ At the end of each month $t$, we obtain the firm-level market capitalization from month $t-1$, and then use the median of firm-level month-end capitalization to represent the market capitalization. As the market capitalization is denominated in US dollars, it is comparable across markets. For the turnover ratio and analyst coverage, we follow a similar procedure.
} 
[Insert Table 3.9 about here.]

To avoid the look-ahead bias and to perform an out-of-sample test, we ensure that all the information used in the double-sorting procedure is from the past. That past information includes the following: (1) Information from last year: GDP per capita, GDP growth rate, and the number of domestic firms. (2) Information from last month: market capitalization, turnover ratio, and analyst coverage. (3) Time-invariant information: individualism, transaction cost, and common language.

The left (right) panel of Table 3.9 reports the results for the market average (composite) portfolio. ${ }^{11}$ Among the nine market-level characteristics employed in the double sorting, six variables generate significant trend premium difference between the low and high groups under both methods. The return difference is more pronounced under the market composite method with significant results for eight out of nine variables.

The trend premium seems to be stronger for the markets with a more advanced level of macroeconomic status. For example, under the market average method, the trend premium difference in the low and high groups of GDP per capita is $-0.48 \%$ and significant at the $1 \%$ level. This result suggests that the trend premium is stronger in the markets with a higher level of GDP per capita. Under the market composite method, the trend premium difference in the low and high groups of GDP growth is $-0.37 \%$ and significant at the $5 \%$ level, indicating a stronger trend strategy in the markets with faster economic growth. These results show that the significance of the trend premium is associated with a market's macroeconomic fundamentals.

When we use capitalization, turnover ratio, and analyst coverage as the marketlevel sorting variables, the trend premium of the low group is higher than that of the high group. For example, when using capitalization as the characteristic variable, the return difference between the low and high groups is $0.88 \%$ and $1.49 \%$ under the market average and composite methods, respectively. The results for turnover ratio and analyst coverage are similar to that of capitalization but show a weaker significance. The results for the three information environment proxies indicate that the trend premium is stronger within the markets with a higher level of information uncertainty.

${ }^{11}$ We exclude Taiwan in Section 3.6 since WDI does not provide macroeconomic data for the Taiwan area. 
We also conduct the bivariate portfolio analysis based on the number of domestic stocks, individualism, and common language. The trend premium of the low group is lower than that of the high group. For example, the differences in the trend premia between the group with a small number of domestic stocks and the group with a large number of domestic stocks are significant and with a magnitude of $-0.81 \%$ and $-0.87 \%$ for the market average and the market composite portfolios, respectively. When it turns to individualism, the differences between the low and high groups are $-0.64 \%$ and $-0.80 \%$ under the market average and composite methods, respectively. This result is consistent with Chui et al. (2010) that the momentum strategy is more profitable in markets with high individualism. Similarly, the differences between the low and high common language groups are significantly negative, suggesting that the accessibility of the market to foreign institutions affects the performance of the trend strategy.

\subsubsection{Fama-MacBeth regression}

In addition to the bivariate portfolio analysis, in this section, we study the relationship between the market-level characteristics and the trend premium in a multivariate regression setting. We run a Fama-MacBeth regression of the market-level trend premium on a battery of explanatory variables. The model is specified as follows:

$$
\text { Trend_ret } t_{i t}=\alpha_{o}+\gamma_{t}^{\prime} X_{i t}+\varepsilon_{i t} \text {, }
$$

where Trend_ret $t_{i t}$ is the trend premium of market $i$ in month $t$, and $X_{i t}$ is the vector of explanatory variables for country $i$ and includes all those characteristic variables used in the bivariate portfolio analysis of Section 3.6.1. The sample in our regression starts from January 1990 due to an insufficient number of market-level observations before that time. We also standardize all variables to have a variance of one to facilitate the interpretation of results.

Table 3.10 reports the results of Fama-MacBeth regression using the equal-weighted trend premium as the dependent variable. Similar to Table 3.6, we adjust the standard errors using the Newey-West method with six lags. Columns (1) to (4) present results when a single group of variables are included each time. In column (5), we include variables that measure macroeconomic fundamentals, culture, and information 
environment. Column (6) reports the regression results when transaction cost and common language are used in addition to the variables used in column (5).

As illustrated in column (1) of Table 3.10, the trend premium is positively related to GDP per capita and GDP growth rate. The significance of GDP per capita persists after controlling for other variables as shown in columns (5) and (6). As we have standardized the independent variables, a one-standard-deviation increase in the GDP per capita leads to an increase in the trend premium by $0.265 \%$ per month as shown in column (6).

The coefficients of firm size in columns (2), (5), and (6) are all significantly negative. These results reveal that the trend strategy is more profitable in markets with small firms, which is consistent with the finding by Han et al. (2016). Small stocks tend to have a higher level of information uncertainty and some fundamental signals like earnings are not precise. As a result, historical signals contain more information about the future price change, resulting in a more significant trend premium. The coefficient of the number of domestic stocks is significantly positive in columns (2), (5), and (6), indicating that the trend strategy is more profitable in markets with a larger number of stocks. If a market has a large number of stocks and investors only have limited attention, prices will not reflect the information quickly and thus are more useful to predict returns. This is consistent with the limited attention hypothesis documented in Hirshleifer et al. (2009). We do not find sound evidence that turnover ratio and analyst coverage can explain the profitability of the trend strategy. Overall, the results show that the trend premium is associated with the information environment.

Moreover, the trend premium is related to culture. The results in column (3) show that a one-standard-deviation increase in individualism indicates an increase in the trend premium by $0.291 \%$ per month, which is significant at the $1 \%$ level. The positive coefficient is consistent with the finding of Chui et al. (2010). However, when we further include more control variables in columns (5) and (6), the effect of individualism becomes weaker and insignificant. We also find that the trend premium is positively associated with the common language variable. The trend strategy is more profitable in markets which are more accessible to foreign investors. A one-standard-deviation increase in common language indicates an increase in the trend premium by $0.253 \%$ 
per month as shown in column (6), which is significant at the $1 \%$ level. To summarize, we find that the trend premium is associated with market characteristics such as macro fundamentals, information environment, and culture. These results confirm the importance of market-level characteristics in explaining asset returns and extend our understanding as to how the cross-market differences affect stock returns.

[Insert Table 3.10 about here.]

\subsection{Conclusion}

In this paper, we assess the effectiveness of the trend strategy in the international stock market using a large sample with more than 72,000 stocks in 49 markets. The results show that the trend strategy that incorporates the short-, intermediate-, and long-term MA signals is widely applicable in the international stock market. The trend strategy generates a statistically significant and economically meaningful return in the global stock market. Moreover, the trend premium could not be explained by the traditional asset pricing models and the trend strategy also survives transaction costs.

Analysis of the information structure of the trend strategy in the international market shows that the short-term signals contribute most to the profitability of the strategy. Nevertheless, incorporating the intermediate- and long-term price signals are still meaningful in improving the strategy's performance. We also find that the trend strategy only outperforms the momentum strategy in a relatively short horizon.

Using both bivariate portfolio analysis and market-level Fama-MacBeth regression, we show that the profitability of the trend strategy is associated with market-level characteristics such as macroeconomic fundamentals, information environment, and culture. The trend premium is more pronounced in markets with a more advanced macroeconomic status, a higher level of information uncertainty and individualism, and better accessibility to foreign investors.

The broad applicability of the trend strategy demands a further understanding of the technical analysis in the financial market. Several vital questions call for further research. The existence of the trend premium calls for a study on international asset pricing models to explain this phenomenon. Future empirical evidence about the channels through which investors deal with the intermediate- and long-term price 
signals would be helpful for a better understanding of the effectiveness of the trend strategy. Schmeling (2009) and Fang and Jacobsen (2019) document the importance of behavior finance factors on explaining the international stock returns. In the future research, it might be worthwhile to explore the explanation for the effectiveness of trend strategy from this prospective. The trend premium might also be related to the firms' news release patterns. This question could be studied using tools from natural language processing. 


\section{References}

Balduzzi, P., Lynch, A. W., 1999. Transaction costs and predictability: some utility cost calculations. Journal of Financial Economics 52, 47-78.

Barberis, N., Greenwood, R., Jin, L., Shleifer, A., 2018. Extrapolation and bubbles. Journal of Financial Economics 129, 203-227.

Barroso, P., Santa-Clara, P., 2015. Momentum has its moments. Journal of Financial Economics 116, 111-120.

Brock, W., Lakonishok, J., LeBaron, B., 1992. Simple technical trading rules and the stochastic properties of stock returns. The Journal of Finance 47, 1731-1764.

Brown, D. P., Jennings, R. H., 1989. On technical analysis. The Review of Financial Studies 2, 527-551.

Carhart, M. M., 1997. On persistence in mutual fund performance. The Journal of Finance 52, 57-82.

Cespa, G., Vives, X., 2011. Dynamic trading and asset prices: Keynes vs. Hayek. The Review of Economic Studies 79, 539-580.

Chan, K., Covrig, V., Ng, L., 2005. What determines the domestic bias and foreign bias? Evidence from mutual fund equity allocations worldwide. The Journal of Finance $60,1495-1534$.

Chan, K., Hameed, A., Tong, W., 2000. Profitability of momentum strategies in the international equity markets. Journal of Financial and Quantitative Analysis 35, 153-172.

Chui, A. C., Titman, S., Wei, K. J., 2010. Individualism and momentum around the world. The Journal of Finance 65, 361-392.

Covel, M., 2004. Trend following: how great traders make millions in up or down markets. FT Press. 
Dang, T. L., Moshirian, F., Wee, C. K. G., Zhang, B., 2015. Cross-listings and liquidity commonality around the world. Journal of Financial Markets 22, 1-26.

Fama, E. F., French, K. R., 1993. Common risk factors in the returns on stocks and bonds. Journal of Financial Economics 33, 3-56.

Fama, E. F., French, K. R., 2012. Size, value, and momentum in international stock returns. Journal of Financial Economics 105, 457-472.

Fang, J., Jacobsen, B., 2019. Cross country differences in the profitability from technical analysis strategies. Unpublished working paper.

Gao, P., Parsons, C. A., Shen, J., 2017. Global relation between financial distress and equity returns. The Review of Financial Studies 31, 239-277.

Greenwood, R., Shleifer, A., 2014. Expectations of returns and expected returns. The Review of Financial Studies 27, 714-746.

Grundy, B. D., Martin, J. S. M., 2001. Understanding the nature of the risks and the source of the rewards to momentum investing. The Review of Financial Studies 14, $29-78$.

Han, Y., Zhou, G., Zhu, Y., 2016. A trend factor: any economic gains from using information over investment horizons? Journal of Financial Economics 122, 352375.

Hirshleifer, D., Li, J., Yu, J., 2015. Asset pricing in production economies with extrapolative expectations. Journal of Monetary Economics 76, 87-106.

Hirshleifer, D., Lim, S. S., Teoh, S. H., 2009. Driven to distraction: extraneous events and underreaction to earnings news. The Journal of Finance 64, 2289-2325.

Hofstede, G., 2001. Culture's consequences: comparing values, behaviors, institutions and organizations across nations. Sage publications.

Hou, K., Karolyi, G. A., Kho, B.-C., 2011. What factors drive global stock returns? The Review of Financial Studies 24, 2527-2574. 
Huang, D., Jiang, F., Tu, J., Zhou, G., 2015. Investor sentiment aligned: a powerful predictor of stock returns. The Review of Financial Studies 28, 791-837.

Ince, O. S., Porter, R. B., 2006. Individual equity return data from thomson datastream: handle with care! Journal of Financial Research 29, 463-479.

Jacobs, H., 2016. Market maturity and mispricing. Journal of Financial Economics 122, 270-287.

Jegadeesh, N., Titman, S., 1993. Returns to buying winners and selling losers: implications for stock market efficiency. The Journal of Finance 48, 65-91.

Kelly, B., Pruitt, S., 2013. Market expectations in the cross-section of present values. The Journal of Finance 68, 1721-1756.

Kelly, B., Pruitt, S., 2015. The three-pass regression filter: a new approach to forecasting using many predictors. Journal of Econometrics 186, 294-316.

Lai, S., Ng, L., Zhang, B., 2014. Does pin affect equity prices around the world? Journal of Financial Economics 114, 178-195.

Lau, S. T., Ng, L., Zhang, B., 2010. The world price of home bias. Journal of Financial Economics 97, 191-217.

Lin, H., Wu, C., Zhou, G., 2018. Forecasting corporate bond returns with a large set of predictors: an iterated combination approach. Management Science 64, 4128-4238.

Lo, A. W., Hasanhodzic, J., 2009. The Heretics of Finance: conversations with Leading Practitioners of Technical Analysis. Bloomberg Press.

Lo, A. W., Mamaysky, H., Wang, J., 2000. Foundations of technical analysis: computational algorithms, statistical inference, and empirical implementation. The Journal of Finance 55, 1705-1765.

Neely, C. J., Rapach, D. E., Tu, J., Zhou, G., 2014. Forecasting the equity risk premium: the role of technical indicators. Management Science 60, 1772-1791. 
Newey, W. K., West, K. D., 1987. A simple, positive semi-definite, heteroskedasticity and autocorrelation consistent covariance matrix. Econometrica 55, 703-708.

Novy-Marx, R., Velikov, M., 2015. A taxonomy of anomalies and their trading costs. The Review of Financial Studies 29, 104-147.

Rapach, D. E., Strauss, J. K., Zhou, G., 2010. Out-of-sample equity premium prediction: combination forecasts and links to the real economy. The Review of Financial Studies $23,821-862$.

Rouwenhorst, K. G., 1998. International momentum strategies. The Journal of Finance $53,267-284$.

Schmeling, M., 2009. Investor sentiment and stock returns: some international evidence. Journal of empirical finance 16, 394-408.

Treynor, J. L., Ferguson, R., 1985. In defense of technical analysis. The Journal of Finance 40, 757-773.

Welch, I., Goyal, A., 2007. A comprehensive look at the empirical performance of equity premium prediction. The Review of Financial Studies 21, 1455-1508.

Zhang, X. F., 2006. Information uncertainty and stock returns. The Journal of Finance $61,105-137$. 


\section{Tables and figures}
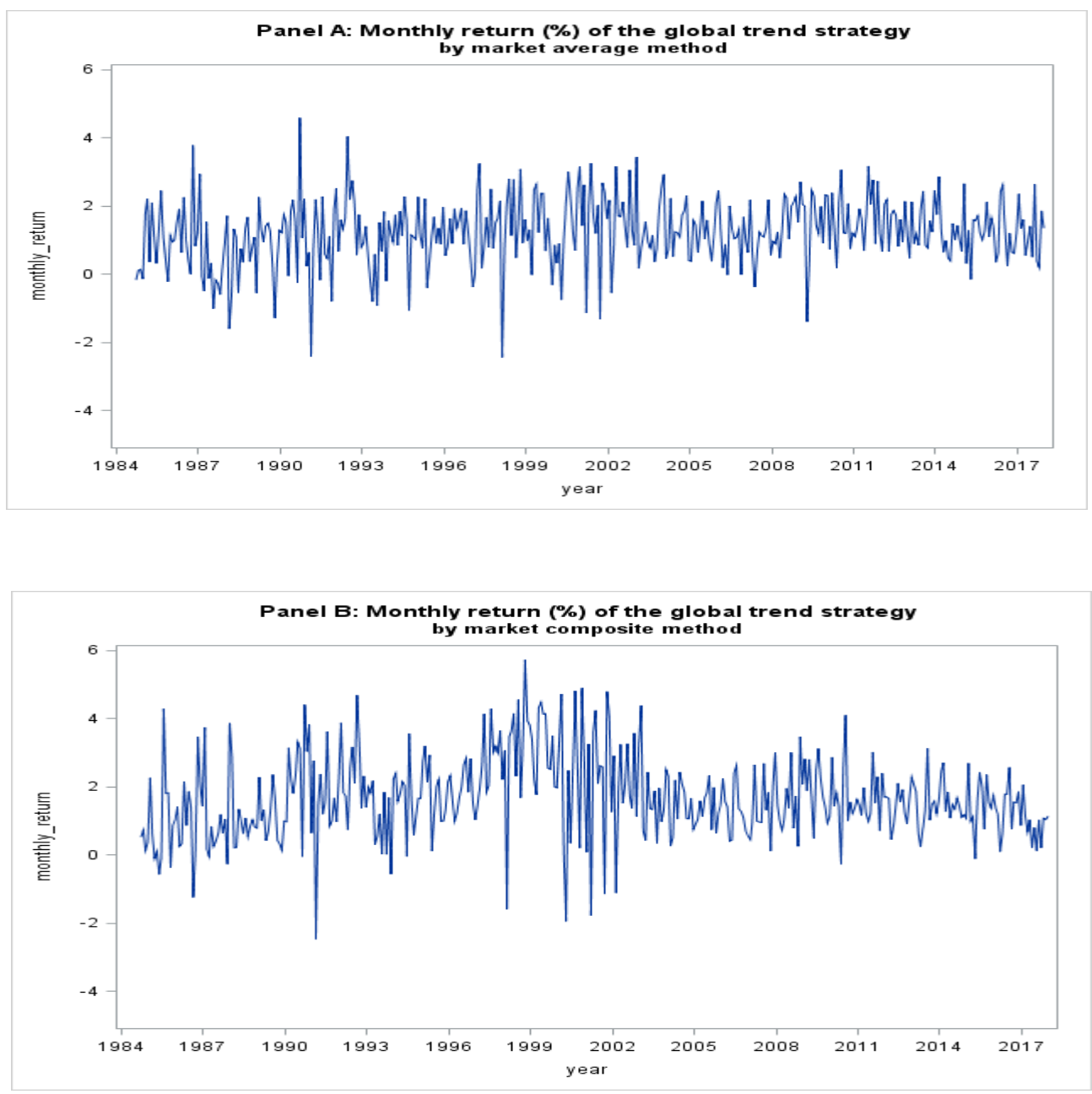

Figure 3.1: Monthly Return of the Global Trend Strategy

This figure shows the monthly return of the global trend strategy. In panel A, we plot the results using the market average method. In panel B, we plot the results using the market composite method. The sample period ranges from September 1984 to December 2017. 


\section{Table 3.1: Sample Summary}

This table reports the summary information of our sample. For each market, we report the sample period, the number of stocks, size, and turnover ratio. To calculate the firm size (turnover ratio) for each market, we first collect the median of market capitalization (turnover ratio) in each month for each market, and then calculate the mean of the monthly median values. The unit for the size is millions of US dollars. The turnover is in percentage.

(1)

Country

Argentina

Australia

Austria

Bangladesh

Belgium

Brazil

Canada

Chile

China

Colombia

Cyprus

Denmark

Egypt

Finland

France

Germany

Greece

Hong Kong

Hungary

India

Indonesia

Israel

Italy

Japan

Kenya

Malaysia

Mexico

Morocco

Netherlands

New Zealand
(2)

(3)

(4)

(5)

(6) Starting Ending Firm No. Size Turnover $(\%)$

$\begin{array}{llccc}01 / 31 / 1982 & 12 / 31 / 2017 & 146 & 60.35 & 0.04 \\ 01 / 31 / 1982 & 12 / 31 / 2017 & 3439 & 16.36 & 0.12 \\ 01 / 31 / 1982 & 12 / 31 / 2017 & 250 & 124.23 & 0.08 \\ 01 / 31 / 1992 & 12 / 31 / 2017 & 407 & 5.79 & 0.19 \\ 01 / 31 / 1982 & 12 / 31 / 2017 & 379 & 76.50 & 0.06\end{array}$

$\begin{array}{lllll}01 / 31 / 1990 & 12 / 31 / 2017 & 393 & 189.60 & 1.50\end{array}$

$\begin{array}{lllll}01 / 31 / 1982 & 12 / 31 / 2017 & 2875 & 50.65 & 0.13\end{array}$

$\begin{array}{lllll}01 / 31 / 1988 & 12 / 31 / 2017 & 307 & 107.41 & 0.02\end{array}$

$\begin{array}{lllll}01 / 31 / 1991 & 12 / 31 / 2017 & 3545 & 322.28 & 1.00\end{array}$

$\begin{array}{lllll}01 / 31 / 1992 & 12 / 31 / 2017 & 120 & 149.65 & 0.03\end{array}$

$\begin{array}{lllll}12 / 31 / 1992 & 12 / 31 / 2017 & 173 & 11.93 & 0.04\end{array}$

$\begin{array}{lllll}01 / 31 / 1982 & 12 / 31 / 2017 & 395 & 50.81 & 0.12\end{array}$

$\begin{array}{lllll}10 / 31 / 1994 & 12 / 31 / 2017 & 307 & 42.41 & 0.11\end{array}$

$\begin{array}{lllll}01 / 31 / 1987 & 12 / 31 / 2017 & 286 & 121.44 & 0.10\end{array}$

$\begin{array}{lllll}01 / 31 / 1982 & 12 / 31 / 2017 & 2346 & 63.66 & 0.06\end{array}$

$\begin{array}{lllll}01 / 31 / 1982 & 12 / 31 / 2017 & 1538 & 84.89 & 0.06\end{array}$

$\begin{array}{lllll}01 / 31 / 1988 & 12 / 31 / 2017 & 427 & 32.63 & 0.12\end{array}$

$\begin{array}{lllll}01 / 31 / 1982 & 12 / 31 / 2017 & 2047 & 84.23 & 0.13\end{array}$

$\begin{array}{lllll}01 / 31 / 1991 & 12 / 31 / 2017 & 115 & 25.39 & 0.11\end{array}$

$\begin{array}{lllll}01 / 31 / 1982 & 12 / 31 / 2017 & 3680 & 1.68 & 0.04\end{array}$

$\begin{array}{lllll}04 / 30 / 1990 & 12 / 31 / 2017 & 666 & 45.27 & 0.05\end{array}$

$\begin{array}{lllll}01 / 31 / 1986 & 12 / 31 / 2017 & 863 & 20.68 & 0.06\end{array}$

$\begin{array}{lllll}01 / 31 / 1982 & 12 / 31 / 2017 & 715 & 193.23 & 0.14\end{array}$

$\begin{array}{lllll}01 / 31 / 1982 & 12 / 31 / 2017 & 5070 & 155.45 & 0.13\end{array}$

$\begin{array}{lllll}01 / 31 / 1991 & 12 / 31 / 2017 & 69 & 29.16 & 0.04\end{array}$

$\begin{array}{lllll}01 / 31 / 1982 & 12 / 31 / 2017 & 1107 & 53.61 & 0.09\end{array}$

$\begin{array}{lllll}06 / 30 / 1982 & 12 / 31 / 2017 & 295 & 260.68 & 0.08\end{array}$

$\begin{array}{lllll}07 / 31 / 1993 & 12 / 31 / 2017 & 110 & 94.39 & 0.04\end{array}$

$\begin{array}{lllll}01 / 31 / 1982 & 12 / 31 / 2017 & 418 & 225.24 & 0.21\end{array}$

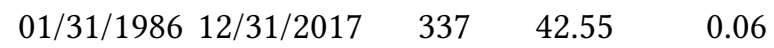

Continued on next page 
Table 3.1 - Continued from previous page

\begin{tabular}{lccccc}
\hline Country & Starting & Ending & Firm No. & Size & Turnover (\%) \\
\hline Norway & $01 / 31 / 1982$ & $12 / 31 / 2017$ & 629 & 88.02 & 0.15 \\
Pakistan & $01 / 31 / 1989$ & $12 / 31 / 2017$ & 433 & 11.16 & 0.06 \\
Peru & $01 / 31 / 1991$ & $12 / 31 / 2017$ & 293 & 18.81 & 0.08 \\
Philippines & $01 / 31 / 1982$ & $12 / 31 / 2017$ & 310 & 36.05 & 0.04 \\
Poland & $04 / 30 / 1991$ & $12 / 31 / 2017$ & 1104 & 17.37 & 0.12 \\
Portugal & $01 / 31 / 1988$ & $12 / 31 / 2017$ & 209 & 54.39 & 0.06 \\
Singapore & $01 / 31 / 1982$ & $12 / 31 / 2017$ & 796 & 79.91 & 0.08 \\
South Africa & $01 / 31 / 1982$ & $12 / 31 / 2017$ & 983 & 63.82 & 0.07 \\
South Korea & $07 / 31 / 1996$ & $12 / 31 / 2017$ & 1795 & 32.87 & 1.37 \\
Spain & $01 / 31 / 1986$ & $12 / 31 / 2017$ & 341 & 413.68 & 0.15 \\
Sri Lanka & $01 / 31 / 1987$ & $12 / 31 / 2017$ & 346 & 5.44 & 6.86 \\
Sweden & $01 / 31 / 1982$ & $12 / 31 / 2017$ & 1342 & 51.20 & 0.15 \\
Switzerland & $01 / 31 / 1982$ & $12 / 31 / 2017$ & 510 & 239.41 & 0.14 \\
Taiwan & $09 / 30 / 1987$ & $12 / 31 / 2017$ & 1099 & 177.33 & 0.55 \\
Thailand & $01 / 31 / 1987$ & $12 / 31 / 2017$ & 908 & 43.42 & 0.13 \\
Turkey & $01 / 31 / 1988$ & $12 / 31 / 2017$ & 502 & 47.32 & 0.69 \\
United Kingdom & $01 / 31 / 1982$ & $12 / 31 / 2017$ & 6532 & 53.72 & 0.18 \\
United States & $08 / 31 / 1979$ & $12 / 31 / 2017$ & 21420 & 186.41 & 0.40 \\
Zimbabwe & $01 / 31 / 1997$ & $12 / 31 / 2017$ & 75 & 17.57 & 0.02 \\
\hline & & & & & \\
\hline
\end{tabular}




\section{Table 3.2: Trend Premium of International Stock Market}

The table reports the mean (RET) and standard deviation (STD) of trend premia in the 49 stock markets. For each market, in each month $t$ we sort stocks in ascending order into quintile portfolios by their forecasted returns using trend signals. We long the stocks in the quintile 5 portfolio (highest predicted returns) and short the stocks in the quintile 1 portfolio (lowest predicted returns). The performance of this long-short portfolio (trend portfolio) measures the trend premium in each market. We consider three different weights to calculate the portfolio return: equal-weighted (EW), value-weighted (VW), and rank-weighted (RW). To determine the rank for a stock under the rank-weighted scheme, for each month in each market, we divide the stocks into deciles based on their market capitalization in ascending order. The rank for a stock is the group it lies in. To forecast a stock return in next month, we first run a cross-sectional regression of stock returns in month $t$ on their moving average (MA) signals of lag lengths 3, 5, 10, 20, 50, 100, 200, 400, 600, 800, and 1000 days at month $t-1$, and obtain the coefficients. We then use the coefficients moving-averaged between month $t$ and $t-11$ and the MA signals at month $t$ to forecast the stock returns in the month $t+1$. We rebalance the portfolio in each month and require there are at least 30 stocks in one month to construct the portfolios. We adjust the standard errors using the Newey-West method with six lags. ${ }^{* * *},{ }^{* * *}$ indicate significance at the $10 \%, 5 \%$, and $1 \%$ levels, respectively.

\begin{tabular}{|c|c|c|c|c|c|c|c|}
\hline \multirow[b]{2}{*}{ Country } & \multicolumn{2}{|c|}{$\mathrm{EW}(\%)$} & \multicolumn{2}{|c|}{$\mathrm{VW}(\%)$} & \multicolumn{2}{|c|}{$\mathrm{RW}(\%)$} & \multirow[b]{2}{*}{ No. of Obs. } \\
\hline & RET & STD & RET & STD & RET & STD & \\
\hline Argentina & $0.69^{*}$ & 6.18 & $1.71^{* * *}$ & 8.53 & $1.11^{* * *}$ & 6.34 & 274 \\
\hline Australia & $2.80^{* \star *}$ & 4.29 & $1.01^{* * *}$ & 5.96 & $1.92^{* \star *}$ & 4.15 & 400 \\
\hline Austria & $0.79^{* * *}$ & 4.73 & 0.18 & 6.26 & $0.51^{*}$ & 4.82 & 400 \\
\hline Bangladesh & 0.51 & 6.66 & 0.72 & 7.90 & 0.48 & 6.42 & 280 \\
\hline Belgium & $1.17^{* * *}$ & 3.34 & $0.76^{* * *}$ & 5.45 & $1.09^{* * *}$ & 3.41 & 400 \\
\hline Brazil & 0.23 & 5.30 & 0.56 & 8.16 & 0.35 & 5.09 & 282 \\
\hline Canada & $3.33^{* * *}$ & 3.92 & $1.47^{* * *}$ & 6.02 & $2.45^{* * *}$ & 3.99 & 400 \\
\hline Chile & $0.67^{* * *}$ & 3.70 & 0.14 & 5.55 & $0.65^{* * *}$ & 3.78 & 310 \\
\hline China & $1.09^{* * *}$ & 4.42 & $0.83^{* * *}$ & 5.51 & $0.92^{* \star *}$ & 4.51 & 286 \\
\hline Colombia & 0.09 & 6.21 & $-1.06^{* *}$ & 8.00 & -0.27 & 6.16 & 280 \\
\hline Cyprus & 0.49 & 7.81 & 0.06 & 8.44 & 0.33 & 7.60 & 215 \\
\hline Denmark & $1.11^{* * *}$ & 3.74 & $1.02^{* * *}$ & 6.08 & $1.01^{* * *}$ & 3.83 & 400 \\
\hline Egypt & 0.39 & 5.68 & 0.33 & 7.24 & 0.36 & 5.53 & 236 \\
\hline Finland & $1.24^{* \star *}$ & 4.71 & 0.73 & 8.19 & $1.16^{* * *}$ & 5.01 & 338 \\
\hline France & $1.82^{* * *}$ & 3.77 & $0.61^{* *}$ & 5.29 & $1.31^{* * *}$ & 3.99 & 400 \\
\hline Germany & $1.74^{* * *}$ & 3.39 & $0.60^{* *}$ & 6.00 & $1.45^{* * *}$ & 3.40 & 400 \\
\hline Greece & $1.87^{* * *}$ & 6.73 & $1.21^{*}$ & 10.47 & $1.42^{* * *}$ & 6.98 & 328 \\
\hline Hong Kong & $1.16^{* * *}$ & 5.16 & $1.05^{* * *}$ & 7.17 & $0.99^{* * *}$ & 5.41 & 400 \\
\hline & & Conti & $d$ on $n$ & ct page & & & \\
\hline
\end{tabular}


Table 3.2 - Continued from previous page

\begin{tabular}{|c|c|c|c|c|c|c|c|}
\hline \multirow[b]{2}{*}{ Country } & \multicolumn{2}{|c|}{ EW (\%) } & \multicolumn{2}{|c|}{ VW (\%) } & \multicolumn{2}{|c|}{ RW (\%) } & \multirow[b]{2}{*}{ No. of Obs. } \\
\hline & RET & STD & RET & STD & RET & STD & \\
\hline Hungary & $2.04^{* *}$ & 11.05 & 0.20 & 9.65 & $1.63^{* *}$ & 8.86 & 229 \\
\hline India & $5.33^{* * *}$ & 6.93 & 0.89 & 8.50 & $4.26^{* * *}$ & 6.50 & 317 \\
\hline Indonesia & 0.35 & 6.41 & 0.38 & 10.77 & 0.43 & 6.92 & 301 \\
\hline Israel & $0.89^{* * *}$ & 3.89 & 0.43 & 7.95 & $0.72^{* \star *}$ & 4.00 & 352 \\
\hline Italy & $0.72^{* * *}$ & 3.96 & $0.53^{*}$ & 5.76 & $0.69^{* * *}$ & 4.15 & 400 \\
\hline Japan & $1.38^{* * *}$ & 3.26 & $0.89^{* * *}$ & 4.93 & $1.23^{* * *}$ & 3.47 & 400 \\
\hline Kenya & $1.39^{* * *}$ & 7.39 & $1.61^{* * *}$ & 8.85 & $1.46^{* * *}$ & 7.56 & 292 \\
\hline Malaysia & $1.12^{* * *}$ & 4.76 & $0.67^{* *}$ & 5.82 & $0.81^{* * *}$ & 4.82 & 365 \\
\hline Mexico & $0.87^{* * *}$ & 4.94 & 0.15 & 6.77 & $0.61^{\text {** }}$ & 5.21 & 332 \\
\hline Morocco & $1.20^{* * *}$ & 4.45 & $0.66^{*}$ & 5.80 & $1.09^{* * *}$ & 4.59 & 262 \\
\hline Netherlands & $0.69^{* * *}$ & 4.19 & -0.12 & 7.08 & $0.59^{* *}$ & 4.37 & 400 \\
\hline New Zealand & $1.42^{* * *}$ & 5.01 & 0.21 & 6.48 & $1.04^{* * *}$ & 4.59 & 341 \\
\hline Norway & $1.17^{* * *}$ & 5.28 & $0.98^{* *}$ & 7.37 & $1.04^{* * *}$ & 5.34 & 400 \\
\hline Pakistan & $1.83^{* * *}$ & 5.63 & $0.63^{*}$ & 7.45 & $1.31^{* * *}$ & 5.64 & 287 \\
\hline Peru & 0.29 & 5.80 & -0.46 & 9.33 & 0.16 & 5.61 & 292 \\
\hline Philippines & $1.88^{* * *}$ & 6.55 & $1.70^{* * *}$ & 8.07 & $1.49^{* * *}$ & 6.73 & 318 \\
\hline Poland & $1.33^{* * *}$ & 5.13 & 0.64 & 7.78 & $1.16^{* * *}$ & 5.41 & 257 \\
\hline Portugal & $1.37^{\star * *}$ & 6.57 & -0.12 & 8.45 & $0.86^{* *}$ & 6.18 & 328 \\
\hline Singapore & $1.67^{* * *}$ & 4.76 & $0.64^{* *}$ & 6.21 & $1.14^{* * *}$ & 4.63 & 400 \\
\hline South Africa & $1.52^{* * *}$ & 4.97 & $0.65^{*}$ & 7.21 & $1.15^{* * *}$ & 4.88 & 400 \\
\hline South Korea & $1.29^{* * *}$ & 5.30 & 0.83 & 7.79 & $0.98^{* *}$ & 5.56 & 226 \\
\hline Spain & $0.89^{* * *}$ & 4.18 & $0.59^{*}$ & 5.93 & $0.86^{* * *}$ & 4.28 & 351 \\
\hline Sri Lanka & $1.68^{* * *}$ & 4.49 & $0.83^{* *}$ & 6.01 & $1.39^{* * *}$ & 4.54 & 335 \\
\hline Sweden & $1.86^{* * *}$ & 4.66 & $1.12^{* * *}$ & 6.90 & $1.59^{* \star *}$ & 4.80 & 400 \\
\hline Switzerland & $1.02^{* * *}$ & 2.76 & $0.68^{* * *}$ & 4.75 & $0.84^{* * *}$ & 2.95 & 400 \\
\hline Taiwan & 0.17 & 4.56 & 0.15 & 5.84 & 0.17 & 4.88 & 332 \\
\hline Thailand & $1.05^{* * *}$ & 4.82 & $1.11^{* * *}$ & 6.51 & $1.02^{* \star *}$ & 5.23 & 340 \\
\hline Turkey & 0.16 & 5.94 & 0.60 & 9.10 & 0.30 & 5.88 & 328 \\
\hline United Kingdom & $0.96^{* * *}$ & 2.86 & $0.64^{* *}$ & 5.84 & $0.97^{\star \star *}$ & 3.19 & 400 \\
\hline United States & $1.21^{* * *}$ & 3.30 & $0.86^{* * *}$ & 3.59 & $1.18^{* * *}$ & 3.33 & 400 \\
\hline Zimbabwe & 0.31 & 11.02 & -0.14 & 10.16 & -0.39 & 9.60 & 66 \\
\hline
\end{tabular}




\section{Table 3.3: Alphas of the Trend Portfolio}

$$
\text { Trend_ret } t_{i t}=a_{i}+b_{i} M K T_{t}+c_{i} S M B_{t}+d_{i} H M L_{t}+e_{i} M O M_{t}+\epsilon_{i, t}
$$

This table reports the alphas of the long-short trend portfolios in each market. The dependent variable Trend_ret $t_{i t}$ is the trend premium of market $i$ in month $t$. The alphas are obtained using the CAPM model, the Fama-French three-factor (FF3) model, and the Carhart four-factor (CAR4) model (FamaFrench three-factor and a momentum factor), respectively. The left, middle, and right panels report the results for equal-weighted (EW), value-weighted (VW) and rank-weighted (RW) portfolios, respectively. The global stock factor data are downloaded from French's data library. All the returns are calculated in US dollars, and the risk-free rate is the one-month T-bill rate. Fama-French three factor data range from July 1990 to December 2017, while the momentum factor data are from December 1990 to December 2017. We adjust the standard errors using the Newey-West method with six lags. ",**, ,*** indicate significance at the $10 \%, 5 \%$, and $1 \%$ levels, respectively.

\begin{tabular}{|c|c|c|c|c|c|c|c|c|c|}
\hline \multirow[b]{2}{*}{ Country } & \multicolumn{3}{|c|}{ EW } & \multicolumn{3}{|c|}{ VW } & \multicolumn{3}{|c|}{ RW } \\
\hline & CAPM & FF3 & CAR4 C & CAPM & FF3 & CAR4 & CAPM & FF3 & CAR4 \\
\hline Argentina & $0.67^{*}$ & 0.60 & 0.64 & $1.67^{* \star *}$ & $1.52^{* * *}$ & $1.62^{* * *}$ & * $1.09^{* * *}$ & $1.01^{* * *}$ & * $1.04^{* *}$ \\
\hline Australia & $3.37^{* * *}$ & $3.36^{* * *}$ & $3.45^{* * *}$ & $1.02^{* * *}$ & $0.97^{* * *}$ & $1.15^{* * *}$ & * $2.30^{* * *}$ & $2.28^{* * *}$ & * $2.39^{* * *}$ \\
\hline Austria & $0.64^{* *}$ & $0.74^{* * *}$ & $0.59^{* *}$ & 0.08 & 0.16 & -0.06 & 0.39 & $0.50^{*}$ & 0.32 \\
\hline Bangladesh & 0.52 & 0.59 & 0.43 & 0.74 & $0.83^{*}$ & 0.71 & 0.51 & 0.57 & 0.43 \\
\hline Belgium & $1.20^{* * *}$ & $1.22^{* * *}$ & * $1.11^{* * *}$ & $0.76^{* * *}$ & $0.81^{* * *}$ & $0.58^{*}$ & $1.09^{* * *}$ & $1.11^{* * *}$ & * $1.02^{\text {*** }}$ \\
\hline Brazil & 0.25 & 0.30 & 0.22 & 0.68 & 0.81 & 0.71 & 0.39 & 0.45 & 0.35 \\
\hline Canada & $3.48^{* * *}$ & $3.51^{* * *}$ & * $3.59^{* * *}$ & $1.44^{* * *}$ & $1.41^{* * *}$ & $1.65^{* * *}$ & * $2.56^{* * *}$ & $2.58^{* * *}$ & * $2.71^{\text {*** }}$ \\
\hline Chile & $0.67^{* * *}$ & $0.73^{* * *}$ & $0.68^{* * *}$ & 0.12 & 0.22 & 0.11 & $0.65^{* * *}$ & $0.71^{* * *}$ & * $0.67^{\text {*** }}$ \\
\hline China & $1.12^{* * *}$ & $1.12^{* * *}$ & ${ }^{*} 1.23^{* * *}$ & $0.85^{* * *}$ & $0.84^{* * *}$ & $0.96^{* * *}$ & * $0.94^{* * *}$ & $0.94^{* * *}$ & * $1.04^{\text {*** }}$ \\
\hline Colombia & 0.11 & 0.01 & 0.00 & $-1.08^{* *}$ & $-1.09^{* *}$ & $-1.14^{* *}$ & -0.28 & -0.35 & -0.37 \\
\hline Cyprus & 0.50 & 0.50 & 0.38 & 0.10 & -0.02 & -0.11 & 0.36 & 0.35 & 0.25 \\
\hline Denmark & $1.21^{* * *}$ & $1.25^{* * *}$ & ${ }^{*} 1.11^{* * *}$ & $1.15^{* * *}$ & $1.22^{* * *}$ & $0.99^{* * *}$ & ${ }^{*} 1.04^{* * *}$ & $1.09^{* * *}$ & * $0.92^{\text {*** }}$ \\
\hline Egypt & 0.37 & 0.35 & 0.57 & 0.33 & 0.39 & 0.65 & 0.34 & 0.35 & $0.57^{*}$ \\
\hline Finland & $1.22^{* * *}$ & $1.21^{* * *}$ & $1.23^{* * *}$ & 0.75 & 0.76 & 0.70 & $1.13^{* * *}$ & $1.11^{* * *}$ & * $1.12^{\text {*** }}$ \\
\hline France & $1.99^{* * *}$ & $1.98^{* * *}$ & * $2.10^{* * *}$ & $0.56^{*}$ & $0.57^{*}$ & $0.73^{* *}$ & $1.42^{* * *}$ & $1.41^{* * *}$ & * $1.50^{\text {*** }}$ \\
\hline Germany & $2.03^{\star \star \star}$ & $1.91^{* * *}$ & $1.75^{* * *}$ & $0.61^{*}$ & 0.49 & 0.17 & $1.71^{* * *}$ & $1.58^{* * *}$ & * $1.39^{\text {*** }}$ \\
\hline Greece & $1.80^{* * *}$ & $1.77^{* * *}$ & $1.52^{* * *}$ & $1.18^{*}$ & $1.16^{*}$ & 0.67 & $1.38^{* * *}$ & $1.36^{* * *}$ & * $1.05^{\text {** }}$ \\
\hline Hong Kong & $1.18^{* * *}$ & $1.19^{* * *}$ & ${ }^{*} \quad 1.28^{* * *}$ & $1.16^{* * *}$ & $1.09^{* * *}$ & $1.19^{* * *}$ & * $1.04^{* * *}$ & $1.05^{* * *}$ & * $1.16^{* * *}$ \\
\hline Hungary & $2.01^{* *}$ & $2.01^{* *}$ & $1.79^{* *}$ & 0.20 & 0.06 & -0.14 & $1.61^{* *}$ & $1.64^{* *}$ & $1.44^{* *}$ \\
\hline India & $5.28^{* * *}$ & $5.32^{* * *}$ & * $5.28^{* * *}$ & 0.88 & $1.03^{*}$ & 0.95 & $4.21^{* * *}$ & $4.23^{* * *}$ & * $4.23^{* * *}$ \\
\hline Indonesia & 0.40 & 0.24 & 0.41 & 0.44 & 0.36 & 0.83 & 0.48 & 0.33 & 0.55 \\
\hline Israel & $0.97^{* * *}$ & $0.94^{* * *}$ & * $0.84^{* *}$ & 0.46 & 0.44 & 0.31 & $0.78^{* * *}$ & $0.74^{* * *}$ & * $0.68^{* *}$ \\
\hline Italy & $1.14^{* * *}$ & $1.15^{* * *}$ & $* 0.85^{* * *}$ & $0.94^{* * *}$ & $0.99^{* * *}$ & 0.62 & $1.12^{* * *}$ & $1.13^{* * *}$ & * $0.83^{* * *}$ \\
\hline
\end{tabular}


Table 3.3 - Continued from previous page

\begin{tabular}{|c|c|c|c|c|c|c|c|c|c|}
\hline \multirow[b]{2}{*}{ Country } & \multicolumn{3}{|c|}{ EW } & \multicolumn{3}{|c|}{ VW } & \multicolumn{3}{|c|}{ RW } \\
\hline & CAPM & FF3 & CAR4 & CAPM & FF3 & CAR4 C & CAPM & FF3 & CAR4 \\
\hline Japan & $1.35^{* * *}$ & $1.34^{* * *}$ & $1.22^{* * *}$ & * $\quad 0.70^{* * *}$ & $0.72^{* * *}$ & * $0.56^{*}$ & $1.14^{* * *}$ & $1.13^{* * *}$ & $1.02^{* * *}$ \\
\hline Kenya & $1.39^{* * *}$ & $1.42^{* * *}$ & $1.39^{* * *}$ & * $1.54^{* * *}$ & $1.56^{* * *}$ & * $1.48^{* * *}$ & ${ }^{*} 1.45^{* * *}$ & $1.45^{* * *}$ & $1.42^{* * *}$ \\
\hline Malaysia & $1.17^{\star \star *}$ & $1.21^{* * *}$ & $1.14^{* * *}$ & $0.70^{* *}$ & $0.67^{* *}$ & 0.49 & $0.85^{* * *}$ & $0.88^{* * *}$ & $0.78^{* *}$ \\
\hline Mexico & $0.97^{* * *}$ & $0.95^{* * *}$ & $1.00^{* * *}$ & * 0.25 & 0.27 & 0.40 & $0.72^{* *}$ & $0.70^{* *}$ & $0.81^{* * *}$ \\
\hline Morocco & $1.27^{* * *}$ & $1.22^{* * *}$ & $1.30^{* * *}$ & $\quad 0.70^{*}$ & $0.69^{*}$ & $0.76^{* *}$ & $1.15^{* * *}$ & $1.13^{* * *}$ & $1.21^{* * *}$ \\
\hline Netherlands & $0.65^{* *}$ & $0.61^{* *}$ & $0.46^{*}$ & -0.29 & -0.27 & -0.44 & $0.48^{*}$ & 0.45 & 0.31 \\
\hline New Zealand & $1.53^{* * *}$ & $1.61^{* * *}$ & $1.67^{* * *}$ & * 0.20 & 0.18 & 0.28 & $1.13^{* * *}$ & $1.19^{* * *}$ & $1.23^{* * *}$ \\
\hline Norway & $1.38^{* * *}$ & $1.38^{* * *}$ & $1.16^{* * *}$ & ${ }^{*} 1.09^{* *}$ & $1.05^{\star *}$ & $0.92^{*}$ & $1.25^{\star * *}$ & $1.25^{* * *}$ & $1.07^{* * *}$ \\
\hline Pakistan & $1.76^{* * *}$ & $1.75^{* * *}$ & $1.80^{* * *}$ & 0.58 & 0.53 & 0.62 & $1.24^{* * *}$ & $1.22^{* * *}$ & $1.32^{* * *}$ \\
\hline Peru & 0.23 & 0.25 & 0.26 & -0.46 & -0.44 & -0.38 & 0.11 & 0.11 & 0.15 \\
\hline Philippines & $1.84^{* * *}$ & $1.75^{* * *}$ & $1.84^{* * *}$ & $\quad 1.71^{* * *}$ & $1.58^{* * *}$ & * $1.76^{* * *}$ & ${ }^{*} 1.46^{* * *}$ & $1.37^{* \star *}$ & $1.46^{* * *}$ \\
\hline Poland & $1.39^{* * *}$ & $1.31^{* * *}$ & $1.29^{* * *}$ & $* 0.75^{*}$ & 0.59 & 0.34 & $1.24^{* * *}$ & $1.15^{* * *}$ & $1.08^{* * *}$ \\
\hline Portugal & $1.40^{* * *}$ & $1.47^{* * *}$ & $1.73^{* * *}$ & ${ }^{*}-0.25$ & -0.17 & 0.21 & $0.84^{* *}$ & $0.90^{* *}$ & $1.21^{* * *}$ \\
\hline Singapore & $2.15^{\star * *}$ & $2.18^{* * *}$ & $2.17^{\star * *}$ & $1.06^{* * *}$ & $1.04^{* * *}$ & * $1.05^{* * *}$ & * $1.50^{* * *}$ & $1.52^{* \star *}$ & $1.49^{* * *}$ \\
\hline South Africa & $1.76^{* * *}$ & $1.81^{* * *}$ & $1.75^{* * *}$ & * $0.84^{* *}$ & $0.95^{* *}$ & $0.77^{\star}$ & $1.39^{* * *}$ & $1.44^{* * *}$ & $1.38^{* * *}$ \\
\hline South Korea & $1.34^{* * *}$ & $1.36^{* * *}$ & $1.40^{* * *}$ & * 0.84 & 0.99 & 0.90 & $0.99^{* *}$ & $1.07^{* \star}$ & $1.05^{* *}$ \\
\hline Spain & $0.99^{* * *}$ & $1.05^{* * *}$ & $0.95^{* * *}$ & * $0.69^{* *}$ & $0.87^{* * *}$ & ${ }^{*} \quad 0.92^{* * *}$ & * $0.98^{* * *}$ & $1.08^{* * *}$ & $1.00^{* * *}$ \\
\hline Sri Lanka & $1.71^{* * *}$ & $1.71^{* * *}$ & $1.80^{* * *}$ & * $0.84^{* *}$ & $0.85^{* *}$ & $0.99^{* *}$ & $1.40^{* * *}$ & $1.40^{* * *}$ & $1.53^{* * *}$ \\
\hline Sweden & $2.01^{* * *}$ & $2.09^{* * *}$ & $1.94^{* * *}$ & ${ }^{*} \quad 1.31^{* * *}$ & $1.40^{* * *}$ & * $1.46^{* * *}$ & ${ }^{*} 1.73^{* * *}$ & $1.83^{* * *}$ & $1.69^{* * *}$ \\
\hline Switzerland & $0.96^{* * *}$ & $1.02^{* * *}$ & $0.89^{* * *}$ & * $0.65^{* *}$ & $0.75^{* *}$ & $0.52^{*}$ & $0.82^{* * *}$ & $0.89^{* * *}$ & $0.75^{* * *}$ \\
\hline Taiwan & 0.11 & 0.18 & 0.24 & 0.07 & 0.16 & 0.18 & 0.10 & 0.17 & 0.24 \\
\hline Thailand & $1.04^{* * *}$ & $0.96^{* * *}$ & $1.08^{* * *}$ & $1.16^{* * *}$ & $1.05^{* * *}$ & * $1.11^{* * *}$ & ${ }^{*} \quad 1.02^{* * *}$ & $0.93^{* * *}$ & $1.07^{* * *}$ \\
\hline Turkey & 0.06 & 0.02 & 0.24 & 0.51 & 0.49 & 0.77 & 0.19 & 0.16 & 0.45 \\
\hline United Kingdom & $1.05^{* * *}$ & $1.14^{* * *}$ & $0.93^{* * *}$ & * $0.61^{* *}$ & $0.77^{\star *}$ & 0.40 & $1.05^{* * *}$ & $1.17^{* \star *}$ & $0.93^{* * *}$ \\
\hline United States & $1.16^{* * *}$ & $1.15^{* * *}$ & $1.10^{* * *}$ & * $0.80^{* * *}$ & $0.77^{* * *}$ & ${ }^{*} \quad 0.86^{* * *}$ & ${ }^{*} \quad 1.12^{* * *}$ & $1.11^{* * *}$ & $1.06^{* * *}$ \\
\hline Zimbabwe & 0.32 & 0.26 & 0.02 & -0.77 & -0.80 & -0.52 & -0.69 & -0.74 & -0.82 \\
\hline
\end{tabular}


Table 3.4: Turnover Ratio and Break-even Transaction Cost of the Trend Portfolios

This table reports the turnover ratio and corresponding break-even transaction cost (BETC) of the trend portfolios in each market. The turnover ratio of the trend portfolio is the turnover of the long-leg (quintile 5) portfolio plus the turnover of the short-leg (quintile 1) portfolio. The BETC is the cost that can completely offset the return of the trend portfolio. A higher BETC indicates that the return is less likely to be wiped out by transaction cost. The left, middle, and right panels report the results for equal-weighted (EW), value-weighted (VW), and rank-weighted (RW) portfolios, respectively.

\begin{tabular}{|c|c|c|c|c|c|c|}
\hline \multirow[b]{2}{*}{ Country } & \multicolumn{2}{|c|}{ EW } & \multicolumn{2}{|c|}{ VW } & \multicolumn{2}{|c|}{ RW } \\
\hline & Turnover & ETC $(\%$ & nover & $\operatorname{ETC}(\%)$ & )Turnover & $\operatorname{ETC}(\%)$ \\
\hline Argentina & 117 & 0.59 & 140 & 1.22 & 122 & 0.91 \\
\hline Australia & 136 & 2.05 & 165 & 0.61 & 139 & 1.38 \\
\hline Austria & 121 & 0.65 & 142 & 0.12 & 126 & 0.41 \\
\hline Bangladesh & 110 & 0.46 & 123 & 0.59 & 113 & 0.42 \\
\hline Belgium & 122 & 0.96 & 147 & 0.52 & 127 & 0.86 \\
\hline Brazil & 127 & 0.18 & 157 & 0.36 & 134 & 0.26 \\
\hline Canada & 139 & 2.40 & 168 & 0.87 & 144 & 1.71 \\
\hline Chile & 102 & 0.66 & 134 & 0.11 & 108 & 0.60 \\
\hline China & 122 & 0.89 & 125 & 0.67 & 122 & 0.76 \\
\hline Colombia & 119 & 0.08 & 141 & -0.75 & 126 & -0.22 \\
\hline Cyprus & 121 & 0.41 & 130 & 0.05 & 125 & 0.27 \\
\hline Denmark & 116 & 0.95 & 138 & 0.74 & 120 & 0.84 \\
\hline Egypt & 125 & 0.31 & 143 & 0.23 & 128 & 0.28 \\
\hline Finland & 126 & 0.99 & 144 & 0.51 & 130 & 0.89 \\
\hline France & 128 & 1.42 & 152 & 0.40 & 132 & 1.00 \\
\hline Germany & 130 & 1.34 & 156 & 0.38 & 134 & 1.08 \\
\hline Greece & 123 & 1.52 & 141 & 0.86 & 126 & 1.13 \\
\hline Hong Kong & 127 & 0.91 & 149 & 0.70 & 130 & 0.76 \\
\hline Hungary & 127 & 1.60 & 155 & 0.13 & 134 & 1.22 \\
\hline India & 131 & 4.08 & 136 & 0.65 & 130 & 3.26 \\
\hline Indonesia & 120 & 0.29 & 143 & 0.27 & 123 & 0.35 \\
\hline Israel & 135 & 0.66 & 157 & 0.27 & 139 & 0.51 \\
\hline Italy & 113 & 0.64 & 136 & 0.39 & 117 & 0.59 \\
\hline Japan & 124 & 1.12 & 142 & 0.63 & 127 & 0.97 \\
\hline Kenya & 117 & 1.19 & 140 & 1.15 & 123 & 1.18 \\
\hline Malaysia & 129 & 0.87 & 147 & 0.46 & 131 & 0.61 \\
\hline Mexico & 113 & 0.76 & 143 & 0.11 & 121 & 0.50 \\
\hline
\end{tabular}


Table 3.4 - Continued from previous page

\begin{tabular}{|c|c|c|c|c|c|c|}
\hline \multirow[b]{2}{*}{ Country } & \multicolumn{2}{|l|}{ EW } & \multicolumn{2}{|c|}{ VW } & \multicolumn{2}{|c|}{ RW } \\
\hline & Turnover $(\%)$ & $\operatorname{ETC}(\%)^{\prime}$ & Turnover (\%) & $\operatorname{BETC}(\%) \mathrm{T}$ & Turnover (\%) & BETC (\%) \\
\hline Morocco & 119 & 1.02 & 144 & 0.46 & 126 & 0.87 \\
\hline Netherlands & 118 & 0.58 & 146 & -0.08 & 123 & 0.48 \\
\hline New Zealand & 127 & 1.12 & 151 & 0.14 & 133 & 0.78 \\
\hline Norway & 127 & 0.92 & 152 & 0.64 & 131 & 0.79 \\
\hline Pakistan & 124 & 1.48 & 142 & 0.44 & 127 & 1.03 \\
\hline Peru & 110 & 0.26 & 134 & -0.35 & 114 & 0.14 \\
\hline Philippines & 123 & 1.53 & 147 & 1.16 & 126 & 1.19 \\
\hline Poland & 131 & 1.01 & 157 & 0.41 & 134 & 0.86 \\
\hline Portugal & 114 & 1.20 & 144 & -0.09 & 121 & 0.71 \\
\hline Singapore & 132 & 1.26 & 150 & 0.43 & 135 & 0.84 \\
\hline South Africa & 128 & 1.18 & 157 & 0.41 & 135 & 0.85 \\
\hline South Korea & 125 & 1.03 & 128 & 0.65 & 125 & 0.79 \\
\hline Spain & 116 & 0.76 & 141 & 0.42 & 122 & 0.70 \\
\hline Sri Lanka & 120 & 1.39 & 135 & 0.61 & 123 & 1.13 \\
\hline Sweden & 128 & 1.46 & 156 & 0.72 & 133 & 1.20 \\
\hline Switzerland & 118 & 0.86 & 144 & 0.47 & 122 & 0.69 \\
\hline Taiwan & 116 & 0.15 & 132 & 0.12 & 118 & 0.14 \\
\hline Thailand & 113 & 0.93 & 131 & 0.85 & 115 & 0.89 \\
\hline Turkey & 126 & 0.12 & 146 & 0.41 & 129 & 0.23 \\
\hline United Kingdom & 124 & 0.77 & 157 & 0.41 & 129 & 0.75 \\
\hline United States & 140 & 0.86 & 151 & 0.57 & 141 & 0.84 \\
\hline Zimbabwe & 110 & 0.28 & 140 & -0.10 & 117 & -0.34 \\
\hline
\end{tabular}




\section{Table 3.5: Trend Strategy at the Global-level}

This table reports the performance of the global trend strategy. We construct the global trend portfolio using the market average method and the market composite method. For the market average method, we use the mean trend premium of markets. For the market composite method, we pool the quintile 1 and quintile 5 stocks within each market to construct the global portfolios. Panel A reports the various return attributes of the global trend portfolios. We show the raw return (RET), standard deviation (STD), turnover ratio, and break-even transaction cost (BETC). The sample period ranges from September 1984 to December 2017 in panel A. Panel B reports the alphas of the global trend strategy and the sample period used to calculate alphas ranges from July 1990 to December 2017. We adjust the standard errors using the Newey-West method with six lags. ${ }^{* * *},{ }^{* * *}$ indicate significance at the $10 \%, 5 \%$, and $1 \%$ levels, respectively. We report $t$-values in the parentheses.

\begin{tabular}{lcccc}
\hline Panel A: & Attributes & & & \\
\hline Method & RET (\%) & STD (\%) & Turnover (\%) & BETC (\%) \\
\hline Average & $1.22^{\text {***}}$ & 0.97 & 122 & 1 \\
Composite & $1.67^{\text {*** }}$ & 1.20 & 128 & 1.30 \\
\hline
\end{tabular}

\begin{tabular}{lccc}
\hline Panel B: & Alphas & & \\
\hline Method & CAPM & FF3 & CAR4 \\
\hline Average & $1.09^{* * *}$ & $1.10^{* * *}$ & $1.07^{* * *}$ \\
& $(17.26)$ & $(16.64)$ & $(15.03)$ \\
Composite & $1.56^{* * *}$ & $1.57^{* * *}$ & $1.54^{* * *}$ \\
& $(19.57)$ & $(19.28)$ & $(17.71)$ \\
\hline
\end{tabular}




\section{Table 3.6: Firm-level Fama-MacBeth Regression}

$$
r_{i, t+1}=\gamma_{0}+\gamma_{1} E_{t}\left[r_{i, t+1}\right]+\gamma_{2} B M_{i t}+\gamma_{3} S_{i z e_{i t}}+\sum_{k=1}^{m} \eta_{k} \text { Othercontrols } s_{i t}^{k}+\epsilon_{i t+1},
$$

This table reports the results of testing whether the trend signals have predictive power at the firm level after controlling for other variables. We pool all the firm-level observations from all non-US markets together to run the Fama-MacBeth regression. The dependent variable $r_{i, t+1}$ is the monthly stock return of firm $i$ in excess of a 30-day US Treasury bill rate in month $t+1 . E_{t}\left[r_{i, t+1}\right]$ is the forecasted return of firm $i$ in month $t+1$ using the MA signals in month $t . B M_{i t}$ is the logarithm of firm $i$ 's book-to-market ratio and $S_{i z e_{i t}}$ is the logarithm of firm size. Following Han et al. (2016), to test whether the trend strategy that aggregates information of different horizons can still be useful after controlling past information from a major single horizon, we add last month's return $\left(r_{i, t-1}\right)$, medium-term return (past 6 months' to past 2 months' return, $r_{i, t-6, t-2}$ ), and long-term return (past 60 months' to past 25 months' return, $\left.r_{i, t-60, t-25}\right)$ to the regression as the other control variables. The sample period ranges from September 1984 to December 2017. We adjust the standard errors using the Newey-West method with six lags. ***,*** indicate significance at the $10 \%, 5 \%$, and $1 \%$ levels, respectively. We report $t$-values in the parentheses.

\begin{tabular}{lcccc}
\hline & $(1)$ & $(2)$ & $(3)$ & $(4)$ \\
& $r_{i t+1}$ & $r_{i t+1}$ & $r_{i t+1}$ & $r_{i t+1}$ \\
\hline Constant & $0.771^{* * *}$ & $1.096^{* * *}$ & $0.700^{* *}$ & $0.977^{* * *}$ \\
& $(2.73)$ & $(3.18)$ & $(2.52)$ & $(2.92)$ \\
$E_{t}\left[r_{i t+1}\right]$ & $0.150^{* * *}$ & $0.160^{* * *}$ & $0.139^{* * *}$ & $0.144^{* * *}$ \\
& $(5.55)$ & $(5.98)$ & $(5.64)$ & $(6.03)$ \\
BM $M_{i t}$ & & $0.780^{* * *}$ & & $0.781^{* * *}$ \\
& & $(13.22)$ & & $(14.48)$ \\
Size $e_{i t}$ & & -0.011 & & -0.010 \\
$r_{i, t-2}$ & & $(-0.40)$ & & $(-0.38)$ \\
& & & $-0.015^{* * *}$ & $-0.012^{* *}$ \\
$r_{i, t-6, t-2}$ & & & $(-3.01)$ & $(-2.58)$ \\
$r_{i, t-60, t-25}$ & & & 0.003 & $0.006^{* * *}$ \\
& & & $(1.39)$ & $(3.02)$ \\
\hline Observations $4,600,268$ & $4,600,268$ & $4,600,153$ & $4,600,153$ \\
$R^{2}$ & 0.013 & 0.027 & 0.031 & 0.044 \\
\hline
\end{tabular}




\section{Table 3.7: Trend Premium Using Information of Different Horizons}

This table reports the difference in trend premium by using different horizon information. We construct the trend portfolios using a different combination of long (l)-, intermediate (m)-, and short (s)-horizon moving average (MA) signals. 1 stands for the MA signals of lag lengths 400, 600, 800, and 1000 days. $\mathrm{m}$ stands for the MA signals of lag lengths 100 and 200 days. s stands for the MA signals of lag lengths $3,5,10,20$, and 50 days. The left panel presents the return differences between the trend portfolio using all information and using single-term information. The right panel reports the improvement of portfolio performance when adding information of different horizons step by step. The sample period ranges from September 1984 to December 2017. We adjust the standard errors using the Newey-West method with six lags. ${ }^{* * *},{ }^{* * *}$ indicate significance at the $10 \%, 5 \%$, and $1 \%$ levels, respectively.

\begin{tabular}{|c|c|c|c|c|c|c|}
\hline \multirow[b]{2}{*}{ Method } & \multirow[b]{2}{*}{ Weight } & \multicolumn{3}{|c|}{ all terms minus single term } & \multicolumn{2}{|c|}{ longer term minus shorter term } \\
\hline & & $(1+m+s)-(1)$ & $(1+m+s)-(m)$ & $(1+m+s)-(s)$ & $(1+m+s)-(m+s)$ & $(\mathrm{m}+\mathrm{s})-(\mathrm{s})$ \\
\hline Average & EW & $0.64^{* * *}$ & $0.34^{* * *}$ & $0.18^{* * *}$ & $0.07^{*}$ & $0.11^{* * *}$ \\
\hline Composite & EW & $1.07^{\star * *}$ & $0.76^{* * *}$ & $0.11^{* *}$ & $0.05^{*}$ & 0.06 \\
\hline Average & VW & $0.44^{* * *}$ & $0.31^{* \star *}$ & $0.17^{* * *}$ & $0.13^{\star *}$ & 0.04 \\
\hline Composite & VW & $0.69^{* \star *}$ & $0.65^{\star \star *}$ & -0.10 & -0.06 & -0.04 \\
\hline Average & RW & $0.55^{* * *}$ & $0.36^{* * *}$ & $0.21^{* * *}$ & $0.10^{* *}$ & $0.11^{* * *}$ \\
\hline Composite & RW & $0.93^{* * *}$ & $0.78^{* * *}$ & $0.08^{*}$ & $0.06^{*}$ & 0.02 \\
\hline
\end{tabular}




\section{Table 3.8: Trend Premium and Momentum}

This table documents the comparison between the global trend strategy and the global momentum strategy using the same holding period, which ranges from one month to six months. To account for the data-overlapping issue, we follow Jegadeesh and Titman (1993) to calculate the holding period return longer than one month. We use both the market average method and the market composite method to construct the portfolios. Besides, to show the robustness of results, we also consider four variants of the momentum strategy, which has different past return measurement period (past 6 months or past 12 months) and whether to skip 1 month or not before the formation of the portfolio. We use abbreviations, like 5/1, to denote those variants of momentum implementations. We report the mean return of the global trend and momentum portfolios and their difference. The return is in percentage. The sample period ranges from September 1984 to December 2017. We adjust the standard errors using the Newey-West method with six lags. ${ }^{* * *},{ }^{* * *}$ indicate significance at the $10 \%, 5 \%$, and $1 \%$ levels, respectively.

\begin{tabular}{|c|c|c|c|c|c|c|c|c|}
\hline \multirow[b]{2}{*}{ Method } & \multirow[b]{2}{*}{ Momentum } & \multirow[b]{2}{*}{ Strategy } & \multicolumn{6}{|c|}{ Holding period } \\
\hline & & & 1 & 2 & 3 & 4 & 5 & 6 \\
\hline \multirow[t]{12}{*}{ Average } & $5 / 1$ & Trend & $1.22^{* * *}$ & $0.75^{* * *}$ & $0.56^{* * *}$ & $0.47^{* * *}$ & $0.41^{* * *}$ & $0.36^{\text {***}}$ \\
\hline & & Momentum & $0.79^{* * *}$ & $0.80^{* * *}$ & $0.78^{* * *}$ & $0.77^{* * *}$ & $0.75^{* * *}$ & $0.74^{\text {*** }}$ \\
\hline & & Difference & $0.43^{* * *}$ & -0.05 & $-0.22^{*}$ & $-0.30^{\star * *}$ & $-0.34^{* * *}$ & $-0.37^{* * *}$ \\
\hline & $6 / 0$ & Trend & $1.22^{* * *}$ & $0.75^{* * *}$ & $0.56^{* * *}$ & $0.47^{* * *}$ & $0.41^{\text {*** }}$ & $0.36^{\text {*** }}$ \\
\hline & & Momentum & 0.16 & $0.48^{* * *}$ & $0.60^{* * *}$ & $0.65^{\text {*** }}$ & $0.67^{* * *}$ & $0.67^{\text {*** }}$ \\
\hline & & Difference & $1.05^{* * *}$ & $0.28^{* *}$ & -0.04 & -0.18 & $-0.25^{* *}$ & $-0.31^{* * *}$ \\
\hline & $11 / 1$ & Trend & $1.22^{* \star *}$ & $0.75^{\text {*** }}$ & $0.56^{* * *}$ & $0.47^{* * *}$ & $0.41^{* * *}$ & $0.36^{\text {*** }}$ \\
\hline & & Momentum & $1.00^{* * *}$ & $0.97^{* * *}$ & $0.90^{* * *}$ & $0.84^{* * *}$ & $0.77^{* * *}$ & $0.71^{\text {*** }}$ \\
\hline & & Difference & 0.21 & -0.21 & $-0.34^{* *}$ & $-0.36^{* * *}$ & $-0.36^{* * *}$ & $-0.35^{* * *}$ \\
\hline & $12 / 0$ & Trend & $1.22^{* * *}$ & $0.75^{* * *}$ & $0.56^{* * *}$ & $0.47^{* * *}$ & $0.41^{* * *}$ & $0.36^{* * *}$ \\
\hline & & Momentum & $0.53^{* * *}$ & $0.71^{* * *}$ & $0.75^{* * *}$ & $0.74^{* * *}$ & $0.70^{* * *}$ & $0.66^{* * *}$ \\
\hline & & Difference & $0.69^{* \star *}$ & 0.05 & -0.19 & $-0.26^{*}$ & $-0.29^{* *}$ & $-0.29^{* *}$ \\
\hline \multirow[t]{12}{*}{ Composite } & $5 / 1$ & Trend & $1.67^{* * *}$ & $0.97^{* * *}$ & $0.68^{* * *}$ & $0.55^{* * *}$ & $0.46^{* * *}$ & $0.40^{* * *}$ \\
\hline & & Momentum & $0.65^{* * *}$ & $0.68^{* * *}$ & $0.66^{* * *}$ & $0.66^{* * *}$ & $0.65^{* * *}$ & $0.64^{* * *}$ \\
\hline & & Difference & $1.01^{* \star *}$ & $0.29^{*}$ & 0.02 & -0.11 & -0.19 & $-0.25^{*}$ \\
\hline & $6 / 0$ & Trend & $1.67^{* \star *}$ & $0.97^{* * *}$ & $0.68^{* * *}$ & $0.55^{\text {*** }}$ & $0.46^{* * *}$ & $0.40^{\text {*** }}$ \\
\hline & & Momentum & 0.04 & $0.36^{* *}$ & $0.48^{* * *}$ & $0.53^{* * *}$ & $0.56^{* * *}$ & $0.57^{\text {***}}$ \\
\hline & & Difference & $1.62^{* \star *}$ & $0.61^{* * *}$ & 0.20 & 0.01 & -0.10 & -0.18 \\
\hline & $11 / 1$ & Trend & $1.67^{* * *}$ & $0.97^{* * *}$ & $0.68^{* * *}$ & $0.55^{\text {*** }}$ & $0.46^{* * *}$ & $0.40^{\text {*** }}$ \\
\hline & & Momentum & $0.89^{* * *}$ & $0.86^{* * *}$ & $0.79^{* \star *}$ & $0.74^{* * *}$ & $0.68^{* * *}$ & $0.61^{* * *}$ \\
\hline & & Difference & $0.78^{* * *}$ & 0.11 & -0.11 & -0.19 & -0.22 & -0.21 \\
\hline & $12 / 0$ & Trend & $1.67^{* * *}$ & $0.97^{* * *}$ & $0.68^{* * *}$ & $0.55^{* * *}$ & $0.46^{* * *}$ & $0.40^{* * *}$ \\
\hline & & Momentum & $0.44^{* *}$ & $0.61^{* * *}$ & $0.65^{* * *}$ & $0.64^{* * *}$ & $0.60^{* * *}$ & $0.56^{\text {*** }}$ \\
\hline & & Difference & $1.23^{* * *}$ & $0.36^{*}$ & 0.03 & -0.09 & -0.14 & -0.16 \\
\hline
\end{tabular}




\section{Table 3.9: Bivariate Portfolio Analysis}

This table presents the results when implementing the market-level bivariate portfolio analysis based on various market characteristics. Following the method in Chui et al. (2010), we first classify markets into three groups based on each market-level characteristic and then construct quintile portfolios based on the forecasted returns by the trend signals within each group. For the market average method, we use the mean trend premium of markets. For the market composite method, we pool the quintile 1 and quintile 5 stocks of all markets within each group to construct portfolios. To avoid look-ahead bias and to perform an out-of-sample test, we ensure that all the information used in the double-sorting is available at the time of strategy implementation. That information includes the following: (1) Information from last year: GDP per capita (GDP capita), GDP growth rate (GDP growth), and the number of domestic firms (Domestic number). (2) Information from last month: market capitalization (Capitalization), turnover ratio (Turnover), and analyst coverage (Analyst). (3) Time-invariant information: individualism, transaction cost, and common language. The sample period ranges from September 1984 to December 2017. We adjust the standard errors using the Newey-West method with six lags. *,* ,** indicate significance at the $10 \%, 5 \%$, and $1 \%$ levels, respectively.

\begin{tabular}{|c|c|c|c|c|c|c|c|c|}
\hline \multirow[b]{2}{*}{ Proxies } & \multicolumn{4}{|c|}{ Market average } & \multicolumn{4}{|c|}{ Market composite } \\
\hline & Low $N$ & Middle & High L & Low-High & Low 1 & Middle & High I & Low-High \\
\hline GDP capita & $1.12^{* \star *}$ & $1.00^{* * *}$ & $1.60^{* * *}$ & $-0.48^{* * *}$ & $1.98^{* * *}$ & ${ }^{*} \quad 1.10^{* * *}$ & ${ }^{*} 1.80^{* * *}$ & 0.18 \\
\hline GDP growth & $1.28^{* * *}$ & $1.31^{* k *}$ & $1.13^{* * *}$ & 0.16 & $1.50^{* * *}$ & $1.65^{* * *}$ & $1.87^{* * k}$ & $-0.37^{* *}$ \\
\hline Domestic number & $0.96^{* * *}$ & $1.03^{* \star *}$ & $1.77^{\star \star *}$ & $-0.81^{* * *}$ & $1.05^{\star * *}$ & $1.12^{* \star *}$ & $1.91^{* * *}$ & $-0.87^{\star * *}$ \\
\hline Turnover & $1.24^{* * *}$ & $1.33^{* * *}$ & $0.98^{* * *}$ & $0.26^{*}$ & $2.29^{\star * *}$ & $1.79^{* * *}$ & $1.26^{* * *}$ & $1.03^{* * *}$ \\
\hline Capitalization & $1.77^{\star \star *}$ & $1.01^{* * \star}$ & $0.88^{* * *}$ & $0.88^{* \star \star}$ & $2.70^{\star * *}$ & $1.23^{* * *}$ & $1.21^{* * k}$ & $1.49^{\star \star \star *}$ \\
\hline Analyst & $1.20^{* * *}$ & $1.45^{\star \star \star \hbar}$ & $1.04^{\star \star \star *}$ & 0.16 & $2.21^{* * *}$ & $1.75^{* * *}$ & $1.33^{* k \star}$ & $0.88^{* * *}$ \\
\hline Individualism & $0.91^{* * *}$ & $1.24^{* * *}$ & $1.54^{* * *}$ & $-0.64^{* * *}$ & $1.00^{* * *}$ & ** $1.92^{* * *}$ & $1.79^{* * *}$ & $-0.80^{* * *}$ \\
\hline Transaction cost & $1.32^{* * *}$ & $1.19^{* * *}$ & $1.29^{* * *}$ & 0.03 & $1.36^{\text {***}}$ & $1.86^{* * *}$ & $2.28^{* * *}$ & $-0.93^{* * *}$ \\
\hline Common language & $1.08^{* * *}$ & $1.07^{\star \star \star *}$ & $1.56^{* * *}$ & $-0.48^{* * *}$ & $1.27^{* * *}$ & $1.18^{* * *}$ & $2.16^{* k *}$ & $-0.89^{* * *}$ \\
\hline
\end{tabular}




\section{Table 3.10: Market-level Fama-MacBeth Regression}

This table reports the results of Fama-MacBeth regression. The dependent variable Trend_ret ${ }_{i t}$ is the equal-weighted trend premium of market $i$ in month $t, X_{i t}$ is the vector of explanatory variables for country $i$ and includes the following: (1) Annually updated measures: the GDP per capita (constant 2010 US) \$ (GDP capita), the annual GDP growth rate of each market (GDP growth), the number of domestic stocks for each market (Domestic number). (2) Monthly updated measures: turnover ratio rate (Turnover), the log of firm size (Capitalization), number of analyst coverage (Analyst). (3) Time invariant measures: individualism, transaction cost, and the common language. The sample period ranges from January 1990 to December 2017. We adjust the standard errors using the Newey-West method with six lags. ${ }^{* * *},{ }^{* * *}$ indicate significance at the $10 \%, 5 \%$, and $1 \%$ levels, respectively. We report $t$-values in the parenthesis.

\begin{tabular}{lcccccc}
\hline & $(1)$ & $(2)$ & $(3)$ & $(4)$ & $(5)$ & $(6)$ \\
& Trend & Trend & Trend & Trend & Trend & Trend \\
\hline Constant & $0.921^{* * *}$ & $2.741^{* * *}$ & $0.759^{* * *}$ & $0.997^{* *}$ & $2.212^{* * *}$ & $2.854^{* * *}$ \\
& $(7.02)$ & $(12.18)$ & $(6.78)$ & $(1.99)$ & $(7.53)$ & $(2.66)$ \\
GDP capita & $0.162^{* * *}$ & & & & $0.254^{* * *}$ & $0.265^{* * *}$ \\
& $(3.15)$ & & & & $(4.01)$ & $(3.83)$ \\
GDP growth & $0.170^{* *}$ & & & & $0.148^{* *}$ & 0.101 \\
& $(2.52)$ & & & & $(2.42)$ & $(1.17)$ \\
Domestic number & & $0.387^{* * *}$ & & & $0.338^{* * *}$ & $0.146^{* *}$ \\
& & $(5.50)$ & & & $(5.16)$ & $(2.07)$ \\
Turnover & & $-0.094^{* *}$ & & & -0.071 & -1.127 \\
& & $(-1.72)$ & & & $(-1.34)$ & $(-0.87)$ \\
Capitalization & & $-0.533^{* * *}$ & & & $-0.557^{* * *}$ & $-0.832^{* * *}$ \\
& & $(-6.68)$ & & & $(-6.32)$ & $(-6.46)$ \\
Analyst & & 0.088 & & & -0.056 & 0.079 \\
& & $(1.37)$ & & & $(-0.90)$ & $(0.95)$ \\
Individualism & & & $0.291^{* * *}$ & & $0.127^{*}$ & 0.071 \\
& & & $(5.92)$ & & $(1.73)$ & $(0.78)$ \\
Transaction cost & & & & -0.001 & & 0.013 \\
Common language & & & & $(-0.01)$ & & $(0.13)$ \\
& & & & $0.365^{* * *}$ & & $0.253^{* * *}$ \\
Observations & 13,646 & 13,646 & 13,646 & 11,239 & 13,646 & 11,239 \\
$R^{2}$ & 0.072 & 0.116 & 0.034 & 0.067 & 0.208 & 0.326 \\
\hline
\end{tabular}




\section{Appendix: Definitions of Variables}

In Table C.1, we list the definitions and sources of the main variables used in our paper. We present the information in three categories: non-US firm-level data, US firm-level data, and market-level data.

[Insert Table C.1 about here.] 


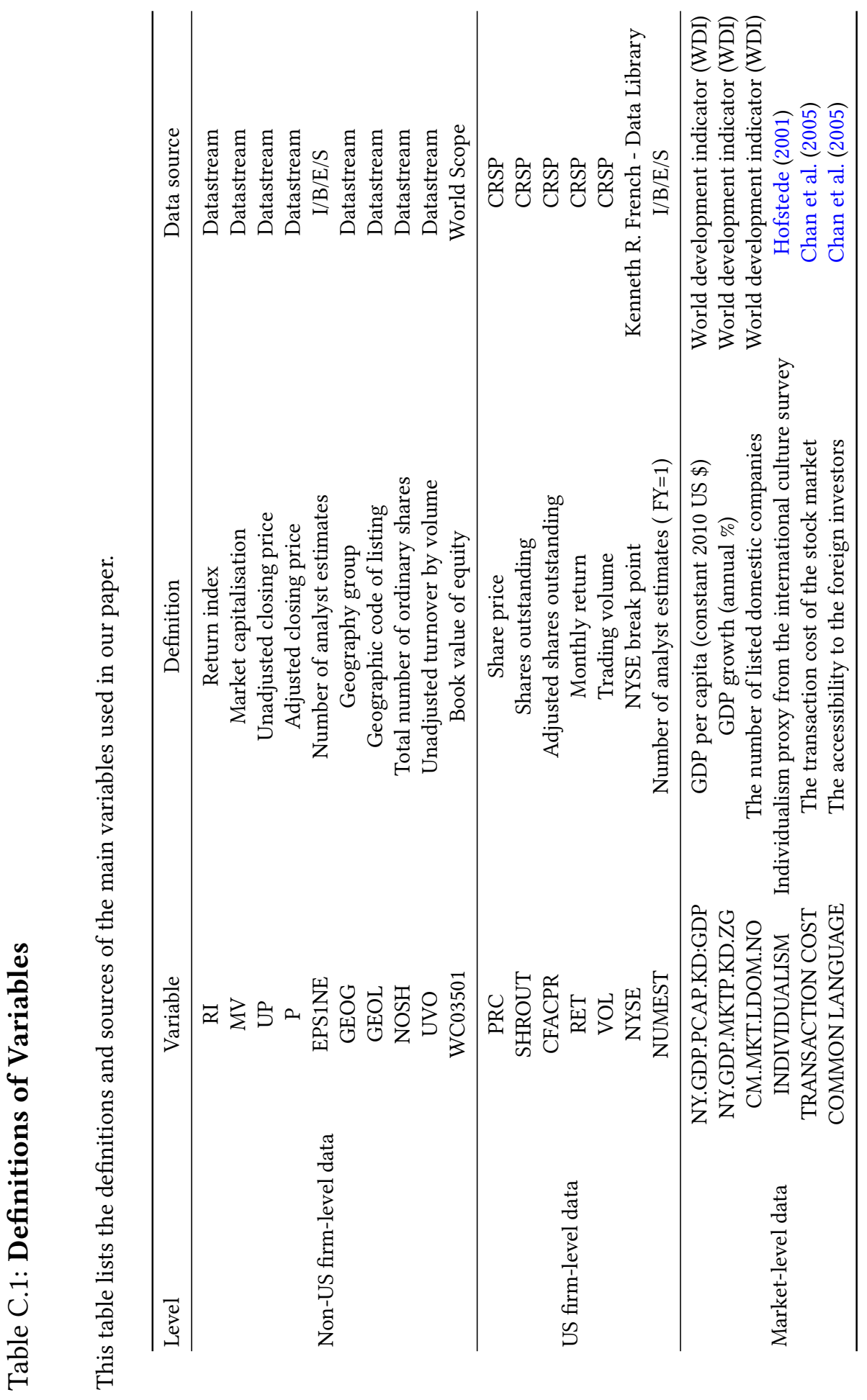




\section{4}

\section{Does Margin-Trading Reflect}

\section{INFORMATION OR SENTIMENT? EVIDENCE} from the Chinese Stock Market

This chapter investigates whether margin-trading in the Chinese stock market reflects information or sentiment. At the aggregate level, we find no evidence of informationdriven or sentiment-driven margin-trading behavior. At the individual stock level, both information-driven and sentiment-driven margin-trading exists, which are relevant to firm characteristics. We also find the likelihood of sentiment-driven margin-trading significantly declined after the regulator enforced tighter rules for margin-trading in 2015. 


\subsection{Introduction}

Information and sentiment are two important drivers of trading. The literature shows that trading driven by information has different predictive power over future stock returns than that driven by sentiment. If stock trading reflects information about the stock's future cash flows or discount rate, this information can positively predict future returns. See for example, Hirose, Kato, and Bremer (2009), Rapach, Ringgenberg, and Zhou (2016), and Kelley and Tetlock (2017). If investors are affected by sentiment, however, their trading adds more volatility to the stock market (Baker and Wurgler, 2006; Mendel and Shleifer, 2012), and tends to have a negative relationship with future stock returns (Stambaugh, Yu, and Yuan, 2012; Huang, Jiang, Tu, and Zhou, 2015). The information from short-selling has been extensively addressed in the literature. It is now well established that most short sellers are informed investors. For example, Bris, Goetzmann, and Zhu (2007), Boehmer, Jones, and Zhang (2013), Rapach et al. (2016), and Kelley and Tetlock (2017) show that short-selling involves useful information with which to forecast stock returns. ${ }^{1}$

Less research has addressed margin-trading. Margin-trading shares the same characteristics as short-selling regarding the use of leverage but aims to profit from stock price increases rather than decreases. The literature explores the effect of margin-trading on market quality and price efficiency, but results are mixed. For example, Seguin (1990) finds that margin-trading has an insignificant effect on market volatility and liquidity in the U.S. market. Hardouvelis and Peristiani (1992) report that a higher requirement of margin-trading in Japan deters speculators and improves market stability. Chang, Luo, and Ren (2014) find that the purchase decisions of margin buyers increases price efficiency and their selling decisions reduce market efficiency in the Chinese stock market. Gui and Zhu (2021) use a difference-in-difference model and find the implementation of a margin-trading program reduces the idiosyncratic

\footnotetext{
${ }^{1}$ Other studies also demonstrate the effect of short-selling. Saffi and Sigurdsson (2011) show that short-selling constraint, measured by the lower supply of lendable stocks, decreases price efficiency. Karpoff and Lou (2010), Massa, Qian, Xu, and Zhang (2015a), and Massa, Zhang, and Zhang (2015b) demonstrate the superior information processing ability of short sellers when detecting misconduct. Geczy, Musto, and Reed (2002), D’Avolio (2002), Cohen, Diether, and Malloy (2007), Kolasinski, Reed, and Ringgenberg (2013), and Aggarwal, Saffi, and Sturgess (2015) also explore supply and demand in the short-selling market.
} 
volatility of the target stocks. Whether margin-trading has return predictive power is inconclusive. Hirose et al. (2009) show that margin-trading by retail investors predicts future returns in Japan, but Chang et al. (2014) show that margin-trading activities could not predict returns in China. Little is known about whether margin-trading reflects information or is affected by sentiment and how it differs among different stocks. This serves as the primary motivation for this paper.

This paper examines whether margin-trading reflects information or is affected by sentiment. Margin-trading is a mechanism with which optimistic investors express their beliefs about the performance of a firm or the overall stock market. If this belief involves relevant information, the margin-trading balance will have a positive relationship with future stock returns. If the margin-trading is sentiment-driven, however, its balance tends to have a negative association with future stock returns.

In this paper, we aim to understand margin buyers in emerging markets, especially a market dominated by retail investors, and use the Chinese stock market in our empirical study. ${ }^{2}$ Leveraged trading in the Chinese stock market was not permitted until March 2010, when the two Chinese stock exchanges, the Shanghai and Shenzhen Stock Exchanges, started to select stocks eligible for margin-trading and short-selling. This was regarded as a significant step in improving the efficiency of the Chinese stock market. This policy change gives us an ideal setting in which to examine the behavior of margin buyers and thus evaluate the overall development of the margin-trading market in China.

We start by running predictive regressions at the aggregate level from 2010 to 2017 . We construct the aggregate margin-trading interest from the daily margin-trading balance of individual stocks and use it to predict the Chinese stock return. We construct two measures of market-level margin-trading interest. The first measure is $M M T I_{\text {all }}$, which is calculated using all eligible firms on the margin-trading list. The second measure is $M M T I_{73}$, which is constructed based on seventy-three eligible stocks that were on the margin-trading and short-selling list from 2010 to $2017 .{ }^{3}$ These seventy-

\footnotetext{
${ }^{2}$ We define investors who use leverage to buy stocks as "margin buyers", which reflects that the investors are taking a long position.

${ }^{3}$ Those 73 stocks are out of the first batch of 90 stocks in the margin trading list from the beginning to ending of our sample period.
} 
three firms have large capitalization and could represent overall market conditions. We do not find that market-level margin-trading interest can predict stock market return. This suggests that neither information nor sentiment is dominant in margin-trading on the Chinese stock market.

We then explore whether margin-trading interest could predict stock returns at the individual stock level. We run a stock-level predictive regression by regressing the stock return on stock-level margin-trading interest for each stock. The results show that there is both information-driven and sentiment-driven margin-trading. Some margin-trading is information-driven and can positively predict the future stock return. There is also much sentiment-driven margin-trading, captured by the significantly negative relationship between stock-level margin-trading interest and its stock return in the following days.

We then study the change in margin-trading behavior before and after the 2015 Chinese stock market crisis. The results show that sentiment-driven margin-trading behavior decreased dramatically after the 2015 Chinese stock market crisis. In a preliminary analysis, we report a decrease in the percentage of sentiment-driven stocks after the 2015 stock market crisis. In the logit model, we further confirm that the post-crisis dummy is significantly negative, suggesting that the decrease of sentimentdriven trading is statistically significant. We propose several reasons, including the tighter rules on margin-trading, more strict risk management implemented by financial intermediaries, and conservative investment choices by investors, to explain this decrease. We do not find a significant change in information-driven trading after the crisis.

The decrease in sentiment-driven margin-trading after 2015 is robust. We use a different definition of pre-crisis and post-crisis to split our sample, and find the conclusion still holds under this new definition. We then use a single multinomial logit model as an alternative model, and the regression shows that the post-crisis dummy is still significant and negative under this new specification.

Our paper is closely related to Chang et al. (2014), however, there are several major differences. First, our data covers a much longer time horizon from 2010 to 2017 than their paper from 2010 to 2012 . This gives us a relatively large sample with which to 
study the behavior of margin-trading in detail. Second, we use a different margintrading behavior measure. Chang et al. (2014) use daily margin purchase volume (or daily covering volume of margin position) scaled by daily trading volume to capture the behavior of margin buyers. This might be affected by the high turnover of the Chinese market. Unlike Chang et al. (2014), we use the daily margin-trading balance scaled by firm capitalization to capture the margin-trading interest. Third, instead of only focusing on whether margin buyers possess superior skills, we also examine changes in the behaviors of margin buyers after the 2015 stock crisis.

This paper contributes to the literature in several ways. First, we provide a comprehensive analysis of margin-trading at both aggregate and individual stock levels and contribute to the literature about leveraged trading. Second, we report the importance of both information and sentiment in affecting margin-trading. We provide empirical support for both rational and behavioral finance (Stambaugh et al., 2012; Hirshleifer, 2015). Third, our empirical analysis uses margin-trading data for the Chinese stock market, which involves more retail investors. Our study thus provides a perspective unlike that from markets dominated by institutional investors (Seguin, 1990; Hardouvelis and Peristiani, 1992; Hirose et al., 2009). Fourth, we show that sentiment-driven margin-trading has decreased dramatically after the 2015 Chinese stock market crisis. These changes demonstrate how the government, financial intermediaries, and investors respond to sudden market crashes (Cong, Grenadier, and Hu, 2020; Swagel, 2015).

The structure of this paper is as follows. Section 2 introduces the margin-trading program in China. Section 3 explains the process used to arrive at our sample and how we construct stock-level and market-level margin-trading interest. In Section 4 , we report the results of predictive regression at the aggregate level and individual stock level. In Section 5, we explore the percentage change in information-driven and sentiment-driven behavior before and after the 2015 stock market crisis. We also run a panel logit model to determine which firm characteristics affect information-driven and sentiment-driven margin-trading. Section 6 reports the robustness check. Section 7 concludes the paper. 


\subsection{Background}

In this section, we first review the history of the margin-trading program on the Chinese stock market, and then introduce the background information about the 2015 stock market crisis and policies carried out by the regulatory body to stabilize the market.

\subsubsection{Margin-trading program}

The margin-trading and short-selling program in the Chinese stock market was implemented on March 31, 2010. Initially, the entry standards were comparatively high, and the program was open only for selected securities, securities companies, and qualified investors. A small group of stocks were selected to participate in the program. The regulatory body chose those ninety eligible stocks based on market capitalization and liquidity. Ninety stocks with large capitalization and high liquidity were on the initial list. Only six security companies were allowed to provide margin-trading and shortselling services, which comprises less than $10 \%$ of all security companies in China. Security companies mainly use the assets and securities on their balance sheet to participate in the program. To ensure the market's stability and protect retail investors, only investors with assets of more than 500,000 Chinese Yuan (around US\$80,000) were allowed to open margin-trading or short-selling accounts. Finally, the cost of participating in the margin-trading program was high. The investors had to pay high loan fees, commission fees, and stamp tax. For example, the standard loan fee was around $8 \%$ for margin traders. ${ }^{4}$

Table 1 shows the development of the margin-trading and short-selling program. Several important points merit further explanation. First, after the initialization of the program, this list was gradually expanded in the subsequent years. The number of stocks selected on the list increased from 90 in 2010 to 950 in 2016. The margin-trading balance increased from 127.61 million Yuan in 2010 to 9357.70 million Yuan in 2016. The regulatory body gradually added the stocks with the highest market capitalization

\footnotetext{
${ }^{4}$ Investors could negotiate with the security companies to reduce the loan fees if the transaction size was large. The $8 \%$ is collected from Sina:https://finance.sina.com.cn/stock/y/2019-09-10/ doc-iicezueu4837789.shtml. This number is conservative to measure the loan fees for the beginning years of the implementation of the margin-trading program.
} 
and highest liquidity into the eligible pool. The support for security companies participating in the program was gradually increased. For example, in October 2011, the Chinese Security Finance Corporation was established to provide financing for security companies, aiming to expand the available funding for margin trading and the available securities for short-selling. The number of investors participating in this program also dramatically increased. Second, the margin-trading balance is much higher than that for short-selling. The short-selling balances in 2010 and 2016 were only 0.11 million and 34.79 million Yuan, respectively, which is almost negligible compared with the margin-trading balance in the same year. For example, the margin-trading balance was more than 268 times higher than the short-selling balance by the end of 2016 . This suggests that margin-trading is the most common way that investors use leverage in the Chinese stock market. ${ }^{5}$ It also shows that there are many more retail investors than institutional investors participating in the margin-trading and short-selling program. At the end of 2016, 4,294,000 retail investors participated in the program, while only 11,000 institutional investors joined this program.

[Insert Table 4.1 about here.]

\subsubsection{The 2015 Chinese stock market crisis}

In 2015, there was one major stock crisis in the Chinese stock market, and most investors suffered losses during this crisis. The HUSHEN 300 index dropped from 5335 points on June 12, 2015, to 3342 points on August 28, 2015. On 27 July 2015, the Shang Hai Composite index decreased by $8.5 \%$, which is the largest decline in eight years. 1717 out of around 3000 stocks' prices decreased and more than a thousand stocks were suspended at the peak of this crisis. The scale of margin trading had reached 2.3 trillion Chinese Yuan. The rapid change of the market is attributed to margin trading by many researchers and professionals (Chu and Fang, 2016). Many non-eligible retail investors in the official and internal margin trading market circumvented the limits by using external capital markets, such as the Homes system, to use high leverage and escape from the close regulations, which further increased the sentiment in the

\footnotetext{
${ }^{5}$ This is another reason why our interest is in margin-trading rather than short-selling in the Chinese stock market.
} 
capital market. As margin-trading and short-selling are important leverage devices, there was much criticism about the effect of margin-trading and short-selling program, resulting in fundamental changes in regulatory policies and investor behavior after the stock crisis. We will explore the change in the percentage of information-driven and sentiment-driven margin-trading after the 2015 stock crisis in the subsequent sections of the paper, which is closely related to the two long-lasting problems of the Chinese stock market. These problems are the one-sided market and the retail investor-dominated market.

The 2015 stock crisis is a good example of the effect of those long-term issues. Retail investors are important players in the Chinese stock market and actively participate in the margin-trading program. Many retail investors use high leverage in the external capital market to circumvent regulations, which further amplifies the sentiment in the stock market. The original aim of implementing the margin-trading and short-selling program was to end the long-term problem of the one-sided market, which means that investors can only profit from an increase in a stock price. The short-selling program implemented in March 2010 was designed to make it possible to profit from the decrease in a stock price, however, it turns out this policy did not work as expected during the implementation of the margin-trading and short-selling program(Chu and Fang, 2016), which can be seen from the sharp distinction between margin-trading balance and short-selling balance in table Table 4.1.

\subsubsection{The implementation of strict regulation}

After the 2015 crisis, the regulators made more effort to reduce the excessive leverage from margin trading in both the internal and external margin trading market. In the internal market, on 13 November 2015, the regulatory body revised the regulation framework for margin trading. The new regulation increases the initial margin ratio from $50 \%$ to $100 \%$ and greatly reduces the leverage ratio of new investors in the margin trading market. Besides, the new regulation mandates that the scale of a security company's margin-trading business should not exceed four times its net capital. The concentration control has been adopted for a large number of eligible stocks in the margin trading list. The security companies strictly limit the maximum 
percentage that a single security could account for in an investor's stock portfolio. Margin trading balances decreased from around 2.3 trillion to 0.95 trillion Yuan after the implementation of these new regulations.

External margin trading markets, such as the Homes system, are also regarded as one of the key factors of the 2015 stock market crisis. The external market has historically received less regulation and monitoring. The Homes system could allow much higher leverage to investors than the internal margin trading market. High leverage means a small decline might be amplified and the accounts in the Homes system will be more likely to be forced to be liquidated. The regulatory body started implementing strict rules for the external margin trading market to stabilize the capital market from the end of August 2015. 60.85\% of related accounts have been closed two weeks later. Those measures reduce the sentiment spillover effect from the external margin trading market to the internal margin trading market.

\subsection{Data and methodology}

In this section, we first describe the data sources and the process used to arrive at our sample. We then introduce the process used to determine the stock-level and market-level margin-trading interest.

\subsubsection{Data and sample}

We acquire the relevant data from the China Stock Market and Accounting Research Database (CSMAR), which is one of the most reliable and comprehensive financial data providers in China and is also one of the data providers for WRDS. One of the main advantages of this database is that we could see the daily margin-trading balance, which enables us to conduct a stock-level analysis. Our sample covers the period from May 2010 to August 2017. ${ }^{6}$ The main variable of interest is the daily margin-trading

\footnotetext{
${ }^{6}$ The pioneering program officially began on 31 March 2010. For the first month (April 2010) of this policy, there were ninety stocks on the margin-trading and short-selling list. The margin-trading balance of many of these firms was 0 , which was presumably caused by the preparation of the system and investors' adapting process to accept this policy. We later need to take the log of the margin-trading interest, and exclude the first month's observations from our predictive regressions to avoid taking the $\log$ of 0 .
} 
balance, which measures the total amount of money that margin buyers borrowed until the data collection day. This stock-level margin-trading balance forms the basis of our independent variable in predictive regressions.

We use three filters to arrive at our sample, as follows: (1) we exclude exchangetraded funds (ETFs) in our study since we focus on the question of exploring the driving factors of stock investment. This results in 1044 different firms that had been on the margin-trading list at some point by August 2017. (2) we then exclude forty-five firms that had been removed from the margin-trading list and re-added to the list later. There are two reasons for this filter. On the one hand, these removals and re-addition events usually involve being special treated or no longer representative of the main stocks in the A-share market. ${ }^{7}$ On the other hand, there was typically a gap of more than ten months between the removal and re-addition events, which creates missing values for our primary variable of interest - margin-trading balance-for these forty-five firms. We aim to limit the influence of these special firms in our study. (3) Another requirement is that each firm needs to have at least ninety observations between May 2010 to August 2017. Twenty-two firms with less than ninety observations are excluded from this step. Therefore, 977 firms are finally used in our study, comprising 93.58\% of the 1044 firms, which is comprehensive and representative of the Chinese stock market.

\subsubsection{Stock-level margin-trading interest}

Stock-level margin-trading interest (SMTI) measures investor optimism about each stock. We use a two-step procedure to generate $S M T I$. Firstly, we obtain the daily margin-trading balance of each stock, measuring the amount of money investors borrowed from security companies to invest in each firm. We normalize this margintrading balance with each firm's circulated capitalization, since the margin-trading balance of individual firms will be related to their capitalization. After obtaining this ratio, we take the log.

Following Rapach et al. (2016), we use the time trend to detrend this log ratio, since

\footnotetext{
${ }^{7}$ Special treatment means the firms have two consecutive years of negative profit. The exchange has dynamically adjusted the list of firms to make sure that those on the margin-trading and short-selling list are representative firms with high capitalization and good liquidity.
} 
there is a natural increasing trend with the improvement of the margin-trading facility. For instance, the establishment of the China Securities Finance Corporation makes more money lendable for stocks. We detrend its log margin-trading ratio of each stock from the first day it appeared on the margin-trading list. The regression used for the detrending process is specified as follows:

$$
\log \left(\frac{\text { margin_trading balance }_{i t}}{\text { circulated } c a p_{i t}}\right)=a+b t+u_{t}
$$

In this regression, margin_trading balance ${ }_{i t}$ is the margin-trading balance of firm $\mathrm{i}$ at day $\mathrm{t}$, and circulated capit is the circulated capitalization of firm $\mathrm{i}$ at day $\mathrm{t}$. $\mathrm{t}$ is the time trend. We use the residual $u_{t}$ from the above detrending regression to measure the margin-trading interest. For the convenience of interpretation, we standardize this residual so that it has a mean of zero and variance of one. This standardized residual is our final SMTI. SMTI can capture fluctuations in the beliefs of margin buyers, measuring the actual change of beliefs rather than simply reflecting the development of the margin-trading facility and the ease of borrowing more money.

\subsubsection{Market-level margin-trading interest}

We use two different methods to measure the market-level margin-trading interest $(M M T I)$. In the first method, we calculate the overall margin-trading measure $M M T I_{\text {all }}$, based on all the firms on the margin-trading list. ${ }^{8}$ We first collect margin-trading balance of each stock and normalize this balance by the firm's circulated capitalization. We employ both an equal-weighted scheme and a value-weighted scheme to form $M M T I_{\text {all }}$. Finally, we take the log of this ratio and detrend it. We normalize the residual from the last step for a more straightforward interpretation, so that the final $M M T I_{\text {all }}$ has a mean of zero and variance of one.

One drawback of the first method is that there were several large-scale addition and deletion events during our sample period, which might bias our measure of the

\footnotetext{
${ }^{8}$ We exclude firms when they are suspended. Since we always aim to incorporate the latest information into our measure, the exclusion of suspension firms for each day will better measure margin-trading interest of the overall market.
} 
margin-trading interest, and result in several sudden decreases or increases in margintrading interest. This creates a problem regarding the accuracy of this measure. In the second method, we calculate margin-trading measure $M M T I_{73}$. We use seventy-three stocks that had been on the margin-trading list from 2010 to 2017 to form the aggregate margin-trading interest. These seventy-three firms are the largest capitalization firms in the Chinese stock market, and represent the overall market condition. We use the same steps as in the first method to obtain the equal-weighted and value-weighted $M M T I_{73}$.

\subsection{Information-driven or sentiment-driven}

This section explores the existence of information-driven and sentiment-driven margintrading in the Chinese stock market. We first run the market-level predicative regressions to explore whether market-level margin-trading interest could predict the overall market return or not. We then run the stock-level predictive regressions. We calculate the percentage of information-driven and sentiment-driven margin-trading in our sample. Finally, we offer explanations about why there may be sentiment-driven trading in the Chinese stock market.

\subsubsection{Market-level analysis}

Margin-trading reflects investor beliefs about future stock return. Theoretically, there are three possible relationships between margin-trading interest and future stock return. (1) If these beliefs are based on information, margin-trading is regarded as informed trading and margin-trading interest positively relates to future stock return. (2) However, if these beliefs are based on sentiment that does not contain information, margin-trading interest tends to have a negative relationship with the future stock return. ${ }^{9}$ During periods of high sentiment, investors tend to increase their margin-trading positions when the price is rising. During periods of low sentiment, investors will decrease their margin-trading position when the price is declining. Those trading are simply influenced by sentiment, which will be corrected shortly. (3) If both information-driven and sentiment-driven margin-trading exist, and neither

\footnotetext{
${ }^{9}$ Huang et al. (2015) show that the market sentiment index negatively predicts future stock return.
} 
dominates the margin-trading market, the relationship between the margin-trading balance and future market return will be insignificant. We test these hypotheses at both the market level and the individual stock level. The market-level analysis will explain whether information or sentiment plays a critical role in the Chinese stock market. The stock-level analysis will help us understand the proportion of information-driven and sentiment-driven trading and determine what characteristics explain the differences.

Rapach et al. (2016) report a negative relationship between aggregate short sell interest and market return, suggesting that short sellers are informed in the U.S. stock market. Kelley and Tetlock (2017) show that retail short-sellers can predict negative stock returns, because they have insights into the retail investor community and the fundamental of small firms. As a counterpart of short-selling, it is interesting to study whether margin buyers are informed or not. We explore whether market-level margin-trading interest can positively predict returns in the Chinese stock market in this subsection. ${ }^{10}$

We focus on the predictive power of margin-trading interest regarding short-term future returns. There are two reasons for this. The Chinese market is a well-known speculative market, which is quite unlike the U.S. stock market, which is famous for its value investment style and institutional investors. The speculative market makes shortterm future returns suitable for our purpose. We consider changes in the behavior of speculative investors after the 2015 stock crisis. We could better understand the behavior change of speculative investors when the focus is on short-term returns.

We follow the framework of Rapach et al. (2016) to study the aggregate margintrading interest and its predictive power for index excess return. We use market-level margin-trading interest $M M T I_{\text {all }}$ and $M M T I_{73}$ to predict the HUSHEN300 index excess return separately.

$$
\text { Indexexcess }_{t: t+h}=\alpha+\beta M M T I_{t}+\varepsilon_{t: t+h} \text { for } h=1 \text { to } 5 \text {, }
$$

\footnotetext{
${ }^{10}$ The shortage of studies about margin-trading means that we have obtained many insights from the literature about short-selling. As noted previously, we expect some similarity regarding the ability to interpret information between margin buyers and short sellers as they are two counterparts that both bear the high risk of pursuing high profit.
} 
In this regression, Indexexcess $t_{t: t}$ is the HUSHEN300 index return minus the corresponding one-year deposit rate within time $t$ to $t+h$. Buying on the HUSHEN300 index is quite accessible and low cost, and it is thus a good representative of the Chinese stock market's overall performance. $M M T I_{t}$ is the market-level margin-trading interest at time $\mathrm{t}$, which can either be $M M T I_{\text {all }}$ or $M M T I_{73}$. Our focus is the future weekly return. We also run the predictive regressions for the upcoming one to four days as a robustness check. We use the Newey-West method to adjust $t$ statistics.

\section{[Insert Table 4.2 about here.]}

In Table 4.2, we report the $\beta$ and $t$ statistic of the market-level predictive regressions using $M M T I_{\text {all }}$ and $M M T I_{73}$ as predictors from May 2010 to August 2017, respectively. We employ both the equal-weighted and value-weighted scheme to construct $M M T I_{\text {all }}$ and $M_{M T I_{73}}$. We do not find a significant relationship between market-level margintrading interest and future index excess return under any method. The upper panel reports the results when we use $M M T I_{\text {all }}$ to predict the index excess return in the upcoming one to five days separately. Most of the $\beta$ are positive but are not significantly either statistically or economically. For the equal-weighted version of $M M T I_{\text {all }}$, the highest $\mathrm{t}$ statistic is only 0.38 when we predict the index excess return in the upcoming two days. For the value-weighted version of $M M T I_{\text {all }}$, the highest $\mathrm{t}$ statistic also arrives when we predict the upcoming two days' index excess return, which is only 0.12. In terms of the economic magnitude, a one standard deviation change in $M M T I_{\text {all }}$ is associated with less than one basis point change of return in the majority of the cases. The lower panel reports the results when we use $M M T I_{73}$ to predict the index excess return.The results are not statistically significant and the economic magnitude of $\beta$ is also minor. All the $\beta$ are negative. The lowest $\mathrm{t}$ statistics are found when we use $M M T I_{73}$ to predict the index excess return in the future week, with the t values as -0.35 and -0.32 for equal-weighted and value-weighted of $M M T I_{73}$, respectively. There could be two reasons for these non-significant results at the market level. Firstly, margin buyers are unlike short-sellers, and they might not be able to forecast future market performance. Secondly, since the aggregate data is calculated from individual stock-level data, there may be some offsets at the stock level. In other words, it is likely that margin buyers may have insights into the stock price movements of some firms. 
However, margin buyers cannot forecast the future return of other firms. When we add all these results together, the predictive power of margin-trading interest have been disguised. This prompts the stock-level analysis in the following subsection.

\subsubsection{Individual stock-level analysis}

With the expectation that the insights of margin buyers into the price of stocks might be confined to some specific firms, we use individual stock-level margin-trading interest $(S M T I)$ to run predictive regressions in this subsection. Unlike the market-level analysis, we run predictive regressions for each stock. We focus on forecasting the upcoming weekly return (five days' return).

The specification for individual-level stock predictive regressions is as follows:

$$
r_{i[t: t+h]}=\alpha+\beta S M T I_{i t}+\varepsilon_{i[t: t+h]} \text { for } h=1 \text { to } 5
$$

In this regression, $r_{i[t: t+h]}=\left(r_{i[t+1]}+\cdots+r_{i[t+h]}\right) / h . r_{i[t+h]}$ is the daily adjusted return of firm $\mathrm{i}$ at day $t+h$, which equals the daily stock return minus the corresponding day's HUSHEN 300 index return. ${ }^{11} S M T I_{i t}$ is the stock-level margin-trading interest at day $\mathrm{t}$ for stock i.

[Insert Table 4.3 about here.]

We report the mean magnitude of $\beta$ from individual-level predictive regressions by sample period in Table 4.3. We regress the future weekly excess return on $S M T I_{i t}$ for each firm. There are a group of firms within each period that have significant coefficients of SMTI. We report the simple mean of $\beta$ for the regressions of those firms. The upper (lower) panel reports the results when we use 10\% (5\%) as the threshold for significance level. We report the results when the p-value of the SMTI is equal to or less than $10 \%(5 \%)$.

Several important observations emerge from Table 4.3. On the one hand, it confirms that information-driven, sentiment-driven trading, and non-significant trading coexist, explaining the overall non-significance when we conduct the market-level analysis.

\footnotetext{
${ }^{11}$ This adjusted return captures the overall judgments of margin buyers about the performance of one specific stock compared with simply buying the HUSHEN300 index in upcoming days.
} 
On the other hand, relatively speaking, the magnitude of the coefficients for the information-driven category is larger than the sentiment-driven category in most of the sample periods (except June 2014-May 2015). In the 10\% significance threshold results between June 2013-May 2014 for example, the mean $\beta$ ranges from 0.64 to 0.92 for information-driven stocks, while the mean $\beta$ ranges from -0.44 to -0.79 for sentiment-driven stocks.

\subsubsection{Why sentiment-driven trading exists}

In the previous subsection, we show that there is both information-driven and sentimentdriven trading in the margin-trading market. One natural question is why sentimentdriven trading exists. Existing research recognizes the critical role played by sentiment. Sentiment has a strong power to explain investor behavior and anomalies. De Long, Shleifer, Summers, and Waldmann (1990) give a broad definition of sentiment as the beliefs of investors about a firm's future cash flows and risks that could not be justified by all the information at hand. Baker and Wurgler (2006) is the landmark research for the study of sentiment and constructs the sentiment index widely used in the literature. Stambaugh et al. (2012) uses sentiment to explore 11 anomalies, and find that sentiment-driven behavior will prompt overpricing of stocks during periods of high sentiment.

The Chinese stock market has only developed in the last thirty years and is still relatively young compared with many mature stock markets, meaning that sentimentdriven trading could exist. The Chinese stock market has long faced three main problems, which can be summarized as follows: the Chinese stock market is closely linked with government policies, is a speculative market, and is a one-sided market. The policy market problem states that government policy strongly influences the performance of the stock market and gives hope to investors that the government will directly intervene during a market crash. For instance, in the 2015 stock crisis, the regulatory body participated directly in buying stocks to maintain the stability of the market, which was a vital sign of intervention.

Unlike many mature stock markets, the Chinese stock market has long been criticized for its speculative retail investors, who account for $98 \%$ of all investors in 
terms of numbers. Institutional investors have still not become the dominant power in this market. Retail investors are inclined to pursue short-term return and are inexperienced. Recent evidence suggests that a retail-dominated market is more likely to be influenced by sentiment (Kumar and Lee, 2006). In our setting, sentiment-driven trading means investors may groundlessly think the price of one stock may rise. This is a combination of sentiment and overconfidence. Over-optimistic sentiment-driven margin buyers are overconfident about their skill during periods of high sentiment. The margin buyers of sentiment-driven firms are those who incur overpricing that will be corrected later (Stambaugh et al., 2012).

With regard to the one-sided market problem, investors are limited to making profit from an increase in stock price, as there is no efficient short-selling market. The one-sided market problem worsened after the implementation of the margin-trading and short-selling program, and the apparent problem is that the short-selling leg did not function properly, as demonstrated by the imbalance between margin-trading and short-selling (Chu and Fang, 2016). Security companies are the main providers of short-selling stocks, and only the stocks inventory owned by these qualified security companies are permitted to loan to short sellers most of the time. However, security companies only have limited inventories that could be lent to investors, compared with the demand from a variety of investors. It is thus common phenomenon in the Chinese short-selling market that the lendable stocks are quickly sold out within the first several minutes of the exchange opening. We thus argue that the one-sided market problem still exists, and the problem is even more pronounced than before, which gives grounds for the existence of sentiment-driven trading.

\subsection{The decrease in sentiment-driven trading}

This section explores the change in the margin-trading market after the 2015 stock crisis. We find a decrease in sentiment-driven trading after the crisis, however, we fail to find a significant change in information-driven trading after the crisis. We present preliminary evidence of the percentage of sentiment-driven trading that has decreased after the crisis, and then use the logit model to quantitatively ascertain the decrease in sentiment-driven trading and the firm characteristics that might be 
related to the probability of sentiment-driven and information-driven trading. We offer several reasons that might explain the decrease in sentiment-driven trading.

\subsubsection{Preliminary analysis}

\section{Analysis method}

We use the yearly horizon to evaluate the overall performance of the Chinese margintrading market, with a focus on whether there were pronounced changes in informationdriven and sentiment-driven trading after the 2015 stock crisis. We center our sample around the stock crisis from June 2012 to August 2017, and exclude the specific crisis time of June 2015 to August 2015, and divide the time into five equal twelve month time intervals. Due to the gradual expansion of the firms on the margin-trading list, we use the percentage of information-driven and sentiment-driven stocks among all eligible firms to evaluate the overall change of the margin-trading market. We mainly focus on the predictive power of margin-trading interest for the weekly return. We also report results for other shorter time horizons to show the robustness of our results.

We use the following method. First, we run the firm-level predictive regressions in each period. we divide the firms into three categories based on the stock-level predictive regressions. (1) The information-driven category consists of firms with a positively significant relationship between their SMTI and their future weekly return. (2) The sentiment-driven category includes firms that display a significantly negative relationship between their SMTI and their upcoming weekly return. (3) The non-significant category contains firms that show a non-significant relationship between their SMTI and their upcoming weekly return. Our main interests is in information-driven and sentiment-driven stocks.

Next, we calculate the rate of firms with significant positive relationships or significantly negative relationships between SMTI and future return in each period. We calculate the overall positive rate and overall negative rate, which are specified in Equations (4) and (5). We require each firm to have at least ninety trading days 
observations during each period. ${ }^{12}$

$$
\begin{aligned}
& \text { positive rate } \text { r }_{t}=\frac{\text { the number of firms in the information }- \text { driven categor } y_{t}}{\text { total number of eligible firms } t} \\
& \text { negative rate } e_{t}=\frac{\text { the number of firms in the sentiment }- \text { driven categor } y_{t}}{\text { total number of eligible firms } s_{t}}
\end{aligned}
$$

\section{Preliminary results}

We report the annual percentage of information-driven and sentiment-driven stocks from June 2012 to August 2017 in Table 4.4. We report the results using 10\% and 5\% as the significance thresholds. Overall, we find that the percentage of sentiment-driven trading decreased dramatically after the 2015 stock crisis. In contrast, there are more fluctuations for the information-driven stocks in our sample period.

\section{[Insert Table 4.4 about here.]}

The upper panel of Table 4.4 reports the percentage of sentiment-driven margintrading, which experiences a considerable decrease from pre-crisis to after-crisis. When we evaluate the weekly return and use $10 \%$ as the threshold for significance, firms in the sentiment-driven category had reached $12 \%$ in 2015 . However, this rate dropped to $4.86 \%$ in 2016 , which is a $60 \%$ decrease. For robustness, we find the decreases in the sentiment-driven trading are more noticeable in short-term returns. The sentimentdriven stocks decreased $66.75 \%, 71.38 \%, 75.35 \%, 75.17 \%$ for four, three, two, one days' return from 2015 to 2016, respectively. If we change the significance criteria to 5\%, then the decrease in the percentage of sentiment-driven trading from 2015 to 2016 is even greater than using $10 \%$ as the significance threshold.

The lower panel of Table 4.4 reports the percentage of information-driven margintrading. We fail to detect distinct changes in the information-driven trading from 2015 to 2016 . When we evaluate the weekly return and use $10 \%$ as the threshold for significance, the proportion of firms in the information-driven category was $8 \%$ in

\footnotetext{
${ }^{12}$ Most firms have more than ninety observations during each period. This requirement is mainly proposed to deal with dynamic adjustments, since some firms were added to the margin-trading and short-selling list by the exchange at the end of each sample period.
} 
2015 and $8.9 \%$ in 2016. For robustness, we also find that the change in the informationdriven stocks is not clear for short-term returns. The percentage of information-driven trading for four to one days' return is $8.30 \%, 8.19 \%, 7.00 \%, 5.10 \%$ in 2016 ,respectively, showing little difference with the corresponding figures of $8.12 \%, 8.24 \%, 7.88 \%, 5.65 \%$ in 2015. One interesting aspect of the percentage of information-driven stocks is that it shows a U-shape, reaching the highest values at the beginning and end of our sample period. This preliminary result is not conclusive, and a quantitative method will be adopted in the next section to explore whether the change in the information-driven trading is statistically significant.

\subsubsection{Panel logit model analysis}

\section{Model and dependent variables}

The previous subsection shows preliminary evidence that sentiment-driven trading decreased dramatically after the 2015 stock crisis, however, the change in the informationdriven trading is still inconclusive. In this subsection, we will employ a panel logit model with a post-crisis dummy to explore whether changes in the information-driven and sentiment-driven trading after the 2015 crisis are statistically significant. We will also study the other firm characteristics that affect the probability of sentiment-driven and information-driven trading.

The analysis in this subsection is based on a two-stage regression. In the first stage, we run the stock-level predictive regressions for the future weekly return during each period, which generate the $\beta$ coefficient for each firm. If the coefficient is significantly positive, we set the CategoryDummy $i$ to 1 for that firm during that period. If the coefficient is significantly negative, we assign the value -1 to CategoryDummy $y_{i t}$. A value of 0 is assigned to the non-significant firms. We use the $10 \%$ significance level as the threshold, which provides an adequate sample for us to run the second stage regression. In the second stage, we use the values $(1,0,-1)$ from the first stage as the dependent variable for the panel logit model. The specification for the second stage is as follows:

$$
\text { CategoryDummy } y_{i t}=\alpha+\beta_{1} \text { PostcrisisDummy }+\beta_{i}^{\prime} X_{i t}^{\prime}+\varepsilon_{i t}
$$


In this regression, Categor $y$ D umm $y_{i t}$ is the dummy we obtain from the stock-level predictive regressions. We divide the time into five periods and generate CategoryDumm $y_{i t}$ in each period. We use two separate panel logit models to quantify the change of probability for information-driven trading (or sentiment-driven trading) after the 2015 stock crisis. The non-significant firms are regarded as the benchmark category in both models. PostcrisisDummy is a dummy that equals one for the time after the 2015 stock crisis and is zero for the time before the 2015 stock crisis. $X_{i t}$ are control variables, which include price-to-book ratio, price-to-sale ratio, turnover ratio, debt ratio, return on assets, market capitalization, idiosyncratic volatility,and the Jensen alpha. We also include firm fixed effects in the model to control the influence of the omitted variables.

\section{Control variables}

Our control variables can be roughly divided into four categories. The detailed definitions of all variables are in the appendix. The first category is a post-crisis dummy, which answers the question of whether the probability of sentiment-driven trading or information-driven trading changed after the crisis. If the time is after the 2015 stock crisis, the post-crisis dummy is set as one, otherwise zero.

The second category is the transaction-related variables, including price-to-book ratio, price-to-sale ratio, and turnover ratio. Price-to-book ratio is calculated by dividing the market capitalization of one stock by its latest net asset value. Price-tosale ratio is market capitalization divided by last year's revenue. Turnover ratio is the trading volume in dollars divided by market capitalization. For price-to-book ratio, price-to-sale ratio, and turnover ratio, we first calculate the daily value and then use its simple average during that period as our final independent variable.

The third category includes the stock market-related variables, including Jensen's alpha and idiosyncratic volatility. We use the CAPM model to calculate the Jensen's alpha and idiosyncratic volatility for each stock. When we run the CAPM model, we use adjusted daily return as the dependent variable and the value-weighted daily return of the A-share stocks as the market portfolio return. ${ }^{13}$ We use the daily rate of the one-year deposit rate to adjust the stock return and market portfolio return. For

\footnotetext{
${ }^{13}$ It includes both the Shanghai exchange's A-share stocks and the Shenzhen exchange's A-share stocks.
} 
each stock during each period, we collect the intercept of the CAPM model as Jensen's alpha, and we obtain the standard deviation of the disturbance term as idiosyncratic volatility.

The final category is fundamental-related variables, including ROA, debt ratio, and market capitalization. ROA measures the return on assets, which is revenue divided by total asset. The debt ratio measures the liability situation, which is total liability divided by total asset. Size is the natural logarithm of circulated capitalization, which is a measure of a firm's information environment.

[Insert Table 4.5 about here.]

The summary statistics of independent variables for our logit model are reported in Table 4.5. The sample includes 3500 firm-year observations, and firms with varying characteristics are included. One main reason for the diversifying attributes of firms is the expansion of the margin-trading list. More firms from different industries and in different phases of development are eligible for margin-trading over the passage of time.

\section{Empirical results}

We report the logit model results for the sentiment-driven category versus nonsignificant category between June 2012 to August 2017 in Table 4.6. We find there is a significant decrease in sentiment-driven trading after the 2015 Chinese stock crisis. The post-crisis dummy is significantly negative at a $1 \%$ level from model (1) to model (7), suggesting that the probability of a firm being in the sentiment-driven category decreased after the 2015 stock crisis. This confirms the preliminary results in the previous subsection.

We also find that ROA has a positive relationship with the probability that a firm is in the sentiment-driven category. In model (7), the coefficient for ROA is 4.66, which is significant at the $10 \%$ level. Higher ROA firms are value firms, and investors are likely to be driven by sentiment to buy these firms. We also find a positive association between idiosyncratic volatility and the probability of sentiment-driven trading, suggesting that it is hard for investors to predict the return of these volatile firms. In model (7), the coefficient for idiosyncratic volatility is 40.90 and is significant at the $10 \%$ level. 
[Insert Table 4.6 about here.]

We report the logit model results for the information-driven category versus nonsignificant category between June 2012 to August 2017 in Table 4.7 . We do not find evidence to support a significant increase in information-driven trading after the 2015 Chinese stock crisis. The post-crisis dummy is positively significant from model (1) to model (4), however, when we add more control variables into the regression for model (5) to model (7), the post-crisis dummy is no longer significant. We conjecture that information-driven trading is more firm-specific and is unlikely to have been affected by the regulatory policy change after the 2015 stock crisis.

[Insert Table 4.7 about here.]

When we examine the firm characteristics that affect the probability of informationdriven trading, the following results emerge. Turnover ratio has a significantly negative relationship with the probability of information-driven trading. Investors are more unlikely to have insights into the performance of firms that are more liquid. Model (7) shows the coefficient for the turnover ratio is -19.31 , which is significant at the $5 \%$ level. We also find a significant negative association between ROA and the probability of information-driven trading, which means investors have less information about value firms than growth firms. In model (7), the coefficient for ROA is -4.70 , which is significant at $5 \%$.

\subsubsection{Reasons for the decline of sentiment-driven trading}

As noted in the preliminary analysis and logit model, there is evidence that sentimentdriven trading decreased after the 2015 stock crisis. The reasons behind this decline are complicated. We are inclined to explain the underlying causes of this decline as influenced by multiple factors. There are four types of major participants in the margin-trading program: retail and institutional investors, security companies, one major financial company that lends money and stocks to other security companies, and the regulatory agencies. The decrease in sentiment-driven behavior is more likely to be due to the interactions between these major participants. 
The most important factor leading to this decrease is that investors learned lessons from the 2015 stock crisis. The 2015 stock crisis was well known among margin-trading investors since many investors suffered considerable losses in this crisis. The main cause of the crisis was attributed to the dramatic increase and unreasonable use of leverage. The margin-trading program was one of the primary sources of leverage. Without the standard functionality of short-selling, the Chinese stock market became more irrational with the influence of the margin-trading program. There were broad discussions about the use of leverage in newspapers and on television, which was an appropriate opportunity to educate both existing and new margin buyers. We conjecture that many investors reflected on their investment style and may have decreased sentiment-driven trading.

The sentiment-driven investment pattern is influenced by regulatory policy change and the improvement in the security companies' risk management. The regulatory policy could be a contributing factor to the decrease in the proportion of sentiment-driven stocks. For example, after the 2015 crisis, the regulatory body basically eliminated the outside money-raising market for investment. This emphasizes the strict implementation of leverage management, contributing to the improvement of risk management and useful for cooling the sentiment of high leverage investors. Security companies dynamically evaluate the investment situations of investors after the crisis, which also contributes to the decrease in sentiment-driven trading. ${ }^{14}$

The regulatory policy and financial intermediaries will act better as cushions to influence sentiment-driven trading than information-driven trading. On the one hand, it is comparatively easier to change sentiment-driven investment behavior, which requires more reflection before following the behavior of other investors. The improvement in the regulating policy and risk management level of security companies might give retail investors more room to reflect on their trading. On the other hand, the increase in their ability to analyze fundamental values of stocks and predict stock return is a long process for retail investors. Information-driven trading is more likely

\footnotetext{
${ }^{14}$ After the crisis,risk management from security companies became stricter. Security companies strictly evaluate whether an investor is qualified to participate in margin-trading and short-selling trading before they enter into the market, and evaluate whether the investments of margin buyers are diversified enough after entering the margin-trading market. Security companies set limits on the proportions that margin buyers can invest in one stock.
} 
to be firm-specific, which is less likely to be influenced by the stock crisis.

\subsection{Robustness checks}

In this section, we use a different division of time to define the pre-crisis and post-crisis and show that the decrease in the sentiment-driven trading is robust to this different time division. We then use an alternative multinomial logit model to show that the decrease in sentiment-driven trading still holds in this new specification.

\subsubsection{Different definition of pre-crisis and post-crisis}

We divide our time sample into five equal twelve month time intervals in the main analysis. To test the robustness of our results to different time division, we recalculate the rate of information-driven and sentiment-driven trading by dividing our sample into pre-crisis and post-crisis. The pre-crisis period is from June 2013 to May 2015. The post-crisis is from September 2015 to August 2017. We rerun the same analysis as in Section 4 and check the change in the percentage of information-driven and sentiment-driven trading from pre-crisis to post-crisis.

[Insert Table 4.8 about here.]

Table 4.8 reports the results of this exercise. Our conclusion still holds when using this different definition of pre-crisis and post-crisis. The percentage of sentimentdriven firms decreased after the 2015 stock crisis. Taking the $10 \%$ significance results as an example, the sentiment-driven trading change from $11.06 \%, 11.41 \%, 11.29 \%$, $11.06 \%, 9.68 \%$ for the future return ranging from fives days to one day before crisis to $6.55 \%, 6.02 \%, 6.44 \%, 6.12 \%, 4.94 \%$ after the crisis.

\subsubsection{Different logit model specification}

We use two separate logit models to test whether there was a significant change after the 2015 stock crisis for sentiment-driven trading and information-driven trading in Section 5, with the non-significant category as the benchmark category in each model. We use a single pooled multinomial logit model to run the regression in this robustness 
check. One major difference in this robustness check is that the dependent variable includes the sentiment-driven stocks, information-driven stocks, and non-significant category in the single multinomial logit model.

[Insert Table 4.9 about here.]

Table 4.9 reports the results of the multinomial logit model. The results show that the post-crisis dummy is significant for sentiment-driven trading. The first row shows that there is a significant decrease in sentiment-driven trading after the 2015 stock crisis. The coefficient of the post-crisis dummy is -0.75 and significant at $1 \%$. The post-crisis dummy is still not significant for the information-driven trading. The coefficient for the post-crisis dummy in the second row of Table 4.9 is 0.15 , which is not significant. Our main conclusion is thus robust to this multinomial logit specification.

\subsection{Conclusion}

Margin-trading is an important way to use leverage in investment. Compared with the voluminous literature on short-selling, the field of margin-trading is still under-studied. This paper serves as our effort to better understand the influence of margin-trading. The margin-trading program implemented from 2010 in the Chinese stock market provides an ideal setting to study this issue. We evaluate the influence of the margintrading using comprehensive margin-trading stock-level data.

Using the stock-level margin-trading data from 2010-2017, we explore the predictive power of margin-trading interest at both the aggregate level and stock level. We make several important discoveries in our study. We first explore whether market-level margin-trading interest could predict the market return. We construct two versions of market-level margin-trading interest, and fail to find the predictive power for any of them at the aggregate level. This leads us to explore the relationship between margin-trading interest and stock return at the stock level. We report that there is both information-driven and sentiment-driven trading in the margin-trading market at the stock level. We also identify the firm characteristics that are related to the probability of information-driven and sentiment-driven margin-trading. Finally, we document a sharp decrease in sentiment-driven trading after the 2015 stock crisis. We propose that 
this decrease might be caused by a number of factors, including the regulatory policy change, the improvement of security company risk management, and the learning behavior of retail investors. 


\section{References}

Aggarwal, R., Saffi, P. A. C., Sturgess, J., 2015. The role of institutional investors in voting: evidence from the securities lending market. The Journal of Finance 70, 2309-2346.

Baker, M., Wurgler, J., 2006. Investor sentiment and the cross-section of stock returns. The Journal of Finance 61, 1645-1680.

Boehmer, E., Jones, C. M., Zhang, X. Y., 2013. Shackling short sellers: the 2008 shorting ban. The Review of Financial Studies 26, 1363-1400.

Bris, A., Goetzmann, W. N., Zhu, N., 2007. Efficiency and the bear: short sales and markets around the world. The Journal of Finance 62, 1029-1079.

Chang, E. C., Luo, Y., Ren, J. J., 2014. Short-selling, margin-trading, and price efficiency: evidence from the Chinese market. Journal of Banking \& Finance 48, 411-424.

Chu, J., Fang, J., 2016. Margin-trading, short-selling, and the deterioration of crash risk. Economic Research Journal 51, 143-158.

Cohen, L., Diether, K. B., Malloy, C. J., 2007. Supply and demand shifts in the shorting market. The Journal of Finance 62, 2061-2096.

Cong, L. W., Grenadier, S. R., Hu, Y., 2020. Dynamic interventions and informational linkages. Journal of Financial Economics 135, 1-15.

D'Avolio, G., 2002. The market for borrowing stock. Journal of Financial Economics 66, 271-306.

De Long, J. B., Shleifer, A., Summers, L. H., Waldmann, R. J., 1990. Noise trader risk in financial markets. Journal of Political Economy 98, 703-738.

Geczy, C. C., Musto, D. K., Reed, A. V., 2002. Stocks are special too: an analysis of the equity lending market. Journal of Financial Economics 66, 241-269.

Gui, P., Zhu, Y., 2021. Margin trading and stock idiosyncratic volatility: evidence from the Chinese stock market. International Review of Economics \& Finance 71, 484-496. 
Hardouvelis, G. A., Peristiani, S., 1992. Margin requirements, speculative trading, and stock price fluctuations: the case of Japan. The Quarterly Journal of Economics 107, 1333-1370.

Hirose, T., Kato, H. K., Bremer, M., 2009. Can margin traders predict future stock returns in Japan? Pacific-Basin Finance Journal 17, 41-57.

Hirshleifer, D., 2015. Behavioral finance. Annual Review of Financial Economics 7, 133-159.

Huang, D., Jiang, F., Tu, J., Zhou, G., 2015. Investor sentiment aligned: a powerful predictor of stock returns. The Review of Financial Studies 28, 791-837.

Karpoff, J. M., Lou, X. X., 2010. Short sellers and financial misconduct. The Journal of Finance 65, 1879-1913.

Kelley, E. K., Tetlock, P. C., 2017. Retail short selling and stock prices. The Review of Financial Studies 30, 801-834.

Kolasinski, A. C., Reed, A. V., Ringgenberg, M. C., 2013. A multiple lender approach to understanding supply and search in the equity lending market. The Journal of Finance 68, 559-595.

Kumar, A., Lee, C. M. C., 2006. Retail investor sentiment and return comovements. The Journal of Finance 61, 2451-2486.

Massa, M., Qian, W., Xu, W., Zhang, H., 2015a. Competition of the informed: does the presence of short sellers affect insider selling? Journal of Financial Economics 118, $268-288$.

Massa, M., Zhang, H., Zhang, H., 2015b. The invisible hand of short selling: does short selling discipline earnings management? The Review of Financial Studies 28, 1701-1736.

Mendel, B., Shleifer, A., 2012. Chasing noise. Journal of Financial Economics 104, 303-320. 
Rapach, D. E., Ringgenberg, M. C., Zhou, G. F., 2016. Short interest and aggregate stock returns. Journal of Financial Economics 121, 46-65.

Saffi, P. A. C., Sigurdsson, K., 2011. Price efficiency and short selling. The Review of Financial Studies 24, 821-852.

Seguin, P. J., 1990. Stock volatility and margin trading. Journal of Monetary Economics $26,101-121$.

Stambaugh, R. F., Yu, J. F., Yuan, Y., 2012. The short of it: investor sentiment and anomalies. Journal of Financial Economics 104, 288-302.

Swagel, P., 2015. Legal, political, and institutional constraints on the financial crisis policy response. Journal of Economic Perspectives 29, 107-22. 


\section{Tables and figures}

\section{Table 4.1: Summary of the Margin-trading and Short-selling Program}

This table reports the summary statistics of the margin-trading and short-selling program in China from 2010 to 2016. The number of stocks eligible for margin-trading and short-selling are static numbers from exchange announcements. Other statistics are based on the year-end figures from the exchange, security regulatory body, and CSMAR. NA means there is no available data for this item.

\begin{tabular}{lccccccc}
\hline Variables & 2010 & 2011 & 2012 & 2013 & 2014 & 2015 & 2016 \\
\hline $\begin{array}{l}\text { Number of eligible stocks } \\
\begin{array}{l}\text { Margin-trading balance } \\
\text { (100 million Yuan) }\end{array}\end{array}$ & 90 & 278 & 278 & 700 & 900 & 900 & 950 \\
$\begin{array}{l}\text { Short-selling balance } \\
\text { (100 million Yuan) }\end{array}$ & 0.11 & 6.59 & 38.21 & 30.57 & 82.83 & 29.60 & 34.79 \\
$\begin{array}{l}\text { Retail investors number } \\
(10 \text { thousand) }\end{array}$ & NA & 34.75 & 50.20 & 136.95 & 301.00 & 401.90 & 429.40 \\
$\begin{array}{l}\text { Institutional investors number } \\
(10 \text { thousand) }\end{array}$ & NA & 0.10 & 0.20 & 0.40 & 0.50 & 0.80 & 1.10 \\
\hline
\end{tabular}




\section{Table 4.2: $\beta$ of Market-level Predictive Regressions}

This table reports the $\beta$ of the market-level predictive regressions from May 2010 to August 2017. The regression is specified as follows::

$$
\text { Indexexcess }_{t: t+h}=\alpha+\beta M M T I_{t}+\varepsilon_{t: t+h} \text { for } h=1 \text { to } 5 \text {, }
$$

In this regression, Indexexcess $t_{t: t}$ is the HUSHEN300 index return minus the corresponding one-year deposit rate within time $\mathrm{t}$ to $\mathrm{t}+\mathrm{h} . M M T I_{t}$ is the market-level margin-trading interest at time t. $M M T I_{t}$ can either be $M M T I_{\text {all }}$ or $M M T I_{73}$, with both the equal-weighted scheme and the value-weighted scheme being used. $M M T I_{\text {all }}$ includes all eligible firms on the margin-trading list, which is updated each year. $M M T I_{73}$ includes stocks that were always on the margin-trading list in our sample period. We run the predictive regressions for the upcoming one to five days separately. The Newey-West adjusted $t$ statistics are reported in parentheses. We report the coefficient in basis points (bps), which equals the change of return induced by one standard deviation increase of $M M T I_{t}$.

\begin{tabular}{cccccc}
\hline Predictors Time interval Equal-weighted Value-weighted \\
\hline \multirow{4}{*}{$M M T I_{A L L}$} & $(0,5)$ & 0.53 & $(0.18)$ & -0.20 & $(-0.08)$ \\
& $(0,4)$ & 0.60 & $(0.20)$ & -0.20 & $(-0.05)$ \\
& $(0,3)$ & 0.88 & $(0.29)$ & 0.08 & $(0.02)$ \\
& $(0,2)$ & 1.23 & $(0.38)$ & 0.40 & $(0.12)$ \\
& $(0,1)$ & 1.01 & $(0.27)$ & 0.24 & $(0.06)$ \\
\hline \multirow{6}{*}{$M M T I_{73}$} & $(0,5)$ & -1.10 & $(-0.35)$ & -1.10 & $(-0.32)$ \\
& $(0,4)$ & -1.00 & $(-0.32)$ & -1.00 & $(-0.30)$ \\
& $(0,3)$ & -0.70 & $(-0.22)$ & -0.70 & $(-0.21)$ \\
& $(0,2)$ & -0.30 & $(-0.09)$ & -0.30 & $(-0.09)$ \\
& $(0,1)$ & -0.50 & $(-0.13)$ & -0.50 & $(-0.11)$ \\
\hline
\end{tabular}




\section{Table 4.3: Results of Firm-level Predictive Regressions}

This table reports the mean $\beta$ of the firm-level predictive regressions in each period. We divide the time into five equal lengths of twelve months periods: 2013 (June 2012-May 2013), 2014 (June 2013-May 2014), 2015 (June 2014-May 2015), 2016 (September 2015-August 2016), and 2017 (September 2016-August 2017). We regress the future weekly return on stock-level margin-trading interest for each stock.

$$
r_{i[t: t+h]}=\alpha+\beta S M T I_{i t}+\varepsilon_{i[t: t+h]} \text { for } h=5
$$

In this regression, $r_{i[t: t+h]}=\left(r_{i[t+1]}+\cdots+r_{i[t+h]}\right) / h . \quad r_{i[t+h]}$ is daily adjusted return at day $\mathrm{t}+\mathrm{h}$, which equals stock daily return minus the corresponding day's HUSHEN 300 index return. $S M T I_{i t}$ is the stock level margin-trading interest at day $\mathrm{t}$ for stock $\mathrm{i}$. In this table, we report the simple mean of significant $\beta$ coefficients when we use $10 \%$ and $5 \%$ as significance thresholds. All the results are based on Newey-West robust $\mathrm{t}$ statistics. We report the $\beta$ in percentage (\%), which equals the mean change of stock return induced by one standard deviation increase of $S M T I_{i t}$.

\begin{tabular}{clrrrrr}
\hline Significance level & Category & 2013 & 2014 & 2015 & 2016 & 2017 \\
\hline \multirow{2}{*}{ Panel A: Mean $\beta$} & & & & & & \\
$10 \%$ & Positive & 0.64 & 0.72 & 0.68 & 0.92 & 0.87 \\
& Negative & -0.44 & -0.46 & -0.74 & -0.79 & -0.42 \\
$5 \%$ & Positive & 0.79 & 0.75 & 0.66 & 1.00 & 0.98 \\
& Negative & -0.47 & -0.45 & -0.85 & -0.90 & -0.41 \\
Panel B: Number of stocks & & & & & & \\
& & & & & & \\
& Total eligible firms & 235 & 672 & 850 & 843 & 904 \\
& Positive & 39 & 66 & 68 & 75 & 149 \\
$10 \%$ & Negative & 15 & 85 & 102 & 41 & 53 \\
& Positive & 25 & 47 & 43 & 52 & 102 \\
$5 \%$ & Negative & 8 & 58 & 63 & 22 & 37 \\
\hline
\end{tabular}




\section{Table 4.4: Percentage of Information-driven and Sentiment-driven Stocks}

This table reports the percentage of the information and sentiment-driven stocks in each sample period. We divide the time into five equal lengths of twelve months' period: 2013 (June 2012-May 2013), 2014 (June 2013-May 2014), 2015 (June 2014-May 2015), 2016 (September 2015-August 2016), and 2017 (September 2016-August 2017). We report results for future one to five days return using $10 \%$ and $5 \%$ as significance thresholds. The units in the figure are percentages (\%). All the results are based on Newey-West robust t statistics.

$$
\begin{gathered}
\text { positive rate }{ }_{t}=\frac{\text { the number of firms in the information-driven categor } y_{t}}{\text { total number of eligible firms } s_{t}} \\
\text { negative rate } \text { r }_{t}=\frac{\text { the number of firms in the sentiment }- \text { driven categor } y_{t}}{\text { total number of eligible firms } s_{t}}
\end{gathered}
$$

\begin{tabular}{|c|c|c|c|c|c|c|c|}
\hline \multicolumn{3}{|c|}{\begin{tabular}{ll} 
& \multicolumn{2}{c}{ Significance Time } \\
Relationship & $\begin{array}{ll}\text { level } & \text { interval }\end{array}$
\end{tabular}} & 2013 & 2014 & 2015 & 2016 & 2017 \\
\hline \multicolumn{3}{|c|}{ Total number of eligible firms } & 235 & 672 & 850 & 843 & 904 \\
\hline \multirow{10}{*}{ Negative } & \multirow{5}{*}{$10 \%$} & $(0,5)$ & 6.38 & 12.65 & 12.00 & 4.86 & 5.86 \\
\hline & & $(0,4)$ & 6.38 & 13.10 & 12.12 & 4.03 & 5.75 \\
\hline & & $(0,3)$ & 5.53 & 12.05 & 11.18 & 3.20 & 6.64 \\
\hline & & $(0,2)$ & 5.53 & 10.57 & 10.59 & 2.61 & 6.31 \\
\hline & & $(0,1)$ & 2.98 & 7.74 & 9.06 & 2.25 & 4.76 \\
\hline & \multirow{5}{*}{$5 \%$} & $(0,5)$ & 3.40 & 8.63 & 7.41 & 2.61 & 4.09 \\
\hline & & $(0,4)$ & 4.26 & 8.18 & 7.06 & 1.90 & 3.98 \\
\hline & & $(0,3)$ & 4.26 & 7.59 & 6.24 & 1.90 & 4.31 \\
\hline & & $(0,2)$ & 2.55 & 6.25 & 6.12 & 1.42 & 4.09 \\
\hline & & $(0,1)$ & 1.28 & 4.76 & 6.35 & 1.42 & 2.99 \\
\hline \multirow{10}{*}{ Positive } & & $(0,5)$ & 16.60 & 9.82 & 8.00 & 8.90 & 16.48 \\
\hline & & $(0,4)$ & 15.74 & 9.23 & 8.12 & 8.30 & 15.82 \\
\hline & $10 \%$ & $(0,3)$ & 13.19 & 8.04 & 8.24 & 8.19 & 14.82 \\
\hline & & $(0,2)$ & 10.21 & 7.59 & 7.88 & 7.00 & 12.61 \\
\hline & & $(0,1)$ & 7.23 & 4.17 & 5.65 & 5.10 & 8.63 \\
\hline & \multirow{5}{*}{$5 \%$} & $(0,5)$ & 10.64 & 6.99 & 5.06 & 6.17 & 11.28 \\
\hline & & $(0,4)$ & 8.94 & 6.70 & 4.94 & 5.69 & 10.62 \\
\hline & & $(0,3)$ & 7.66 & 6.40 & 5.18 & 4.74 & 9.07 \\
\hline & & $(0,2)$ & 7.23 & 5.51 & 4.82 & 3.68 & 8.30 \\
\hline & & $(0,1)$ & 1.70 & 1.49 & 2.71 & 3.08 & 3.10 \\
\hline
\end{tabular}




\section{Table 4.5: Summary Statistics of Variables Used in Logit Model}

This table reports the summary statistics of variables used in the logit regression. $P B$ ratio is defined as market capitalization/latest net asset value. PS ratio is defined as market capitalization/last year sales revenue. Turnover ratio is the trading volume in dollars divided by market capitalization. For $P B$ ratio, $P S$ ratio, and turnover ratio, we first calculate its daily value and then use its simple average during that period as our final independent variables. $R O A$ is revenue divided by total asset. Debt ratio is total liability divided by total asset. Size is the natural logarithm of circulated market capitalization. We use the CAPM model to calculate each stock's Jensen's alpha and idiosyncratic volatility. The detailed definitions of variables is in the appendix.

\begin{tabular}{lrrrrr}
\hline Independent variables & $\mathrm{N}$ & Mean & \multicolumn{2}{c}{ Std Dev } & Minimum \\
\hline Turnover ratio & 3,504 & 0.021 & 0.017 & 0.000 & 0.148 \\
PB ratio & 3,503 & 4.538 & 17.791 & 0.317 & 893.971 \\
PS ratio & 3,504 & 7.238 & 23.007 & 0.070 & 614.681 \\
Jensen's alpha & 3,504 & 0.000 & 0.002 & -0.007 & 0.010 \\
Idiosyncratic volatility & 3,504 & 0.021 & 0.007 & 0.005 & 0.059 \\
ROA & 3,504 & 0.044 & 0.064 & -0.775 & 0.450 \\
Debt ratio & 3,504 & 0.500 & 0.218 & 0.016 & 1.280 \\
Log (capitalization) & 3,504 & 16.428 & 0.975 & 13.637 & 21.171 \\
\hline
\end{tabular}




\section{Table 4.6: Logit Model Results for Sentiment-driven Category Versus Non-significant Category}

This table reports the results of the logit model in which we include the sentiment-driven category and non-significant category into the regression.

$$
\text { CategoryDummy } y_{i t}=\alpha+\beta_{1} \text { PostcrisisDummy }+\beta_{i}^{\prime} x_{i t}^{\prime}+\varepsilon_{i t}
$$

In this regression, Categorydummy $y_{i t}$ equals -1 for 296 stocks that are in the sentimentdriven category or 0 for 2,811 stocks that are in the non-significant category. We set non-significant category stocks as the reference category in the regression. For every twelve months, we obtain the Categorydummy $y_{i t}$ based on the results from the stock-level predictive regressions by regressing the future weekly stock return on SMTI. Categorydummy is set as -1 if the coefficient from predictive regression is significantly negative at the $10 \%$ level. If the coefficient is not significant at the $10 \%$ level, the Categorydumm $y_{i t}$ will be 0 . PostcrisisDummy is generated based on time relative to the 2015 stock crisis. For the time after the crisis (September 2015-August 2017), it is set as one. For the time before the crisis, it is set as zero. The model controls for firm fixed effect. P-values based on Wald Chi-Square are reported in parentheses. * ${ }^{* *}$, and ${ }^{* *}$ denote the statistical significance at the $10 \%, 5 \%$, and $1 \%$ levels, respectively.

\begin{tabular}{|c|c|c|c|c|c|c|c|}
\hline $\begin{array}{l}\text { Independent } \\
\text { variables }\end{array}$ & (1) & (2) & (3) & (4) & (5) & (6) & (7) \\
\hline $\begin{array}{l}\text { Post-crisis } \\
\text { dummy }\end{array}$ & $\begin{array}{l}-1.074^{* \star *} \\
(0.000)\end{array}$ & 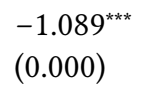 & $\begin{array}{l}-1.026^{* * *} \\
(0.000)\end{array}$ & $\begin{array}{l}-1.020^{\text {*** }} \\
(0.000)\end{array}$ & $\begin{array}{l}-0.989^{* \star *} \\
(0.000)\end{array}$ & $\begin{array}{l}-0.855^{* * *} \\
(0.000)\end{array}$ & $\begin{array}{l}-1.012^{* * *} \\
(0.000)\end{array}$ \\
\hline $\mathrm{PB}$ ratio & & $\begin{array}{l}-0.000 \\
(0.912)\end{array}$ & $\begin{array}{l}-0.001 \\
(0.864)\end{array}$ & $\begin{array}{l}-0.001 \\
(0.746)\end{array}$ & $\begin{array}{l}-0.0002 \\
(0.995)\end{array}$ & $\begin{array}{l}-0.002 \\
(0.724)\end{array}$ & $\begin{array}{l}-0.002 \\
(0.729)\end{array}$ \\
\hline PS ratio & & $\begin{array}{l}0.006 \\
(0.356)\end{array}$ & $\begin{array}{l}0.003 \\
(0.621)\end{array}$ & $\begin{array}{l}0.004 \\
(0.579)\end{array}$ & $\begin{array}{l}-0.0007 \\
(0.994)\end{array}$ & $\begin{array}{l}-0.000 \\
(0.958)\end{array}$ & $\begin{array}{l}-0.000 \\
(0.955)\end{array}$ \\
\hline $\begin{array}{l}\text { Turnover } \\
\text { ratio }\end{array}$ & & & $\begin{array}{l}15.244^{\star * *} \\
(0.009)\end{array}$ & $\begin{array}{l}15.573^{\star * \star} \\
(0.008)\end{array}$ & $\begin{array}{l}15.601^{* * *} \\
(0.007)\end{array}$ & $\begin{array}{l}-0.187 \\
(0.981)\end{array}$ & $\begin{array}{l}0.847 \\
(0.915)\end{array}$ \\
\hline Debt ratio & & & & $\begin{array}{l}1.397 \\
(0.250)\end{array}$ & & $\begin{array}{l}1.885 \\
(0.145)\end{array}$ & $\begin{array}{l}1.700 \\
(0.188)\end{array}$ \\
\hline ROA & & & & & $\begin{array}{l}3.618 \\
(0.124)\end{array}$ & $\begin{array}{l}4.991^{* *} \\
(0.040)\end{array}$ & $\begin{array}{l}4.664^{*} \\
(0.057)\end{array}$ \\
\hline Size & & & & & & & $\begin{array}{l}0.350 \\
(0.146)\end{array}$ \\
\hline $\begin{array}{l}\text { Idiosyncratic } \\
\text { volatility }\end{array}$ & & & & & & $\begin{array}{l}59.176^{* * *} \\
(0.002)\end{array}$ & $\begin{array}{l}40.900^{*} \\
(0.076)\end{array}$ \\
\hline Jensen's alpha & & & & & & & $\begin{array}{l}60.205 \\
(0.315)\end{array}$ \\
\hline Adjust $R^{2}$ & 0.098 & 0.100 & 0.112 & 0.114 & 0.116 & 0.137 & 0.142 \\
\hline Negative & 296 & 296 & 296 & 296 & 296 & 296 & 296 \\
\hline Non-signif. & 2,811 & 2,811 & 2,811 & 2,811 & 2,811 & 2,811 & 2,811 \\
\hline
\end{tabular}




\section{Table 4.7: Logit Model Results for Information-driven Category Versus Non-significant Category}

This table reports the results of the logit model in which we include the information-driven category and non-significant category into the regression.

$$
\text { CategoryDummy } y_{i t}=\alpha+\beta_{1} \text { PostcrisisDummy }+\beta_{i}^{\prime} X_{i t}^{\prime}+\varepsilon_{i t}
$$

In this regression, Categorydummy $y_{i t}$ equals 1 for 397 stocks that are in the informationdriven category or 0 for 2,811 stocks that are in the non-significant category. We set non-significant category stocks as the reference category in the regression. For every twelve months, we obtain the Categorydummy $y_{i t}$ based on the results from the stock-level predictive regressions by regressing the future weekly stock return on SMTI. Categorydumm $y_{i t}$ is set as 1 if the coefficient from predictive regression is significantly positive at the $10 \%$ level. If the coefficient is not significant at the $10 \%$ level, the Categorydummy $y_{i t}$ will be 0 . PostcrisisDummy is generated based on time relative to the 2015 stock crisis. For the time after the crisis (September 2015-August 2017), it is set as one. For the time before the crisis, it is set as zero. The model controls for firm fixed effect. P-values based on Wald Chi-Square are reported in parentheses. *, **, and *** denote the statistical significance at the $10 \%, 5 \%$, and $1 \%$ levels, respectively.

\begin{tabular}{|c|c|c|c|c|c|c|c|}
\hline $\begin{array}{l}\text { Independent } \\
\text { variables }\end{array}$ & (1) & (2) & (3) & (4) & (5) & (6) & (7) \\
\hline $\begin{array}{l}\text { Post-crisis } \\
\text { dummy }\end{array}$ & $\begin{array}{l}0.281^{\star *} \\
(0.015)\end{array}$ & $\begin{array}{l}0.284^{* *} \\
(0.014)\end{array}$ & $\begin{array}{l}0.201^{*} \\
(0.093)\end{array}$ & $\begin{array}{l}0.204^{*} \\
(0.090)\end{array}$ & $\begin{array}{l}0.130 \\
(0.296)\end{array}$ & $\begin{array}{l}0.050 \\
(0.758)\end{array}$ & $\begin{array}{l}0.006 \\
(0.971)\end{array}$ \\
\hline PB ratio & & $\begin{array}{l}0.049 \\
(0.151)\end{array}$ & $\begin{array}{l}0.062 \\
(0.112)\end{array}$ & $\begin{array}{l}0.057 \\
(0.147)\end{array}$ & $\begin{array}{l}0.061 \\
(0.168)\end{array}$ & $\begin{array}{l}0.051 \\
(0.263)\end{array}$ & $\begin{array}{l}0.059 \\
(0.223)\end{array}$ \\
\hline PS ratio & & $\begin{array}{l}-0.001 \\
(0.881)\end{array}$ & $\begin{array}{l}-0.000 \\
(0.958)\end{array}$ & $\begin{array}{l}0.000 \\
(0.967)\end{array}$ & $\begin{array}{l}-0.000 \\
(0.955)\end{array}$ & $\begin{array}{l}-0.000 \\
(0.981)\end{array}$ & $\begin{array}{l}-0.001 \\
(0.842)\end{array}$ \\
\hline $\begin{array}{l}\text { Turnover ra- } \\
\text { tio }\end{array}$ & & & $\begin{array}{l}-22.681^{\text {***}} \\
(0.000)\end{array}$ & $\begin{array}{l}-22.904^{* * \star} \\
(0.000)\end{array}$ & $\begin{array}{l}-22.428^{* * *} \\
(0.000)\end{array}$ & $\begin{array}{l}-23.150^{* k *} \\
(0.000)\end{array}$ & $\begin{array}{l}-19.311^{\text {** }} \\
(0.025)\end{array}$ \\
\hline Debt ratio & & & & $\begin{array}{l}0.803 \\
(0.441)\end{array}$ & & & $\begin{array}{l}0.221 \\
(0.842)\end{array}$ \\
\hline ROA & & & & & $\begin{array}{l}-4.409^{\star *} \\
(0.036)\end{array}$ & $\begin{array}{l}-4.709^{* *} \\
(0.028)\end{array}$ & $\begin{array}{l}-4.699^{* *} \\
(0.038)\end{array}$ \\
\hline Size & & & & & & $\begin{array}{l}0.213 \\
(0.437)\end{array}$ & $\begin{array}{l}0.191 \\
(0.487)\end{array}$ \\
\hline $\begin{array}{l}\text { Idiosyncratic } \\
\text { volatility }\end{array}$ & & & & & & & $\begin{array}{l}-1.554 \\
(0.933)\end{array}$ \\
\hline Jensen's alpha & & & & & & & $\begin{array}{l}-72.866 \\
(0.136)\end{array}$ \\
\hline Adjust $R^{2}$ & 0.008 & 0.011 & 0.030 & 0.031 & 0.037 & 0.038 & 0.041 \\
\hline Positive & 397 & 397 & 397 & 397 & 397 & 397 & 397 \\
\hline Non-signif. & 2,811 & 2,811 & 2,811 & 2,811 & 2,811 & 2,811 & 2,811 \\
\hline
\end{tabular}




\section{Table 4.8: Percentage of Information-driven and Sentiment-driven Stocks}

This table reports the results of the robustness check in which we use a different method to define the pre-crisis and after-crisis. We divide the time into two equal lengths twenty-four month periods: pre-crisis (June 2013-May 2015) and post-crisis (September 2015-August 2017). We report results for one to five days return using $10 \%$ and $5 \%$ as significance thresholds. The units in the figure are in percentages (\%). All the results are based on Newey-West robust $t$ statistics.

$$
\begin{gathered}
\text { positive rate }_{t}=\frac{\text { the number of firms in the information }- \text { driven categor } y_{t}}{\text { total number of eligible firms } s_{t}} \\
\text { negative rate } e_{t}=\frac{\text { the number of firms in the sentiment }- \text { driven categor } y_{t}}{\text { total number of eligible firms } s_{t}}
\end{gathered}
$$

\begin{tabular}{|c|c|c|c|c|}
\hline \multicolumn{3}{|c|}{ Total number of eligible firms } & \multirow{2}{*}{$\begin{array}{c}868 \\
11.06\end{array}$} & \multirow{2}{*}{$\begin{array}{r}931 \\
6.55\end{array}$} \\
\hline \multirow{10}{*}{ Negative } & \multirow{5}{*}{$10 \%$} & $(0,5)$ & & \\
\hline & & $(0,4)$ & 11.41 & 6.02 \\
\hline & & $(0,3)$ & 11.29 & 6.44 \\
\hline & & $(0,2)$ & 11.06 & 6.12 \\
\hline & & $(0,1)$ & 9.68 & 4.94 \\
\hline & \multirow{5}{*}{$5 \%$} & $(0,5)$ & 7.26 & 3.65 \\
\hline & & $(0,4)$ & 6.57 & 3.22 \\
\hline & & $(0,3)$ & 6.34 & 3.65 \\
\hline & & $(0,2)$ & 6.45 & 3.76 \\
\hline & & $(0,1)$ & 5.99 & 3.33 \\
\hline \multirow{10}{*}{ Positive } & \multirow{5}{*}{$10 \%$} & $(0,5)$ & 6.34 & 9.99 \\
\hline & & $(0,4)$ & 5.53 & 10.10 \\
\hline & & $(0,3)$ & 5.18 & 9.24 \\
\hline & & $(0,2)$ & 4.95 & 7.95 \\
\hline & & $(0,1)$ & 3.23 & 5.05 \\
\hline & \multirow{5}{*}{$5 \%$} & $(0,5)$ & 3.69 & 5.91 \\
\hline & & $(0,4)$ & 3.46 & 5.16 \\
\hline & & $(0,3)$ & 3.57 & 4.51 \\
\hline & & $(0,2)$ & 2.77 & 3.54 \\
\hline & & $(0,1)$ & 1.38 & 2.36 \\
\hline
\end{tabular}

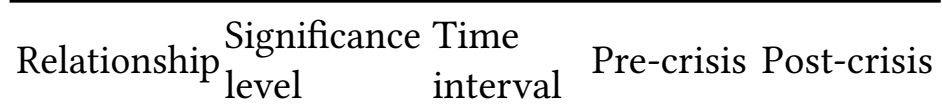




\section{Table 4.9: Multinomial Logit Model}

This table reports the results of the robustness check in which we include the informationdriven, sentiment-driven, and non-significant categories into the single multinomial logit model. This model includes 397 information-driven stocks, 296 sentiment-driven stocks, and 2,811 stocks that are in the non-significant category.

$$
\text { CategoryDummy } y_{i t}=\alpha+\beta_{1} \text { PostcrisisDummy }+\beta_{i}^{\prime} x_{i t}^{\prime}+\varepsilon_{i t}
$$

In this regression, Categorydummy $y_{i t}$ equals -1 or 0 or 1 . We set the non-significant category as the benchmark category. For every twelve months, we obtain the Categorydummy based on the results from the stock-level predictive regressions by regressing the future weekly stock return on SMTI. Categorydummy it is set as -1 if the coefficient from predictive regression is significantly negative at the $10 \%$ level. Categorydummy $y_{i t}$ are set as 1 if the coefficient from predictive regression is significantly positive at the $10 \%$ level. If the coefficient is not significant at the $10 \%$ level, the Categorydumm $y_{i t}$ will be 0 . PostcrisisDummy is generated based on time relative to the 2015 stock crisis. For the time after the crisis (September 2015-August 2017), it is set as one. For the time before the crisis, it is set as zero. p-values based on Wald Chi-Square are reported. *, **, and *** denote the statistical significance at the $10 \%, 5 \%$, and $1 \%$ levels, respectively.

\begin{tabular}{lrcc}
\hline Independent variables & Category & Coefficient & P value \\
\hline Post-crisis dummy & -1 & $-0.750^{* * *}$ & 0.00 \\
& 1 & 0.151 & 0.18 \\
PB ratio & -1 & -0.002 & 0.78 \\
& 1 & -0.002 & 0.68 \\
PS ratio & -1 & 0.000 & 0.94 \\
& 1 & 0.002 & 0.28 \\
Turnover ratio & -1 & $9.810^{* *}$ & 0.04 \\
& 1 & -8.275 & 0.11 \\
Debt ratio & -1 & -0.039 & 0.91 \\
& 1 & 0.140 & 0.64 \\
ROA & -1 & -0.175 & 0.88 \\
& 1 & -0.887 & 0.35 \\
Size & -1 & $0.150^{* *}$ & 0.04 \\
& 1 & $0.111^{*}$ & 0.08 \\
Idiosyncratic volatility & -1 & 4.563 & 0.74 \\
& 1 & $22.224^{*}$ & 0.06 \\
Jensen's alpha & -1 & $76.642^{*}$ & 0.09 \\
Adjust $R^{2}$ & 1 & $-134.400^{* * *}$ & 0.00 \\
Positive & & & \\
Negative & 0.026 & & \\
Non-signif. & 397 & & \\
\hline
\end{tabular}




\section{Appendix: Definitions of Variables}

Table D.1: Definitions of Variables

\begin{tabular}{ll}
\hline Variable & \multicolumn{1}{c}{ Definition } \\
Margin-trading interest & \\
SMTI & Stock-level margin-trading interest. We use a two- \\
step procedure to generate $S M T I$. First, we obtain \\
each stock's daily margin-trading balance, mea- \\
suring the amount of money investors borrowed \\
from security companies to invest in one specific \\
firm. We normalize this margin-trading balance \\
by each firm's circulated capitalization. After get- \\
ting this ratio, we take its log. We then use the \\
time trend to detrend this log ratio, since there is a \\
natural increasing trend with the improvement of \\
the margin-trading facility. For the convenience of \\
interpretation, we standardize the residual so that \\
the final $S M T I$ has a mean of zero and variance of \\
one. \\
Market-level margin-trading interest based on all \\
eligible firms on the margin-trading list. We \\
firstly collect each stock's margin-trading balance \\
and normalize this balance by the firm's circu- \\
lated capitalization. Then, we employ an equal- \\
weighted scheme (or value-weighted scheme) to \\
form market-level margin-trading interest. Finally, \\
we take the log of this ratio and detrend it. For the \\
convenience of interpretation, we standardize the \\
residual so that the final $M M T I_{\text {all }}$ has a mean of \\
zero and variance of one.
\end{tabular}

Continued on next page 
Table D.1 - continued from previous page

Variable Definition

$\mathrm{MMTI}_{73}$

Market-level margin-trading interest based on seventy-three eligible stocks. We use seventythree stocks that have always been on the margintrading list from 2010 to 2017 to form the marketlevel margin-trading interest. These seventy-three firms are the largest capitalization firms in the Chinese stock market and represent the overall market condition. We first collect margin-trading balance of each stock and normalize this balance by the firm's circulated capitalization. We then employ an equal-weighted scheme (or value-weighted scheme) to form overall market interest. Finally, we take the log of this ratio and detrend it. For the convenience of interpretation, we standardize the residual so that the final $M M T I_{73}$ has a mean of zero and variance of one.

\section{Dummy variables}

Category Dummy

We check whether a firm's SMTI can predict its future weekly return or not in each period. If the coefficient in the predictive regression is not significant, we give Category Dummy a value of 0 . If there is a significantly positive relationship between SMTI and its future weekly return, we will set Category Dummy as 1 for this period. If this relationship is negatively significant, the corresponding Category Dummy is -1 for this period. We use $10 \%$ as the significance threshold.

Post-crisis dummy

This dummy is generated based on time relative to the 2015 stock crisis. For the time after the crisis (September 2015-August 2017), it is set as one. For the time before the crisis, it is set as zero. 
Table D.1 - continued from previous page

Variable Definition

\section{Return variables}

HUSHEN300 return

Interest rate

This is the return of the HUSHEN300 index, which is one of the most popular indexes in the Chinese stock market and contains the 300 most important stocks from the Shanghai Exchange and Shenzhen Exchange. It is a value-weighted index with the circulated capitalization as the weight.

We use the one-year deposit rate of the Chinese Yuan as the interest rate, and transfer it into the corresponding daily rate matching the return horizon.

\section{Transaction variables}

Turnover ratio

Turnover ratio is defined as trading volume in dollar/circulated capitalization. We first calculate the daily turnover ratio and then use its simple average during the sample period as our final independent variable.

$\mathrm{PB}$ ratio

Price-to-book ratio is defined as market capitalization/latest net asset value. We first calculate the daily $\mathrm{PB}$ ratio and then use its simple average during the sample period as our final independent variable.

PS ratio

Price-to-sale ratio is defined as market capitalization/last year sales revenue. We first calculate the daily PS ratio and then use its simple average during the sample period as our final independent variable. 
Table D.1 - continued from previous page

Variable Definition

Jensen's alpha

Idiosyncratic volatility
This is defined as the intercept from the CAPM model. When we run the CAPM model, we use daily return as the dependent variable and the value-weighted daily return of A-share stocks as the market portfolio return. We use the daily rate of the Chinese Yuan one-year deposit rate to adjust the stock return and market portfolio return. We collect the intercept of the CAPM model as the Jensen's alpha for each stock during each period.

This is defined as the standard deviation of the disturbance term in the CAPM model. When we run the CAPM model, we use daily return as the dependent variable and the A-share stocks' valueweighted daily return as market portfolio return. We use the daily rate of the Chinese Yuan one-year deposit rate to adjust the stock return and market portfolio return. We collect the standard deviation of the disturbance term as idiosyncratic volatility for each stock during each period.

\section{Fundamental variables}

ROA

Debt ratio

Size
Return on asset is defined as revenue/total asset.

Debt ratio is defined as total liability/total asset.

Size is defined as Log(circulated capitalization). 



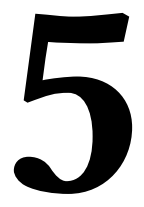

\section{Discussion}

This chapter summarizes the main findings of the thesis, discusses the implications of the findings, and points out the future direction for research. 


\subsection{Discussion for Chapter 2}

Chapter 2 identifies the positive side of equity ETF ownership on the cost of debt, which highlights the importance of financial innovation in financial markets. This paper serves as a new effort to understand the equilibrium between passive and active investing. It documents a negative association between equity ETF ownership and the bond spreads. The subsample analysis further shows that this negative association is more pronounced for firms with weaker information environments and lower bond ratings. It further explores the channels through which the equity ETF ownership could influence bond pricing. It identifies the disciplinary effect of the short-selling channel facilitated by ETFs as the main channel and find no support for the improvement of the corporate governance as the channel. It addresses the endogeneity concerns and performs several robustness checks of our findings

This chapter highlights the positive side of equity ETF ownership and contributes to the ongoing debate between passive and active investing. As commented by Lettau and Madhavan (2018), ETF research is still in its infancy, so more research is needed to understand the ETFs' influence better. Corum, Malenko, and Malenko (2020), Bond and Garcia (2018), and Easley, Michayluk, O’Hara, and Putniňš (2020) have, however, shown that it is of great importance to study the gradual shifting of shares between passive and active investment. This paper serves as one such effort to benefit academics, practitioners, and policymakers.

\subsection{Discussion for Chapter 3}

Chapter 3 confirms the predictive power of the trend signal globally. It shows a trend signal exploiting the short-, intermediate-, and long-term price information that can predict stock returns cross-sectionally. The trend strategy could generate the alpha, survive the transaction cost, and is applicable in most of the markets in our sample. It also shows that the trend premium is more pronounced in markets with a more advanced macroeconomic status, a higher level of information uncertainty and individualism, and better accessibility to foreign investors.

Two points merit further discussion. First, some more advanced methods to extract useful information from existing return predictors might be fruitful in future research. 
The trend strategy is essentially a new method to extract information from stock prices. The strength of this method lies in the fact it extracts information about stock prices from different horizons. For empirical asset pricing, methods such as machine learning, deep learning, and natural language processing provide researchers with powerful assistance in predicting the future return. Recent studies have shown that a more advanced machine learning method can extract information more effectively from more variables than the standard regression methods. See, for example, Rapach, Strauss, and Zhou (2013), Kozak, Nagel, and Santosh (2018), Gu, Kelly, and Xiu (2018); Kelly, Pruitt, and Su (2019), and Feng, Giglio, and Xiu (2019). It is thus of interest to explore whether the performance of the trend strategy could be improved by using a more advanced machine learning method or more technical signals like trading volume. Second, this chapter identifies the differences when implementing the trend strategies in different countries. One implication of this chapter is that some crosscountry differences will influence the magnitude of the return. International finance is important in this sense of finding the factors that will influence the applicability of the return predictors and further develop the financial theory.

\subsection{Discussion for Chapter 4}

Chapter 4 analyzes the margin-trending program in the Chinese stock market. It constructs two versions of market-level margin-trading interest and fails to find the predictive power of any of them at the aggregate level. This leads us to explore the relationship between margin-trading interest and stock return at the stock level. It documents that there exists both information-driven and sentiment-driven trading in the margin-trading market at the stock level. Besides, it documents a sharp decrease in sentiment-driven trading after the 2015 stock crisis. The decrease in sentiment-driven might be caused by a number of factors, including the regulatory policy change, the improvement in security company risk management, and the learning behavior of retail investors.

There are several directions that might worth exploring in the future. First, the question of how informed margin buyers are is not fully addressed. It might be useful to find proper events to test whether investors in information-driven firms are informed 
about fundamental performance or other factors. If they are informed, there might be some in advance reactions of margin-trading interest. Second, this paper is limited because we do not have access to the identities of the margin buyers. If we can distinguish between retail margin buyers and institutional margin buyers, we can test whether institutional margin buyers are more informed than retail margin buyers. Another interesting question is whether the decrease in sentiment-driven investment is transitory or long-term. On the one hand, in a market dominated by retail investors, those retail investors may soon forget the lesson they learned from years ago, which may imply this effect is transitory. On the other hand, if the regulatory policy change and the risk management improvement of security companies are the driving force, we might expect the decrease in sentiment-driven trading to have a long-term effect. Testing of this question in the future might be interesting with the accumulation of more data. 


\section{References}

Bond, P., Garcia, D., 2018. The equilibrium consequences of indexing. Unpublished working paper.

Corum, A. A., Malenko, A., Malenko, N., 2020. Corporate governance in the presence of active and passive delegated investment. Unpublished working paper.

Easley, D., Michayluk, D., O’Hara, M., Putninšs, T. J., 2020. The active world of passive investing. Unpublished working paper.

Feng, G., Giglio, S., Xiu, D., 2019. Taming the factor zoo: a test of new factors. The Journal of Finance, forthcoming.

Gu, S., Kelly, B., Xiu, D., 2018. Empirical asset pricing via machine learning. The Review of Financial Studies, forthcoming.

Kelly, B. T., Pruitt, S., Su, Y., 2019. Characteristics are covariances: a unified model of risk and return. Journal of Financial Economics, forthcoming.

Kozak, S., Nagel, S., Santosh, S., 2018. Interpreting factor models. The Journal of Finance 73, 1183-1223.

Lettau, M., Madhavan, A., 2018. Exchange-traded funds 101 for economists. Journal of Economic Perspectives 32, 135-54.

Rapach, D. E., Strauss, J. K., Zhou, G., 2013. International stock return predictability: what is the role of the United States? The Journal of Finance 68, 1633-1662. 